\title{
MODELAGEM ESPAÇO-TEMPORAL PARA DADOS DE INCIDÊNCIA DE DOENÇAS EM PLANTAS
}

\author{
Renato Ribeiro De Lima
}

\author{
Tese apresentada à Escola Superior de \\ Agricultura "Luiz de Queiroz", Universidade \\ de São Paulo, para obtenção do título de \\ Doutor em Agronomia, Área de Concentração: \\ Estatística e Experimentação Agronômica.
}

P I R A C I C A B A

Estado de São Paulo - Brasil

Janeiro - 2005 


\title{
MODELAGEM ESPAÇO-TEMPORAL PARA DADOS DE INCIDÊNCIA DE DOENÇAS EM PLANTAS
}

\author{
Renato Ribeiro De Lima
}

Zootecnista

Orientadora: $\operatorname{Prof}^{\underline{a} \underline{a}} \operatorname{Dr}^{\underline{a}}$ CLARICE GARCIA BORGES DEMÉTRIO

\begin{abstract}
Tese apresentada à Escola Superior de Agricultura "Luiz de Queiroz", Universidade de São Paulo, para obtenção do título de Doutor em Agronomia, Área de Concentração: Estatística e Experimentação Agronômica.
\end{abstract}

P I R A C I C A B A

Estado de São Paulo - Brasil

Janeiro - 2005 
Dados Internacionais de Catalogação na Publicação (CIP) DIVISÃO DE BIBLIOTECA E DOCUMENTAÇÃO - ESALQ/USP

Lima, Renato Ribeiro de

Modelagem espaço-temporal para dados de incidência de doenças em plantas / Renato Ribeiro de Lima. - - Piracicaba, 2005.

149 p. : il.

Tese (Doutorado) - - Escola Superior de Agricultura Luiz de Queiroz, 2005. Bibliografia.

1. Análise espacial 2. Cancro-cítrico 3. Citricultura 4. Controle fitossanitário 5. Doença de planta 6. Métodos MCMC 7. Modelagem matemática 8. Processo estocástico I. Título

CDD 519.5

"Permitida a cópia total ou parcial deste documento, desde que citada a fonte - O autor" 


\section{DEDICATÓRIA}

A

DEUS

força maior de todo ser humano, a saúde e a força que nunca me

deixaram esmorecer.

Aos meus pais,

Mauro Maurício de Lima e

Maria Aparecida Ribeiro de Lima,

os inúmeros bons exemplos que propiciaram e que me impulsionam na batalha do dia-a-dia.

À minha esposa Viviane, o amor, a compreensão, o apoio e, principalmente, por se manter sempre forte e zelar pela saúde e bem-estar de nossos filhos, nos momentos em que estive ausente.

Aos meus filhos Gabriel e Vinícius, que alegram minha vida dando-me motivos e estímulos para progredir. 


\section{AGRADECIMENTOS}

À Prof ${ }^{a} \operatorname{Dr}^{\underline{a}}$ Clarice Garcia Borges Demétrio, a orientação, o constante estímulo, a amizade e a confiança depositada no meu trabalho.

Ao Prof. Martin S. Ridout, a supervisão, o apoio, a paciência e os ensinamentos transmitidos durante o meu período de estudos no Institute of Mathematics, Statistics and Actuarial Science da University of Kent, Canterbury, Inglaterra.

À CAPES o fundamental suporte financeiro concedido.

À Universidade Federal de Viçosa e aos professores de Estatística do Departamento de Informática, o afastamento concedido para a realização deste trabalho.

Aos professores e funcionários do Departamento de Ciências Exatas da ESALQ/USP que me propiciaram condições para a realização deste trabalho.

Aos colegas e amigos de doutorado, em especial a João Mauricio, Adriano, Osmir, Antonio Carlos, Telde, Ana Maria e Suely, a força, a amizade, a troca de conhecimentos e a atenção recebida em todos os momentos.

Aos colegas e amigos da Universidade de Kent, Alex, Marcel, Lauana, Nícia, Adolfo, Leonardo, Ana, Jim, Thomé, Miguel e tantos outros, os bons momentos compartilhados em terra tão distante.

Ao Prof. Dr. Paulo Justiniano Ribeiro Júnior, a amizade e a ajuda na condução desse trabalho.

A Prof ${ }^{\underline{a}} \operatorname{Dr}^{\underline{a}} \stackrel{a}{ }$ Lilian Amorim, da ESALQ/USP e ao pesquisador Renato B. Bassanezi, do Fundecitrus, por terem cedido os dados utilizados neste trabalho A todos que, de forma direta ou indireta, contribuíram para a realização deste trabalho. 


\section{SUMÁRIO}

Página

LISTA DE FIGURAS . . . . . . . . . . . . . . . . . viii

LISTA DE TABELAS . . . . . . . . . . . . . . . . . xiii

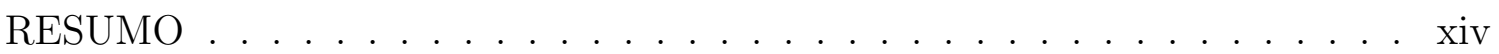

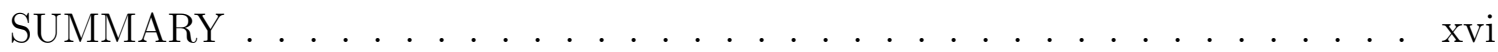

$1 \quad$ INTRODUÇÃ $O \ldots \ldots \ldots \ldots \ldots$

2 REVISÃO DE LITERATURA . . . . . . . . . . . . 4

2.1 Citricultura - aspectos econômicos . . . . . . . . . . . . . 4

2.2 Doenças dos citros - cancro cítrico e MSC . . . . . . . . . . . . 6

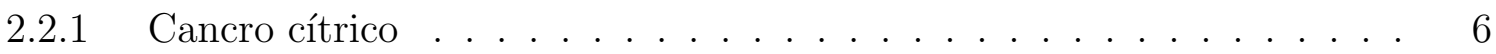

2.2 .2 Morte Súbita dos Citros . . . . . . . . . . . . . . . . . . . 10

2.3 Padrão espacial de doenças em plantas . . . . . . . . . . . . . . . 14

2.3.1 Avaliação de padrões espaciais . . . . . . . . . . . . . . . . 17

2.3.2 Apresentação dos dados para o estudo de padrões espaciais . . . . . 20

2.3.3 Algumas técnicas para a avaliação de padrões espaciais . . . . . . . . 26

2.3.3.1 Distribuições de probabilidades para a incidência de doenças . . . . . 26

2.3.3.2 Índices de dispersão . . . . . . . . . . . . . . . . . . . . . . . . . . 29

2.3.3.3 Correlação intraclasse . . . . . . . . . . . . . . . . . . . . . . . . 32

2.3.3.4 Lei de potência binária . . . . . . . . . . . . . . . . . 37

2.3.3.5 Métodos de classes de distâncias . . . . . . . . . . . . . . . . . 42

2.3.3.6 Autocorrelação espacial . . . . . . . . . . . . . . . . . . . . . 47

2.3.3.7 Modelos estocásticos espaço-temporais . . . . . . . . . . . . . . 53

$2.4 \quad$ Métodos de Monte Carlo baseado em cadeias de Markov (MCMC) . . 57 
2.4.1 Cadeias de passeios aleatórios (random walk chains) . . . . . . . . 61

$2.4 .2 \quad$ Algoritmo de Metropolis-Hastings . . . . . . . . . . . . . . . . . 62

2.5 Estimação dos parâmetros nos modelos estocásticos espaço-temporais utilizando métodos MCMC . . . . . . . . . . . . . . . . . . . 64

3 MATERIAL E MÉTODOS . . . . . . . . . . . 71

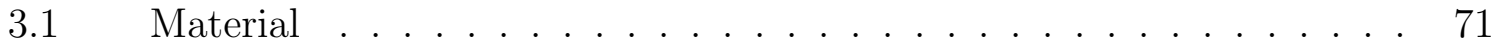

3.1.1 Dados simulados . . . . . . . . . . . . . . . . 71

3.1.1.1 Conjunto 1. simulado a partir de um modelo com um parâmetro . . . 75

3.1.1.2 Conjunto 2. simulado a partir de modelo com dois parâmetros . . . . 76

3.1.2 Dados de incidência de doenças em plantas . . . . . . . . . . . . . 77

3.1.2.1 Dados de cancro cítrico . . . . . . . . . . . . . . . . . 77

3.1.2.2 Dados de morte súbita dos citros . . . . . . . . . . . . . . . . . 79

3.1.2.3 Dados de tristeza dos citros . . . . . . . . . . . . . . . . . . . . . 82

3.1.2.4 Dados de viroses do lúpulo . . . . . . . . . . . . . . . . . . 82

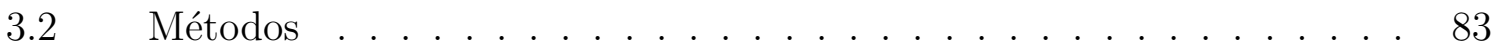

3.2.1 Processo proposto para a estimação dos parâmetros nos modelos estocásticos espaço-temporais utilizando métodos MCMC . . . . . . . . 86

3.2.1.1 Processo de estimação para o caso de modelos com um parâmetro 86

3.2.1.2 Processo de estimação para o caso do modelo com dois parâmetros . . 94

4 RESULTADOS E DISCUSSÃO . . . . . . . . . . . . . . 99

$4.1 \quad$ Dados simulados . . . . . . . . . . . . . . . . . . . . . 99

4.1.1 Dados simulados a partir de um modelo com um parâmetro . . . . . . 99

4.1.2 Dados simulados a partir de um modelo com dois parâmetros . . . . . 104

4.2 Dados reais . . . . . . . . . . . . . . . . . . 114

4.2.1 Tristeza dos citros . . . . . . . . . . . . . . . . . 114

4.2 .2 Viroses do lúpulo . . . . . . . . . . . . . . 116

4.2 .3 Cancro cítrico . . . . . . . . . . . . . . . . . . 120

4.2.4 Morte súbita dos citros . . . . . . . . . . . . . . 125

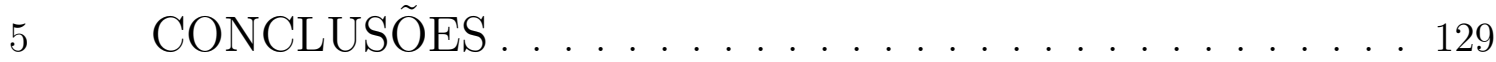


REFERÊNCIAS BIBLIOGRÁFICAS . . . . . . . . . . . . . . . . . 131 APENDICE . . . . . . . . . . . . . . . . . . . . . . . 144 


\section{LISTA DE FIGURAS}

Página

1 Lesões causadas pelo cancro cítrico nos frutos, galhos e folhas . . . . . 7

2 Vistas aéreas de pomares em que se vê o método de erradicação adotado no Estado de São Paulo . . . . . . . . . . . . . . . . . . . . . 9

3 Planta com sintomas de MSC e vista aérea de um pomar com várias plantas infectadas . . . . . . . . . . . . . . . . . . . 11

4 Padrões espaciais pontuais hipotéticos, em que cada ponto representa uma planta doente. (a) padrões regular, aleatório e agregado ou agrupado; (b) padrão espacial que não é visualmente caracterizado (adaptado de Campbell \& Madden, 1990) . . . . . . . . . . . . . . . . . . . . . 15

5 Localização dos quadrats para estudos de padrões espaciais. (a) quadrats localizados aleatoriamente; (b) um grid de quadrats contíguos (adaptado de Campbell \& Madden, 1990; Ripley, 1981) . . . . . . . . . . . . . . . . 24

6 Quatro tamanhos de quadrats e um padrão agregado de pontos com grupos de indivíduos localizados regularmente (adaptado de Campbell \&

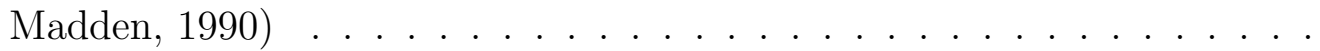

7 Padrões de proximidade típicos utilizados na análise de autocorrelação espacial, em que $\times$ representa uma planta de referência, $*$ representa as plantas vizinhas consideradas na comparação e $\cdot$ representa as demais plantas . . . . . . . . . . . . . . . . . . . . . . .

8 Padrões de proximidade apresentados por Gumpertz et al. (1997), em que $\times$ representa uma planta de referência, $*$ representa as plantas vizinhas consideradas na comparação e $\cdot$ representa as demais plantas . . . . . . . 50 
9 Padrões de proximidade apresentados por Gumpertz et al. (1997), em que $x$ representa um quadrat de referência, $*$ representa os quadrats considerados na comparação e $\cdot \cdot$ representa os demais quadrats . . . . . 50

10 Mapas representando as posições espaciais das plantas sadias e infectadas por cancro cítrico, em que • são as plantas infectadas e •, as plantas sadias. A. Talhão C02, B. Talhão K026 e C. Talhão K097 . . . . . . . . . . 78

11 Mapas representando as posições espaciais das plantas sadias e infectadas por morte súbita dos citros, em que • são as plantas infectadas e •, as plantas sadias. A. Talhão 107C, vistoriado em 27/08/01, 31/12/01 e 10/05/02, B. Talhão 303, vistoriado em 01/08/01, 07/11/01 e 08/05/02 .

12 Mapa representando as posições espaciais das plantas sadias e infectadas com tristeza dos citros, em que • são as infecções identificadas em 1981, $\triangle$, as infecções identificadas em 1982 e •, as plantas sadias . . . . . . . .

13 Mapa representando as posições espaciais das plantas sadias e infectadas por A. Hop latent virus, B. Hop mosaic virus e C. Apple mosaic virus, em que • são as infecções identificadas em 1996, $\triangle$, as infecções identificadas em 1997 e •, as plantas sadias . . . . . . . . . . . . . .

14 Mapas simulados considerando um látice 11x11 e o modelo apresentado em (25), em que $\oplus$ representa a planta doente inicialmente, • são as novas plantas infectadas e referem-se às plantas sadias. Os valores do parâmetro utilizados nas simulações foram: A. $\alpha=0,5$; B. $\alpha=1,0$; C. $\alpha=2,0$ e D. $\alpha=3,0 \ldots \ldots \ldots$. . . . . . . . . . . . 100

15 Valor exato (o) e estimativas de $\pi(\alpha \mid \mathcal{E})$, obtidas pelo método proposto por Gibson (1997b) (+) e proposto neste trabalho (-), para os dados da Figura 14, considerando o modelo (25). Valores de $\alpha$ utilizados nas simulações: A. $\alpha=0,5$; B. $\alpha=1,0$; C. $\alpha=2,0$ e D. $\alpha=3,0$. . . . . 102 
16 Mapas simulados considerando um látice 25x25 e utilizando o modelo apresentado em (26), em que $\oplus$ representa a planta doente inicialmente, - são as novas plantas doentes e • são as plantas sadias. Os valores dos parâmetros utilizados foram: A. $\alpha_{1}=0,1, \alpha_{2}=0$; B. $\alpha_{1}=0, \alpha_{2}=2,0$; C. $\alpha_{1}=0,1, \alpha_{2}=2,0$ e D. $\alpha_{1}=0,1, \alpha_{2}=1,0 \ldots \ldots$. . . . . 105

17 Gráficos com as verossimilhanças aproximadas, $\hat{\pi}(\boldsymbol{\alpha} \mid \mathcal{E})$, padronizadas, de tal forma que o máximo seja igual a 1,0 e gráficos de contornos, obtidos utilizando-se as metodologias de Gibson (A) e proposta (B), considerando o látice apresentado na Figura 16A, simulado utilizando-se o modelo (26), com parâmetros: $\alpha_{1}=0$ e $\alpha_{2}=2$, em que $\bullet$ representa o máximo da verossimilhança . . . . . . . . . . . . . . . . . . . 108

18 Gráficos com as verossimilhanças aproximadas, $\hat{\pi}(\boldsymbol{\alpha} \mid \mathcal{E})$, padronizadas, de tal forma que o máximo seja igual a 1,0 e gráficos de contornos, obtidos utilizando-se as metodologias de Gibson (A) e proposta (B), considerando o látice apresentado na Figura 16B, simulado utilizando-se o modelo (26), com parâmetros: $\alpha_{1}=0,1$ e $\alpha_{2}=2$, em que $\bullet$ representa o máximo da verossimilhança . . . . . . . . . . . . . . . . . . 109

19 Gráficos com as verossimilhanças aproximadas, $\hat{\pi}(\boldsymbol{\alpha} \mid \mathcal{E})$, padronizadas, de tal forma que o máximo seja igual a 1,0 e gráficos de contornos, obtidos utilizando-se as metodologias de Gibson (A) e proposta (B), considerando o látice apresentado na Figura 16C, simulado utilizando-se o modelo (26), com parâmetros: $\alpha_{1}=0,1$ e $\alpha_{2}=1$, em que $\bullet$ representa o máximo da verossimilhança . . . . . . . . . . . . . . . . . 110

20 Gráficos com as verossimilhanças aproximadas, $\hat{\pi}(\boldsymbol{\alpha} \mid \mathcal{E})$, padronizadas, de tal forma que o máximo seja igual a 1,0 e gráficos de contornos, obtidos utilizando-se as metodologias de Gibson (A) e proposta (B), considerando o látice apresentado na Figura 16D, simulado utilizando-se o modelo (26), com parâmetros: $\alpha_{1}=0,1$ e $\alpha_{2}=0 \ldots \ldots \ldots$. . . . . . . . 111 
21 Estimativas de $\pi(\alpha \mid \mathcal{E})$, obtidas pelo método proposto por Gibson (1997b) $(+)$ e proposto neste trabalho (-), para os dados da Figura 12, con-

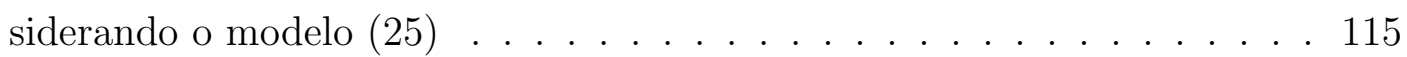

22 Gráficos com as verossimilhanças aproximadas, $\hat{\pi}(\boldsymbol{\alpha} \mid \mathcal{E})$, padronizadas, de tal forma que o máximo seja igual a 1,0 e gráficos de contornos, obtidos utilizando-se as metodologias de Gibson (A) e proposta (B), considerando o látice apresentado na Figura 13A e o modelo (26). • representa o máximo da verossimilhança . . . . . . . . . . . . . . . . 117

23 Gráficos com as verossimilhanças aproximadas, $\hat{\pi}(\boldsymbol{\alpha} \mid \mathcal{E})$, padronizadas, de tal forma que o máximo seja igual a 1,0 e gráficos de contornos, obtidos utilizando-se as metodologias de Gibson (A) e proposta (B), considerando o látice apresentado na Figura 13B e o modelo (26). • representa o máximo da verossimilhança . . . . . . . . . . . . . . . . 118

24 Gráficos com as verossimilhanças aproximadas, $\hat{\pi}(\boldsymbol{\alpha} \mid \mathcal{E})$, padronizadas, de tal forma que o máximo seja igual a 1,0 e gráficos de contornos, obtidos utilizando-se as metodologias de Gibson (A) e proposta (B), considerando o látice apresentado na Figura $13 \mathrm{C}$ e o modelo (26). • representa o máximo da verossimilhança . . . . . . . . . . . . . . . 119

25 Gráficos com as verossimilhanças aproximadas, $\hat{\pi}(\boldsymbol{\alpha} \mid \mathcal{E})$, padronizadas, de tal forma que o máximo seja igual a 1,0 e gráficos de contornos, obtidos utilizando-se as metodologias de Gibson (A) e proposta (B), considerando o látice apresentado na Figura 10A e o modelo (26). • representa o máximo da verossimilhança . . . . . . . . . . . . . . . . . 122

26 Gráficos com as verossimilhanças aproximadas, $\hat{\pi}(\boldsymbol{\alpha} \mid \mathcal{E})$, padronizadas, de tal forma que o máximo seja igual a 1,0 e gráficos de contornos, obtidos utilizando-se as metodologias de Gibson (A) e proposta (B), considerando o látice apresentado na Figura 10B e o modelo (26). • representa o máximo da verossimilhança . . . . . . . . . . . . . . . . 123 
27 Gráficos com as verossimilhanças aproximadas, $\hat{\pi}(\boldsymbol{\alpha} \mid \mathcal{E})$, padronizadas, de tal forma que o máximo seja igual a 1,0 e gráficos de contornos, obtidos utilizando-se as metodologias de Gibson (A) e proposta (B), considerando o látice apresentado na Figura 10C e o modelo (26). • representa o máximo da verossimilhança . . . . . . . . . . . . . . . . . 124

28 Estimativas dos parâmetros $\alpha_{1}$ e $\alpha_{2}$, obtidas em diferentes tempos, $t$, de avaliação dos talhões A. 107C e B. 303. —— são as estimativas obtidas utilizando-se a metodologia original e — , a proposta nesse trabalho 128 


\section{LISTA DE TABELAS}

Página

1 Tabela com a representação dos resultados das significâncias das SCF

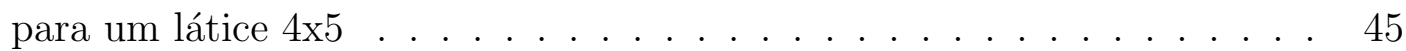

2 Descrição dos talhões $107 \mathrm{C}$ e 303, infectados com morte súbita dos citros 81

3 Estimativas de $\alpha$, do modelo (25), para o caso dos mapas apresentados nas Figuras 14A, 14B e 14C, obtidas através de três metodologias diferentes 103

4 Estimativas de $\alpha_{1}$ e $\alpha_{2}$, do modelo (26), para o caso dos látices apresentados na Figura 16 . . . . . . . . . . . . . . . . . . . . . . . . 112

$5 \quad$ Estimativas de $\alpha_{1}$ e $\alpha_{2}$, do modelo (26), para o caso dos látices apresen-

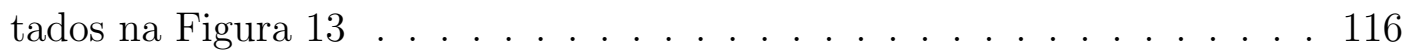

6 Estimativas de $\alpha_{1}$ e $\alpha_{2}$, do modelo (26), para o caso dos látices apresentados na Figura 10 . . . . . . . . . . . . . . . . . 125

7 Estimativas de $\alpha_{1}$ e $\alpha_{2}$, do modelo (26), para o caso dos talhões 107C e 303, apresentados na Figura 11 . . . . . . . . . . . . . . . 127 


\title{
MODELAGEM ESPAÇO-TEMPORAL PARA DADOS DE INCIDÊNCIA DE DOENÇAS EM PLANTAS
}

\author{
Autor: Renato Ribeiro De Lima

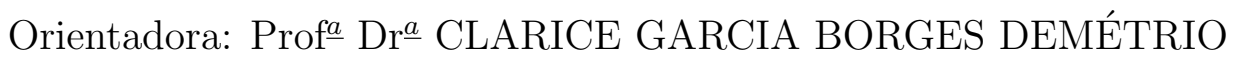

RESUMO

A informação sobre a dinâmica espaço-temporal de doenças de plantas é de importância fundamental em estudos epidemiológicos, podendo ser utilizada para descrever e entender o desenvolvimento das doenças, desenvolver planos de amostragem, planejar experimentos controlados e caracterizar perdas na produção ocasionadas pela doença. O estudo de padrões espaciais de doenças de plantas, que são reflexos do processo de dispersão dos patógenos, é importante em estudos epidemiológicos, como o de doenças dos citros, para se definirem estratégias mais adequadas para o controle das doenças, diminuindo os prejuízos causados. A Citricultura é uma das principais atividades agrícolas do Brasil e representa a principal atividade econômica de mais de 400 municípios do Triângulo Mineiro e do Estado de São Paulo, onde se encontra a maior área de citros do país e a maior região produtora 
de laranjas do mundo. Na avaliação do padrão espacial, diferentes métodos têm sido utilizados, dentre os quais incluem-se o ajuste de distribuições, como, por exemplo, a distribuição beta-binomial, o estudo da relação variância-média, o cálculo de correlação intraclasse, a utilização de técnicas de autocorrelação espacial, métodos de classes de distâncias e o ajuste de modelos estocásticos espaço-temporais. Diante da importância de se estudarem padrões espaciais da incidência de doenças em plantas e da necessidade de se conhecer melhor a epidemiologia da morte súbita dos citros e do cancro cítrico, uma técnica baseada em verossimilhança para o ajuste de modelos estocásticos espaço-temporais foi utilizada na caracterização de padrões espaciais. Modificações na metodologia original, buscando uma diminuição do tempo gasto nas análises, foram propostas nesse estudo. Os resultados mostram que as modificações propostas resultaram em uma diminuição significativa no tempo de análise, sem perda de acurácia na estimação dos parâmetros dos modelos considerados. 


\title{
SPATIOTEMPORAL MODELLING OF PLANT DISEASE INCIDENCE
}

\author{
Author: Renato Ribeiro De Lima \\ Adviser: Prof $\underline{a}$ Dr $\underline{a}$ CLARICE GARCIA BORGES DEMÉTRIO
}

SUMMARY

The information about the spatial-temporal dynamics is of fundamental importance in epidemiological studies for describing and understanding the development of diseases, for developing efficient sampling plans, for planning controlled experiments, for evaluating the effect of different treatments, and for determining crop losses. The Citriculture is the major economic activity of more than $400 \mathrm{mu}-$ nicipalities in Minas Gerais and São Paulo States. This is the largest citrus area in Brazil, and the largest sweet orange production area in the world. Therefore, it is very important to study and to characterize spatial patterns of plant diseases, such as citrus canker and citrus sudden death. In the spatial dynamics study, many different methods have been used to characterize the spatial aggregation. These include the fitting of distributions, such as the beta-binomial distribution, the study of variance-mean relationships, the calculation of intraclass correlation, the use of 
spatial autocorrelation techniques, distance class methods and, the fitting of continuous time spatiotemporal stochastic models. In this work, an improved technique for fitting models to the spatial incidence data by using MCMC methods is proposed. This improved technique, which is used to investigate the spatial patterns of plant disease incidence, is considerably faster than Gibson's methodology, in terms of computational time, without any loss of accuracy. 


\section{INTRODUÇÃO}

A informação sobre a dinâmica espaço-temporal de doenças em plantas é de importância fundamental em estudos epidemiológicos, podendo ser utilizada para descrever e entender o desenvolvimento das doenças (Bassanezi et al., 2003; Gibson, 1997a, 1997b; Gibson \& Austin, 1996; Gottwald, 1995; Gottwald et al., 1996, 1999, 2002; Turechek \& Madden, 1999a, 2000; Xu \& Ridout, 2000, 2001), desenvolver planos de amostragem (Hughes \& Madden, 1994; Madden \& Hughes, 1999; Madden et al., 1996; Marion et al., 2003; Miller et al., 1997; Turechek \& Madden, 2001), planejar experimentos controlados (Hughes \& Madden, 1995), avaliar o efeito de diferentes tratamentos (Madden, 1993; Madden \& Hughes, 1995; Zadoks \& van den Bosch, 1994) e caracterizar perdas na produção ocasionadas pela doença (Ferrandino, 1989; Hughes, 1988; Madden \& Nutter, 1995). O conhecimento detalhado desta dinâmica espaço-temporal possibilita uma visão mais completa da estrutura e do comportamento de patossistemas (Bergamin Filho et al., 2002).

A análise temporal de patossistemas recebeu mais atenção por muitos anos, não por ser mais relevante e sim por ser mais simples e de fácil aplicação (Bergamin Filho et al., 2002). Porém, nas duas últimas décadas, o estudo da dinâmica espacial, que consiste na caracterização de padrões espaciais de doenças em plantas, tem se destacado. O padrão espacial de uma determinada doença é o reflexo do processo de dispersão dos patógenos e, portanto, sua caracterização é importante em estudos epidemiológicos (Bergamin Filho et al., 2003; Hughes et al., 1997). Na caracterização desse padrão espacial, diferentes métodos têm sido utilizados, dentre os quais incluem-se o ajuste de distribuições, como, por exemplo, a 
distribuição beta-binomial, a dados provenientes de quadrats (Hughes \& Madden, 1993; Madden \& Hughes, 1995, 1999; Turechek \& Madden, 2001) e o estudo da relação variância-média para esses dados, freqüentemente estabelecida pela lei de potência binária (Hughes \& Madden, 1992; Madden \& Hughes, 1995, 1999; Ridout \& Xu, 2000; Turechek \& Madden, 2001; Xu \& Ridout, 2000), o cálculo de correlação intraclasse (Ridout \& Xu, 2000; Ridout et al., 1999; Xu \& Ridout, 1998, 2000, 2001), a utilização de técnicas de autocorrelação espacial (Campbell \& Madden, 1990; Gottwald, 1995; Madden \& Hughes, 1995; Ridout \& Xu, 2000; Turechek \& Madden, 2001; Xu \& Ridout, 1998, 2001), métodos geoestatísticos (Chellemi et al., 1988; Gottwald et al., 1996, 2002; Stein et al., 1994), métodos de classes de distâncias (Ferrandino, 1996, 1998; Gottwald, 1995; Gray et al., 1986; Nelson, 1995; Nelson et al., 1992) e o ajuste de modelos estocásticos espaço-temporais (Gibson, 1997a, 1997b; Gibson \& Austin, 1996; Gottwald et al., 1999).

A Citricultura é uma das principais atividades agrícolas do Brasil e representa a principal atividade econômica de 440 municípios do Estado de São Paulo e do Triângulo Mineiro (Fundecitrus, 2004f), onde se encontra a maior área de citros do país e a maior região produtora de laranjas do mundo. Segundo um estudo de mapeamento do sistema agroindustrial citrícola desenvolvido pelo Programa de Estudos dos Negócios do Sistema Agroindustrial da Universidade de São Paulo PENSA/USP, com o apoio do Fundo de Defesa da Citricultura (Fundecitrus), o setor citrícola movimentou US\$3,23 bilhões em 2003 (sem contar atacado e varejo), sendo US\$1,33 bilhão referentes à exportação (Abecitrus, 2004; Fundecitrus, 2004c). Portanto, o estudo epidemiológico de doenças em citros é de fundamental importância para se definirem estratégias mais adequadas para o controle das doenças, diminuindo os prejuízos causados.

O cancro cítrico e a morte súbita dos citros (MSC) são duas das principais doenças que causam grandes prejuízos à citricultura brasileira. A morte súbita dos citros (MSC) é uma nova doença, de etiologia ainda desconhecida, que foi descrita pela primeira vez em 2001, com base nos sintomas apresentados pelas plantas 
doentes, observadas em pomares do Triângulo Mineiro e Estado de São Paulo. A MSC representa uma séria ameaça e um grande desafio para a citricultura nacional, pois as plantas enxertadas sobre limão 'Cravo', que representam $85 \%$ dos pomares paulistas e mineiros, são suscetíveis (Bassanezi et al., 2003; Jesus Júnior \& Bassanezi, 2004). O cancro cítrico é o mais grave problema fitossanitário dos citros (Bergamin Filho et al., 2002) e, como não há medidas de controle capazes de eliminar completamente o cancro cítrico, a principal medida adotada tem sido a destruição das plantas infectadas e "expostas", o que causa grande prejuízo à citricultura.

Diante da importância de se estudarem padrões espaciais da incidência de doenças em plantas e da necessidade de se conhecer melhor a epidemiologia da MSC e do cancro cítrico, o presente trabalho teve como objetivos:

(i) fazer uma revisão de literatura sobre padrões espaciais e metodologias utilizadas na sua caracterização;

(ii) estudar a metodologia proposta por Gibson \& Austin (1996) e modificada por Gibson (1997b), a qual utiliza uma técnica baseada em verossimilhança para o ajuste de modelos estocásticos espaço-temporais e propor modificações na metodologia original, buscando uma otimização do tempo gasto nas análises;

(iii) simular dados de incidência de doenças em plantas, representando condições reais e utilizar esses dados na comparação de diferentes modelos estocásticos, os quais diferem na forma como a transmissão da doença será representada e na verificação se as modificações propostas surtiram algum efeito;

(iv) implementar os métodos em programas computacionais;

(v) caracterizar o padrão espacial da incidência de cancro cítrico e MSC em pomares do Triângulo Mineiro e do Estado de São Paulo, utilizando modelos estocásticos espaço-temporais e métodos de Monte Carlo via cadeias de Markov (MCMC) para a estimação dos parâmetros. 


\section{REVISÃO DE LITERATURA}

\subsection{Citricultura - aspectos econômicos}

A fruticultura é estratégica para o agronegócio brasileiro. Com superávit de US\$267 milhões em 2003, o setor ocupa uma área de 3,4 milhões de hectares. O Brasil é o terceiro maior produtor mundial de frutas, com uma produção anual de cerca de 38 milhões de toneladas, sendo 21 milhões de toneladas absorvidas pelo mercado interno e o restante destinado à exportação (Ministério da Agricultura, Pecuária e Abastecimento, 2004). Dentro da fruticultura, deve-se destacar a citricultura, a qual, apesar de englobar laranja, limão, lima, tangerina e pomelo, tem como principal produto a laranja.

Segundo um estudo de mapeamento do sistema agroindustrial citrícola desenvolvido pelo PENSA - Programa de Estudos dos Negócios do Sistema Agroindustrial da Universidade de São Paulo (USP), com o apoio do Fundo de Defesa da Citricultura (Fundecitrus), o setor citrícola movimentou US $\$ 3,23$ bilhões em 2003 (sem contar atacado e varejo), sendo US\$1,33 bilhão referentes à exportação. Esse setor representa cerca de 1,87\% do total das exportações brasileiras e 4,47\% das exportações de produtos do agronegócio (Abecitrus, 2004; Fundecitrus, 2004c; NOVA avaliação..., 2004). Segundo o PENSA, a laranja representa $49 \%$ de toda a produção brasileira de frutas, sendo o Brasil o maior produtor mundial de laranjas. A área cultivada de laranjas corresponde a 820 mil hectares, dos quais $77 \%$ estão na região Sudeste (Abecitrus, 2004). De acordo com a Food and Agriculture Organization of the United Nations - FAO (FAOSTAT data, 2004), o Brasil foi responsável por 
28,21\% da produção mundial de laranjas em 2003, que foi cerca de 60 milhões de toneladas, seguido pelo EUA com 17,44\%.

De acordo com a Secretaria de Agricultura e Abastecimento do Estado de São Paulo (2003), o Estado de São Paulo, onde se concentra a maior área produtora de laranjas do mundo, é responsável pela produção de $78 \%$ da laranja brasileira, o que corresponde a cerca de $22 \%$ da produção mundial e é responsável por $97 \%$ das exportações brasileiras. A citricultura é a principal atividade econômica de 440 municípios paulistas e do Triângulo Mineiro (Fundecitrus, 2004f), sendo responsável por mais de 400 mil empregos diretos e movimentando US\$7 bilhões anualmente (Souza, 2001).

O principal produto de exportação brasileiro é o suco de laranja concentrado e congelado, o FCOJ - frozen concentrate orange juice. O Brasil é o maior produtor e exportador mundial de suco de laranja, a ponto de chegar a fornecer aproximadamente $80 \%$ de todo o suco distribuído no mundo (FNP, 2004). Do total das exportações do setor citrícola, 95,5\% corresponde a suco de laranja, sendo que este ocupou em 2003 a segunda posição entre os produtos comercializados no mercado internacional, ficando atrás apenas das exportações de aviões (Ministério da Agricultura, Pecuária e Abastecimento, 2004). Os EUA também são grandes produtores de suco de laranja, porém praticamente toda a produção é voltada para atender seu próprio mercado interno.

Várias dificuldades são encontradas pelos produtores de citros, como por exemplo os problemas fitossanitários. Nos últimos 20 anos, novas pragas e doenças importantes foram identificadas, exigindo acompanhamento e avaliação, assim como um estudo detalhado do comportamento e do desenvolvimento dessas pragas e doenças. Dentre elas podem-se citar a clorose variegada dos citros (CVC) ou amarelinho, identificada oficialmente no Brasil em 1987, a larva minadora dos citros que causa ferimentos nas folhas, facilitando a contaminação pela bactéria do cancro cítrico e aumentando os índices dessa doença, a morte súbita dos citros (MSC), identificada em 2001 e sem causa ainda confirmada e, mais recentemente, o green- 
ning, considerada a doença mais importante em muitos países e que foi identificada nos pomares brasileiros em março de 2004 (Fundecitrus, 2004g; Fundecitrus, 2004h; FNP, 2004).

\subsection{Doenças dos citros - cancro cítrico e MSC}

\subsubsection{Cancro cítrico}

O cancro cítrico é uma doença causada pela bactéria Xanthomonas axonopodis pv. citri (sin. Xanthomonas campestris pv. citri) que provoca lesões necróticas típicas nas folhas, frutos e galhos (Figura 1), causando a queda prematura dos frutos, queda das folhas, seca de ponteiros e declínio generalizado da planta. Essa bactéria se espalha facilmente pelo pomar, sendo o próprio homem um dos maiores disseminadores. Folhas, frutos e ramos jovens são mais facilmente contaminados, enquanto que os mais velhos têm que apresentar algum tipo de ferimento para a contaminação pela bactéria. Esses ferimentos normalmente são causados por material de collheita, pelo vento ou por veículos que transitam pelo pomar e que também podem trazer a bactéria, entre outros (Fundecitrus, 2004a). Como conseqüência da doença, além da perda de qualidade dos frutos e diminuição da produção, têm-se restrições na comercialização nacional e internacional de mudas e frutos in natura para regiões livres da doença (Christiano, 2003).

Essa doença é originária do Sudoeste Asiático, onde ocorre endemicamente e é conhecida no mundo inteiro, ocorrendo na Flórida (EUA), em alguns países da África e em vários países da América do Sul, como Argentina, Brasil, Paraguai e Uruguai, dentre outros países do mundo (Gottwald et al., 2002; Feichtenberger et al., 1997; Schubert et al., 2001). Em alguns países, como África do Sul e Nova Zelândia, a doença foi erradicada. Na Austrália, onde a doença havia sido erradicada, foi identificado um foco no Estado de Queensland em julho de 2004, o que levou à destruição de 8000 árvores (Scott, 2004; Queensland Government, 2004). 

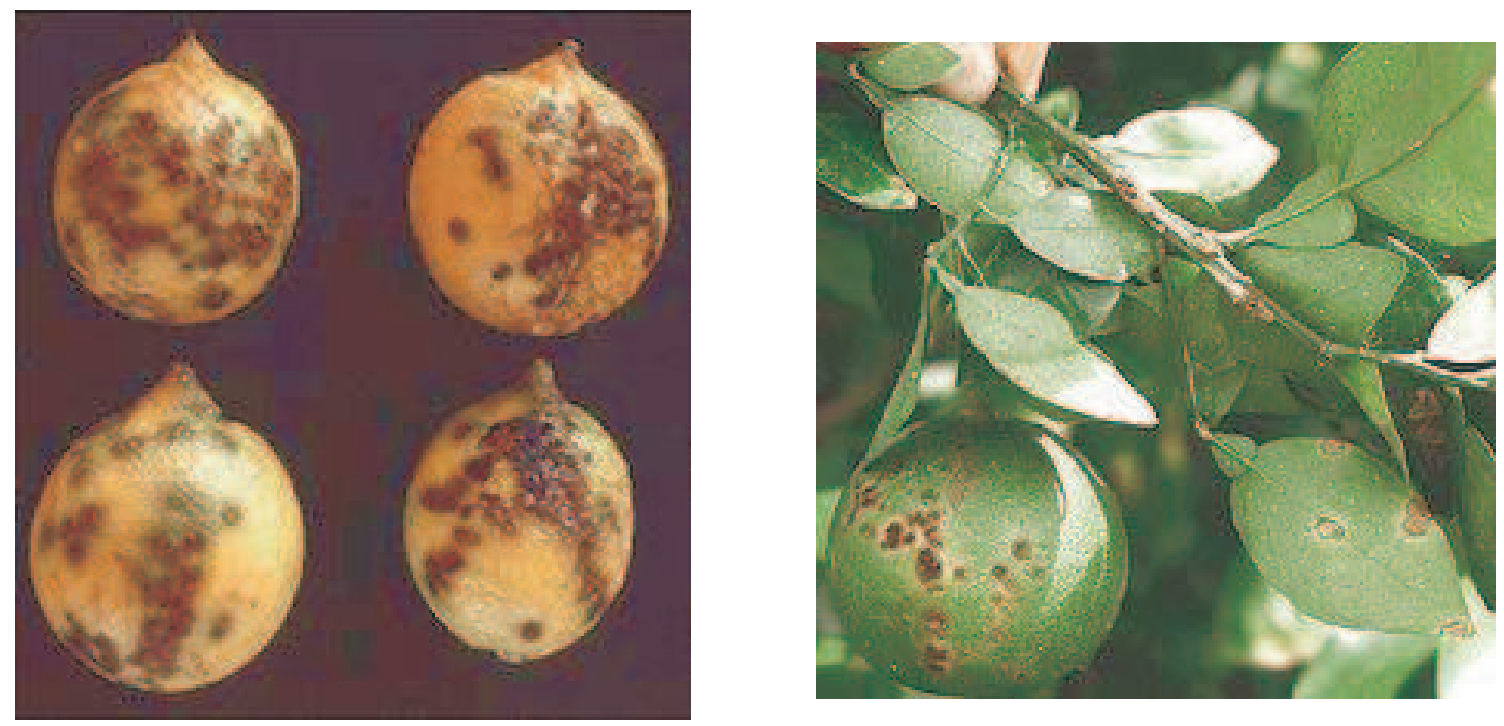

Figura 1 - Lesões causadas pelo cancro cítrico nos frutos, galhos e folhas

O cancro cítrico sempre constituiu séria ameaça para a citricultura brasileira. De acordo com Feichtenberger et al. (1997), foi constatado pela primeira vez no Brasil em 1957, na região de Presidente Prudente, SP, de onde se disseminou para outras regiões paulistas e outros estados, como Minas Gerais, Mato Grosso do Sul, Mato Grosso, Paraná, Santa Catarina e Rio Grande do Sul.

A disseminação do cancro cítrico dentro de um pomar ocorre entre folhas, frutos e galhos de uma mesma planta infectada e também entre plantas. Além do homem, como principal responsável pela disseminação da doença, a bactéria pode ser disseminada pelas gotas de chuva que, quando associada a ventos, pode alcançar distâncias maiores e por mudas contaminadas, o que contribui para a disseminação entre propriedades e regiões diferentes. A disseminação da doença em um pomar pode ser muito rápida, dependendo da variedade ou espécie cítrica, idade e condição do pomar, ocorrência de chuvas com ventos, trânsito de pessoas, da adoção ou não de medidas para a prevenção da doença, entre outros fatores (Fundecitrus, 2004a; Christiano, 2003). De acordo com o Fundecitrus (2004a), quando se tem um número pequeno de plantas infectadas, existe a tendência dessas plantas se localizarem mais próximas umas das outras, formando grupos e, com o tempo, todo o pomar pode ser 
infectado, principalmente se houver condições favoráveis à disseminação da doença, como estar na estação chuvosa por exemplo.

Um fator agravante, que tem favorecido a disseminação do cancro cítrico na Flórida, nos EUA e no Brasil, é a presença de um inseto: a larva minadora dos citros, Phyllocnistis citrella. Esse inseto foi detectado pela primeira vez em 1993, na Flórida e em 1996 no Brasil. Ela facilita a contaminação pela bactéria do cancro cítrico pois, uma vez que se alimenta das folhas, provoca ferimentos que servem de porta de entrada para a doença (Gottwald et al., 2002; Fundecitrus, 2003). De acordo com Bergamin Filho et al. (2000), a interação entre a doença e a presença do inseto foi evidente. No Estado de São Paulo, o número de talhões de cancro cítrico aumentou de 25, em 1995, para 4.180 em 1999 aliado a uma mudança no padrão espacial da doença: padrões agregados, típicos de 1957 a 1995, deram lugar a padrões menos agregados ou aleatórios.

Como não há medidas de controle capazes de eliminar completamente o cancro cítrico, a principal medida adotada para se controlar a disseminação da doença e tentar sua erradicação, tem sido a destruição das plantas infectadas e "expostas", ou seja, aquelas que estão num raio de 30 m. No Estado de São Paulo, talhões que apresentam incidência da doença maior do que $0,5 \%$ são completamente eliminados. No caso de talhões abaixo de 0,5\% de plantas doentes, apenas estas e as plantas "expostas" são destruídas. Na Figura 2 podem ser observadas áreas onde as plantas foram destruídas (Bergamin Filho et al., 2000; Fundecitrus, 2003).

Graças à adoção de medidas de exclusão e erradicação pela Campanha Nacional de Erradicação do Cancro Cítrico (CANECC), tem-se conseguido manter a doença sob controle nas principais regiões produtoras nacionais. Por exemplo, de maio a novembro de 1999, o Fundo de Defesa da Citricultura (Fundecitrus) e a Secretaria de Agricultura e Abastecimento do Estado de São Paulo realizaram a maior ação de campo da história da citricultura brasileira para identificar e erradicar árvores de citros contaminadas por cancro cítrico no Estado de São Paulo e parte do Triângulo Mineiro (Feichtenberger et al., 1997). De acordo com Bergamin Filho 


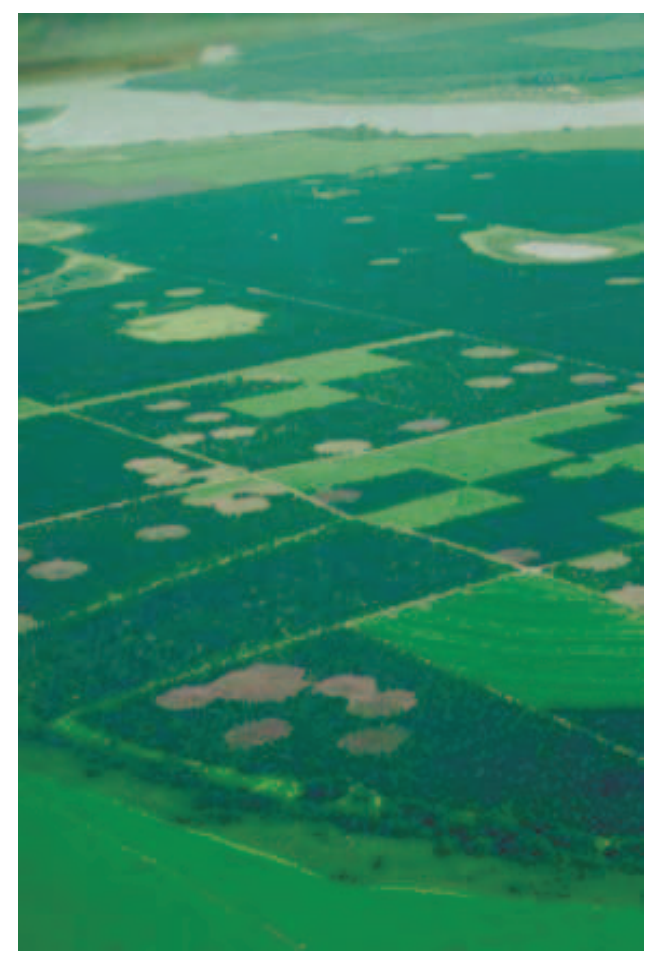

Figura 2 - Vistas aéreas de pomares em que se vê o método de erradicação adotado no Estado de São Paulo

\& Hughes (2000) e Bergamin Filho et al. (2000), o cancro cítrico foi detectado em 299.856 plantas no ano de 1999 e, como consequência, 1.737 .545 árvores foram destruídas. A campanha de erradicação ainda não conseguiu eliminar totalmente o cancro cítrico no Estado de São Paulo, porém tem mantido a doença sob controle, impedindo que esta se dissemine por toda a área produtora (Christiano, 2003). De acordo com o último levantamento do cancro cítrico realizado pelo Fundecitrus (Fundecitrus, 2004b), a incidência da doença em todo o Estado de São Paulo diminuiu de 0,22\% no levantamento de 2003 para 0,14\% em 2004, o que é apontado como uma conseqüência da intensificação da inspeção do Fundecitrus e da erradicação executada pela Secretaria da Agricultura e Abastecimento do Estado de São Paulo.

O conhecimento da epidemiologia do cancro cítrico é indispensável para se definirem estratégias mais adequadas para o controle da doença e para que se aumentem as chances de erradicação total da mesma. Para isso é importante o estudo da dinâmica espaço-temporal da doença, utilizando-se de técnicas e métodos estatísticos específicos para esse fim. 


\subsubsection{Morte Súbita dos Citros}

A morte súbita dos citros (MSC) é uma nova doença, de etiologia ainda desconhecida, que foi descrita pela primeira vez em 2001 (Gimenes-Fernandes \& Bassanezi, 2001) com base nos sintomas apresentados pelas plantas doentes, observadas em pomares do Triângulo Mineiro e de São Paulo. De acordo com Bassanezi et al. (2003a), as primeiras observações da doença foram feitas no município de Comendador Gomes, no Triângulo Mineiro em 1999.

A MSC é uma doença associada ao porta-enxerto (Centro de Citricultura, 2004) e seu diagnóstico é realizado com base nos sintomas apresentados pelas plantas doentes, pois não é possível diagnosticar a MSC antes do aparecimento desses sintomas, uma vez que ainda não se conhece o agente causal e não se tem um teste para o diagnóstico precoce. Plantas infectadas com sintomas da doença podem ser vistas na Figura 3. As plantas doentes apresentam definhamento generalizado, o que não permite o diagnóstico preciso da doença, pois tratam-se de sintomas característicos da ausência de um sistema radicular abundante e funcional (Bassanezi et al., 2003b). Inicialmente, ocorre a perda generalizada do brilho das folhas das plantas doentes, perdendo a coloração verde-escura, que é uma característica de folhas bem nutridas e sadias, ficando de cor verde-claro, tendendo para o amarelo-esverdeado. Com a evolução da doença, ocorre a desfolha parcial das plantas, as quais apresentam poucas brotações e ausência de brotações internas. O sistema radicular apresenta grande quantidade de raízes podres e mortas. A morte do sistema radicular

é conseqüência do bloqueio dos vasos do floema, que transportam a seiva elaborada das folhas para as raízes. O sintoma característico da doença é o aparecimento de coloração amarela, tendendo para o alaranjado, na parte interna da casca do portaenxerto, logo abaixo da zona de enxertia (Bassanezi et al., 2003b; Jesus Júnior \& Bassanezi, 2004; Fundecitrus, 2004e). 

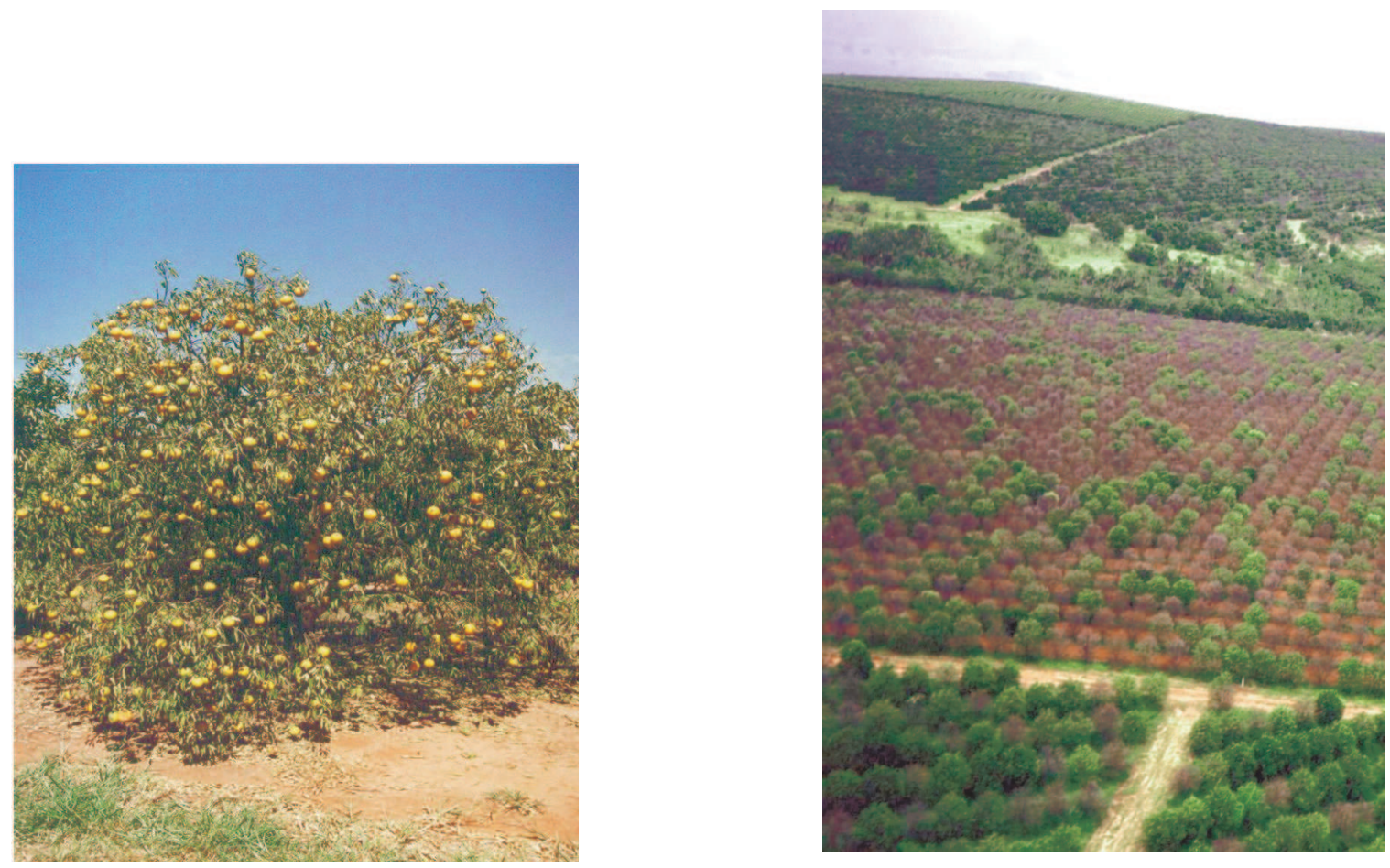

Figura 3 - Planta com sintomas de MSC e vista aérea de um pomar com várias plantas infectadas

A MSC foi detectada e se manteve restrita a municípios do norte e noroeste do Estado de São Paulo e sul do Triângulo Mineiro (Bassanezi et al., 2003b). Um levantamento realizado pelo Fundecitrus e apresentado em fevereiro de 2004 (Fundecitrus, 2004d) constatou a doença em 29 municípios do Estado de São Paulo e Sul do Triângulo Mineiro, sendo verificado um avanço de $60 \mathrm{~km}$ pela MSC em um ano. Ainda segundo o Fundecitrus (2004d), em 2002 a doença estava presente em cinco municípios de São Paulo, com cerca de 22 mil plantas doentes. Já em 2003, a doença foi constatada em 18 municípios e em mais de 44 mil plantas, retirando as plantas erradicadas no período. A estimativa, segundo Fundecitrus, é de que 400 mil plantas tenham sido erradicados no Estado de São Paulo devido à MSC, o que representa um prejuízo de US\$8 milhões. Porém, a maior parte das plantas com MSC, mais de 90\% das plantas doentes (Bassanezi et al., 2003b), se encontram em Minas Gerais e, considerando esses dados, estima-se que 2 milhões de árvores tenham sido afetadas pela MSC desde o aparecimento da doença, o que representa 
um prejuízo de US\$40 milhões (Fundecitrus, 2004d).

A MSC representa uma séria ameaça e um grande desafio para a citricultura paulista e nacional, pois as plantas enxertadas sobre limão 'Cravo', que representam 85\% dos pomares paulistas e mineiros, são suscetíveis (Bassanezi et al., 2003b; Jesus Júnior \& Bassanezi, 2004; Fundecitrus, 2004e).

O agente causal da doença ainda não foi confirmado. Porém, considerando as semelhanças entre a MSC e a tristeza dos citros, que é causada pelo CTV (Citrus tristeza virus, família Closteroviridae) e ocorre em laranjeira doce enxertada sobre laranjeira 'Azeda' (Citrus aurantium L.), uma das hipóteses para a etiologia da MSC é que a doença seja causada por um vírus disseminado por um vetor, de maneira semelhante à tristeza dos citros na sua forma de declínio rápido (Bassanezi et al., 2003b; Jesus Júnior \& Bassanezi, 2004; Fundecitrus, 2004e; Secretaria de Agricultura e Abastecimento do Estado de São Paulo, 2003). Bassanezi et al. (2003b) apresentam uma série de observações e evidências relacionadas à semelhança entre a MSC e a tristeza dos citros. Segundo esses autores, as duas doenças afetam plantas com porta-enxertos específicos, o limão 'Cravo' no caso da MSC e a laranja 'Azeda' no caso da tristeza, sendo que, com a troca dos porta-enxertos, as plantas se recuperam e as duas doenças apresentam semelhanças na sintomatologia, progresso das doenças e distribuição espacial das plantas doentes.

Mais recentemente (Brito, 2004), foi anunciado que a Alellyx Applied Genomics, uma empresa de biotecnologia, identificou o vetor responsável pela transmissão do Citrus Sudden Death Virus (CSDV) ou vírus da morte súbita dos citros, um novo tipo de vírus da família Tymoviridae descoberto em 2003 por esta empresa e que pode estar associado à MSC. O vírus foi encontrado em três espécies de pulgões, Toxoptera citricida, Aphis spiraecola e Aphis gossypii, coletados nas regiões norte de São Paulo e sul do Triângulo Mineiro. Porém, a pesquisa ainda não foi encerrada e não está totalmente comprovado que este vírus seja o agente causal da MSC.

Com relação ao padrão espacial, Bassanezi et al. (2003b) e Jesus Júnior \& Bassanezi (2004) concluem que a distribuição espacial das plantas com MSC é 
muito semelhante ao de plantas com sintomas da tristeza dos citros em regiões onde ocorre o pulgão-marrom, Toxoptera citricida, o que indica que os processos de disseminação sejam os mesmos, ou seja, que a MSC seja causada por um agente biótico transmitido por um vetor, como é o caso da tristeza dos citros. Segundo Jesus Júnior \& Bassanezi (2004), as epidemias de MSC se iniciam com focos unitários distribuídos de maneira aleatória no talhão e com o progresso da doença a tendência é que ocorra um aumento no número desses focos, relativamente distantes uns dos outros, sendo que não ocorre um aumento muito pronunciado no número de plantas doentes em cada um desses focos. Este comportamento também foi detectado por Gottwald et al. (1999) em talhões com tristeza dos citros, onde o principal vetor era o T. citricida.

Os métodos utilizados na avaliação do padrão espacial da MSC nesses três trabalhos foram diferentes. Bassanezi et al. (2003b) utilizaram ordinary runs analysis (Madden et al., 1982) ou teste run, segundo Bergamin Filho et al. (2002), o índice de dispersão (D) obtido a partir da distribuição beta-binomial (Madden \& Hughes, 1995), o coeficiente de correlação intraclasse estimado a partir de D (Xu \& Ridout, 2000) e as estimativas dos coeficientes da equação da lei de potência binária ou lei de potência de Taylor na forma binária (Hughes \& Madden, 1992), enquanto Jesus Júnior \& Bassanezi (2004) utilizaram a análise de dinâmica e estrutura de focos (ADEF) (Laranjeira et al., 1998; Nelson, 1996). Gottwald et al. (1999) ajustaram modelos estocásticos espaço-temporais utilizando métodos de Monte Carlo via cadeias de Markov (MCMC), propostos por Gibson (1997a).

O padrão espacial e o comportamento ou o progresso da MSC ao longo do tempo fornecem informações importantes que podem auxiliar no esclarecimento da etiologia de uma doença (Bassanezi et al., 2003a; Jesus Júnior \& Bassanezi, 2004). De acordo com Bassanezi et al. (2003a), o estudo comparativo entre uma doença cuja etiologia seja desconhecida e uma doença muito bem descrita (como a tristeza do citros, por exemplo) pode auxiliar nesse esclarecimento. Portanto, o estudo da dinâmica espacial e temporal da MSC é muito importante para que se possa formular e dar suporte a hipóteses levantadas em relação à sua etiologia. 


\subsection{Padrão espacial de doenças em plantas}

No estudo das doenças em plantas, Gilligan $(1983)^{1}$, citado por Bergamin Filho et al. (2002), define padrão espacial como o arranjo ou posicionamento das plantas doentes, umas em relação às outras. Assim, em um estudo de padrões espaciais o interesse está na localização das plantas doentes, que são os eventos observados, em uma determinada área, como um talhão ou um pomar. Cressie (1993) diz que quando a variável de interesse a ser analisada é a localização ou a posição dos eventos surge o que se define por padrões pontuais. Diggle (1983) chama os conjuntos de dados apresentados na forma de pontos distribuídos dentro de uma região por padrão espacial pontual e os pontos identificados são chamados de eventos, para diferenciá-los de pontos arbitrários dentro da região em questão. Dados apresentados nessa forma de pontos aparecem com freqüência em diferentes áreas de estudo. Alguns exemplos são: as posições das árvores de uma determinada espécie em uma floresta, de ninhos em uma colônia de pássaros, de núcleos de células em uma secção microscópica de um tecido ou de plantas doentes em um determinado talhão ou pomar.

Campbell \& Madden (1990) dizem que o estudo de padrões espaciais fornece uma descrição de características espaciais das doenças e auxiliam no desenvolvimento de hipóteses em relação aos aspectos biológicos e ambientais associados à dispersão da doença. Estes autores apresentam três classificações para o padrão espacial de plantas doentes: regular, aleatório e agregado ou agrupado, que estão apresentados na Figura 4a. Além disso, segundo esses autores, no padrão regular tem-se que a variância é menor do que a média, indicando subdispersão; para o padrão aleatório, a variância e a média são iguais, tendo-se, portanto, dispersão ou distribuição independente ou aleatória das plantas doentes; já para o padrão agregado, em que a variância é maior do que a média, tem-se superdispersão. Na Figura

\footnotetext{
${ }^{1}$ GILLIGAN, C.A. Modeling of soilborne pathogens. Annual Review of Phytopathology, v.21, p.45-64, 1983.
} 
4b, é apresentada uma situação na qual uma avaliação estatística é necessária para se determinar o padrão espacial.
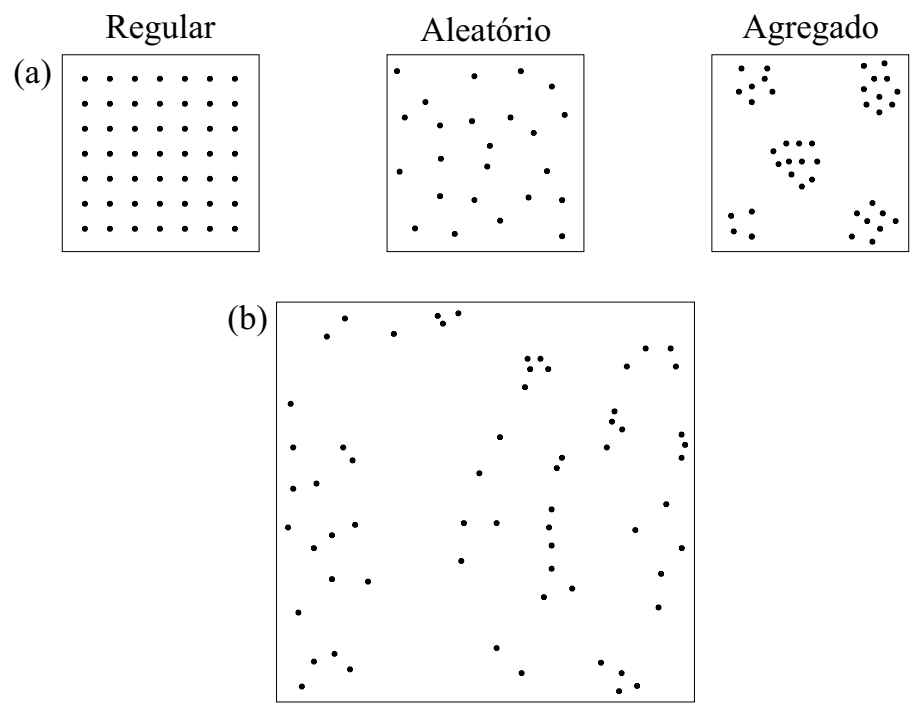

Figura 4 - Padrões espaciais pontuais hipotéticos, em que cada ponto representa uma planta doente. (a) padrões regular, aleatório e agregado ou agrupado; (b) padrão espacial que não é visualmente caracterizado (adaptado de Campbell \& Madden, 1990)

De acordo com Bergamin Filho et al. (2002), o padrão espacial aleatório está relacionado a iguais oportunidades de infecção e o agregado ocorre quando, em condições naturais, o patógeno dispersa-se apenas a curtas distâncias, como por exemplo, através de respingos da chuva e, assim, a probabilidade de que uma planta situada próxima à fonte de inóculo se torne infectada é maior do que a de plantas distantes dessa fonte de infecção. Já o padrão regular, segundo esses mesmos autores, não ocorre de forma natural, mas pode ser provocado com o plantio alternado de variedades resistentes e suscetíveis, por exemplo. Nesse caso, as plantas doentes e sadias ocorreriam de forma alternada.

A comparação da variância com a média, como apresentada por Campbell \& Madden (1990), é amplamente utilizada na literatura sobre padrões espaciais. 
Madden \& Hughes (1995) afirmam que muitos pesquisadores assumem que a distribuição de Poisson é o modelo apropriado para o caso de um padrão aleatório. Isto explica o fato deste tipo de padrão espacial estar associado à igualdade da variância com a média, que é uma propriedade da distribuição de Poisson.

Para explicar a associação da distribuição de Poisson com a ocorrência aleatória de plantas doentes ou de pontos em uma determinada área, pode-se considerar um raciocínio semelhante ao utilizado na obtenção da distribuição de Poisson a partir da distribuição binomial, como apresentado por Upton \& Fingleton (1985). Parte-se da distribuição binomial e considera-se $n \rightarrow \infty, p \rightarrow 0$, de modo que $n p \rightarrow \lambda$ e seja constante (Meyer, 1983).

Considere uma determinada área $A$, em alguma unidade de área conveniente, onde se têm $x$ pontos localizados aleatoriamente e, portanto, independentes. Assim, tem-se uma intensidade de $\lambda=\frac{x}{A}$ pontos por unidade de área. Suponha que a área $A$ seja composta por $n$ sub-regiões extremamente pequenas, de sorte que a probabilidade de que cada uma dessas sub-regiões contenha mais de um ponto seja desprezível. Suponha ainda que, cada um desses $x$ pontos tenha a mesma probabilidade $p$ de estar localizado em qualquer uma das $n$ sub-regiões. Portanto, pode-se assumir que têm-se $x$ sucessos obtidos em $n$ realizações de um ensaio e, sendo $X$ a variável aleatória que representa esse número de sucessos, $X \sim \operatorname{Bin}(n, p)$, ou seja,

$$
P(X=x)=\left(\begin{array}{l}
n \\
x
\end{array}\right) p^{x}(1-p)^{n-x} I_{\{0,1, \ldots, n\}}(x) .
$$

Sendo $\lambda=n p$, o qual representa o número esperado de sucessos por unidade de espaço, ou seja, a intensidade ou o número de pontos por unidade de área, como sendo constante e substituindo $p=\lambda / n$ na eq. (1), tem-se 


$$
\begin{aligned}
P(X=x) & =\left(\begin{array}{l}
n \\
x
\end{array}\right)\left(\frac{\lambda}{n}\right)^{x}\left(1-\frac{\lambda}{n}\right)^{n-x} \\
& =\frac{n !}{x !(n-x) !} \frac{\lambda^{x}}{n^{x}}\left(1-\frac{\lambda}{n}\right)^{n}\left(1-\frac{\lambda}{n}\right)^{-x} \\
& =\frac{n(n-1)(n-2) \ldots(n-x+1)(n-x) !}{x !(n-x) !} \frac{\lambda^{x}}{n^{x}}\left(1-\frac{\lambda}{n}\right)^{n}\left(1-\frac{\lambda}{n}\right)^{-x} \\
& =\frac{\lambda^{x}}{x !} \frac{(n-1)(n-2) \ldots(n-x+1)}{n^{x-1}}\left(1-\frac{\lambda}{n}\right)^{n}\left(1-\frac{\lambda}{n}\right)^{-x} .
\end{aligned}
$$

Note que,

$$
\begin{aligned}
\frac{(n-1)(n-2) \ldots(n-x+1)}{n^{x-1}} & =\frac{(n-1)}{n} \frac{(n-2)}{n} \ldots \frac{(n-x+1)}{n} \\
& =\left(1-\frac{1}{n}\right)\left(1-\frac{2}{n}\right) \ldots\left(1-\frac{x-1}{n}\right)
\end{aligned}
$$

e, portanto

$$
P(X=x)=\frac{\lambda^{x}}{x !}\left(1-\frac{1}{n}\right)\left(1-\frac{2}{n}\right) \ldots\left(1-\frac{x-1}{n}\right)\left(1-\frac{\lambda}{n}\right)^{n}\left(1-\frac{\lambda}{n}\right)^{-x} .
$$

Considerando $n \rightarrow \infty$, o que estaria relacionado a um número grande de subregiões, o termo $\left(1-\frac{\lambda}{n}\right)^{n} \rightarrow e^{-\lambda}$, pela própria definição do número $e$ e os termos $\left(1-\frac{a}{n}\right) \rightarrow 1$, em que $a=1,2, \ldots, x-1$ e $a=\lambda$. Assim,

$$
P(X=x)=\frac{\lambda^{x} e^{-\lambda}}{x !} I_{\{0,1,2, \ldots\}}(x)
$$

que corresponde à distribuição de Poisson.

\subsubsection{Avaliação de padrões espaciais}

Historicamente, segundo Freeman (1953) e Madden \& Hughes (1995), os primeiros a trabalharem com a caracterização de padrões espaciais foram Cochran (1936) e Todd (1940), ambos considerando a distribuição binomial na caracterização de padrões espaciais. Desde aquela época até os dias atuais, vários métodos estatísticos têm sido propostos para a caracterização de padrões espaciais. Segundo Turechek 
\& Madden (1999b), as metodologias podem ser separadas em categorias com base no tipo geral de análise (padrão pontual versus correlação) (Upton \& Fingleton, 1985) ou se os dados consistem de observações mapeadas ou não (Diggle, 1983).

Madden \& Hughes (1995) apresentam uma revisão sobre algumas propriedades estatísticas da incidência de doenças em plantas, descrevendo as distribuições e alguns métodos utilizados para se quantificar a heterogeneidade espacial. Segundo estes autores, o padrão espacial de uma determinada doença pode ser descrito pelo parâmetro de agregação da distribuição beta-binomial, por índices de dispersão e estatísticas relacionadas, por parâmetros da forma binária da lei de potência e por medidas de autocorrelação espacial entre unidades amostrais.

Os métodos apresentados por Madden \& Hughes (1995) são baseados em contagens por unidade amostral e, com exceção de métodos que consideram a autocorrelação espacial, os demais fornecem medidas diretas de heterogeneidade ou variabilidade dos dados entre as unidades amostrais, as quais são funções da associação espacial dos indivíduos dentro dessas unidades amostrais.

De acordo com Ferrandino (1996), caracterizar padrões não aleatórios em termos de uma estatística representada por um único valor ou ajustando distribuições teóricas, não fornece informação sobre a escala física de agregação. Além disso, desde que a maioria das culturas agrícolas são plantadas em linhas, existe razão para se acreditar que o contágio é dependente da direção. Gray et al. (1986) propuseram uma metodologia que incorpora tanto a direção quanto a distância entre as plantas doentes. Essa metodologia, conhecida como um dos métodos de classes de distâncias, foi mais tarde formalizada e utilizada no programa computacional 2DCLASS (Nelson et al., 1992) e estendida para incluir informação temporal, no programa computacional STCLASS (Nelson, 1995).

Com o 2DCLASS e STCLASS, os pares de plantas doentes são contados e separados em classes de distâncias, representadas na forma $[X, Y]$, em que $X$ e $Y$ representam as distâncias entre as plantas em unidades de espaçamento entre linhas e dentro da linha, respectivamente. Freqüências esperadas e limites de confiança são 
calculados estocasticamente utilizando simulação por Monte Carlo, considerando um padrão espacial aleatório. Assim, pode-se determinar se as freqüências calculadas são significativamente diferentes das freqüências esperadas em um determinado padrão espacial. Ferrandino (1996) discute problemas associados à metodologia proposta por Gray et al. (1986) e apresenta como solução um método analítico para o cálculo das freqüências esperadas e para a determinação dos limites de confiança.

Entretanto, essa metodologia pode apresentar deficiências, como, por exemplo, ser sensitiva a pequenos agregados que aparecem nas bordas de uma área. Para corrigir isso, Ferrandino (1998) apresenta o método 2DCORR, que considera, além dos pares de plantas doente-doente, os pares doente-sadia, sadia-doente e sadiasadia na determinação das diferenças significativas entre as freqüências observadas e esperadas em um padrão espacial conhecido.

Turechek \& Madden (1999b) dizem que, como uma alternativa aos métodos de padrões pontuais, várias formas de estatísticas espaciais, como autocorrelações espaciais e semivariâncias, podem ser utilizadas para se obter informação explícita com relação ao grau de associação da intensidade da doença entre as unidades amostrais. Chellemi et al. (1988), Gottwald et al. (1996) e Gottwald et al. (2002) utilizaram métodos geoestatísticos e a função K de Ripley modificada para estudar e descrever características espaciais de doenças de plantas.

Uma aproximação alternativa para o entendimento da dinâmica espaço-temporal é representar os processos biológicos que governam a dispersão das doenças, na forma de modelos matemáticos, os quais podem ser utilizados como ferramentas de pesquisa (Gibson \& Austin, 1996). Assim, Gibson \& Austin (1996), propuseram uma técnica baseada na verossimilhança para o ajuste de modelos estocásticos espaço-temporais a dados de doenças de plantas. Essa metodologia, que considera apenas modelos com um único parâmetro, foi modificada posteriormente por Gibson (1997b) e estendida para o caso de modelos com dois parâmetros por Gibson (1997a). No caso de modelos com um único parâmetro, esse método também apresenta a mesma deficiência criticada por Ferrandino (1996), de que o padrão espa- 
cial seria caracterizado em termos de uma única medida, a estimativa do parâmetro do modelo. Com certeza, não se têm informações sobre a escala física de agregação, ou seja, se há um único grupo agregado de plantas doentes ou vários grupos em um mesmo talhão. Porém, esse problema pode ser solucionado com a utilização de modelos com dois parâmetros, quando esses dois tipos de padrões espaciais agregados podem ser identificados, como pode ser visto em Gibson (1997a).

\subsubsection{Apresentação dos dados para o estudo de padrões espaciais}

A interpretação ecológica adequada do padrão espacial de doenças, ou da distribuição de espécies, depende da experiência do pesquisador para se obterem adequadamente dados que sejam precisos e acurados (Campbell \& Madden, 1990). Métodos para obtenção adequada de dados são bastante discutidos por Campbell \& Madden (1990) e um resumo sobre conceitos de amostragem para o caso de incidência de doença em plantas é apresentado por Madden \& Hughes (1999).

De acordo com van Maanen \& Xu (2003), no estudo da heterogeneidade espacial de doenças de plantas, os pesquisadores consideram os dados de duas maneiras diferentes. Na primeira, a incidência da doença é avaliada dentro de unidades amostrais, como os quadrats por exemplo, ou seja, conta-se o número de plantas doentes e sadias dentro de cada quadrat e, conseqüentemente tem-se a proporção de plantas doentes por quadrat. Na segunda maneira, cada planta é classificada como doente ou sadia individualmente, tendo-se sua localização definida por coordenadas e, assim, a distância entre as plantas é considerada nas análises. Esses autores também dizem que se pode considerar uma mistura das duas maneiras apresentadas, como por exemplo, a avaliação da incidência da doença dentro dos quadrats e considerar a localização espacial dos quadrats nas análises.

Campbell \& Madden (1990) apresentam a classificação das técnicas utilizadas nos estudos de padrão espacial em três categorias, dependendo do tipo de apresentação dos dados: 1. a técnica é baseada no posicionamento de plantas sadias 
e doentes dentro de uma linha ou seqüências de linhas; 2. a metodologia é baseada em dados de contagens, provenientes de unidades amostrais definidas ou quadrats; 3. a distância entre plantas doentes é levada em consideração. Pode-se observar que as duas últimas categorias coincidem com a classificação apresentada por van Maanen \& $\mathrm{Xu}(2003)$.

No estudo de padrões espaciais de doenças em plantas cultivadas, a escolha do tipo de informação a ser analisada depende da metodologia escolhida pelo pesquisador ou pode ser definida pelo tipo de cultura, na qual a doença está sendo estudada. Geralmente, em culturas perenes, como é o caso dos citros, tem-se um espaçamento constante entre as linhas de cultivo e entre as plantas dentro de cada linha. Portanto, pode-se facilmente determinar a distância entre duas plantas, assim como se podem considerar unidades amostrais dentro da área e contar o número de plantas doentes e sadias nessas unidades. A escolha da forma de tratamento dos dados dependerá do pesquisador e, conseqüentemente, da metodologia escolhida. Porém, no caso de culturas anuais, como milho e feijão por exemplo, o espaçamento entre linhas é fixo mas entre plantas dentro da linha pode variar, o que impossibilitaria o cálculo da distância entre plantas. Neste caso, devem-se considerar dados de contagem de plantas doentes e sadias por unidades amostrais.

Os dados de contagens provenientes de unidades amostrais, como os quadrats, têm sido bastante utilizados na caracterização de padrões espaciais em doenças de plantas. Assim, um aspecto importante é a determinação das unidades amostrais. Pielou $(1977)^{2}$, citado por Campbell \& Madden (1990), definiu três tipos de situações na análise espacial de organismos biológicos, nas quais a definição da unidade amostral é diferente:

1. Os organismos ou doenças, assim como os locais ou unidades onde esses estão localizados, são discretos ou contáveis. Neste caso, a unidade amostral é formada naturalmente. Exemplos desse tipo de unidade amostral incluem número de lesões em raízes, galhos, folhas ou frutos. Assim, a planta ou uma parte da

\footnotetext{
${ }^{2}$ PIELOU, E.C. Mathematical Ecology. New York: Wiley, 1977. 385p.
} 
planta é considerada uma unidade amostral e conta-se o número de lesões em cada uma dessas unidades;

2. Os indivíduos são discretos mas o organismo ocupa um espaço contínuo e, portanto, não ocorre uma formação natural da unidade amostral. Essa é uma situação comum em estudos de patógenos de plantas presentes no solo, alguns insetos vetores de viroses e plantas infectadas por uma doença. Assim, para que o número de indivíduos doentes por unidade amostral seja determinado, deve-se definir a unidade amostral arbitrariamente. Um quadrat ou unidade amostral retangular de tamanho predeterminado pode ser utilizado. Como uma alternativa, pode-se utilizar a linha da cultura como unidade amostral;

3. Não existe uma unidade amostral natural e não existe uma definição clara de quem sejam os indivíduos a serem contados. Neste caso, os organismos ocupam um espaço contínuo e crescem por reprodução vegetativa através do espaço. Como exemplos destes organismos, têm-se fungos presentes no solo, que são amostrados durante o período de crescimento vegetativo ativo.

Além dessas três, Campbell \& Madden (1990) apresentam uma quarta situação: quando os locais habitáveis são discretos (por exemplo, plantas ou folhas de uma planta) mas os indivíduos não são contáveis. Isso ocorre quando se avalia severidade de uma doença (por exemplo, porcentagem da área foliar doente).

$\mathrm{Na}$ avaliação da incidência de doenças em plantas, a amostragem em grupos é facilmente obtida. Nesse caso, as plantas individuais ou partes das plantas são classificadas como doentes ou sadias, sendo que, os indivíduos ocorrem em grupos que se formam naturalmente (por exemplo, folhas ou raízes de uma planta) ou artificialmente (por exemplo, plantas num quadrat). Dessa forma, avaliam-se $n_{g}$ indivíduos em cada grupo, de um total de $N$ grupos. Como exemplos, têm-se:

- classificação de $n_{g}$ folhas ou $n_{g}$ raízes como doentes, ou não, $g=1,2, \ldots, N$, em cada uma de $N$ plantas diferentes, sendo que, geralmente, $n_{g}$ varia de planta para planta; 
- classificação de $n_{g}$ plantas como doentes, ou não, $g=1,2, \ldots, N$, em cada um de $N$ quadrats, sendo $n_{g}$, geralmente, constante.

Algumas dificuldades surgem na determinação dos quadrats, como, por exemplo, a localização, a forma e o tamanho do quadrat. A localização dos quadrats pode ser aleatória (Figura 5a) ou sistemática e exaustiva (Figura 5b), dependendo do tipo de pesquisa a ser executada (Campbell \& Madden, 1990; Ripley, 1981). Segundo Campbell \& Madden (1990) na maioria das pesquisas em relação a padrões espaciais de doenças de plantas são utilizados grids de quadrats, como apresentado na Figura $5 \mathrm{~b}$.

Quando não existe a definição natural do tamanho do quadrat, deve-se preocupar com a determinação desse tamanho. Se o padrão de distribuição das plantas doentes é aleatório, o tamanho do quadrat não é importante, pois uma alteração desse tamanho simplesmente altera a magnitude da média, a qual é proporcional ao tamanho do quadrat, mas a interpretação do padrão espacial permanece a mesma. Porém, se existe agregação, a alteração no tamanho do quadrat pode afetar o grau de dependência espacial entre os quadrats e, portanto, alterar a interpretação dos resultados, como pode ser visto na Figura 6. Segundo Campbell \& Madden (1990), o padrão será aparentemente aleatório no caso de quadrat do tamanho A, agregado para o $\mathrm{B}$ (todo quadrat contém poucos ou muitos indivíduos e assim $s^{2}>\bar{x}$ ), aleatório no tamanho $\mathrm{C}$ e regular para $\mathrm{D}$.

Alguns trabalhos discutem o efeito do tamanho e da forma do quadrat sobre as conclusões finais em relação ao padrão espacial ou heterogeneidade da doença, assim como esse efeito sobre estatísticas espaciais. De acordo com Ridout \& Xu (2000), o índice de dispersão, definido como a razão entre a variância do número de plantas infectadas por quadrat e a variância teórica da distribuição binomial, é maior no caso de quadrats quadrados e se torna menor à medida que o quadrat se torna alongado ou retangular. Porém, esses autores afirmam que o efeito do tamanho do quadrat é bem mais pronunciado do que o da forma, sendo que o índice de dispersão aumenta, aproximadamente de forma linear, com o aumento do 


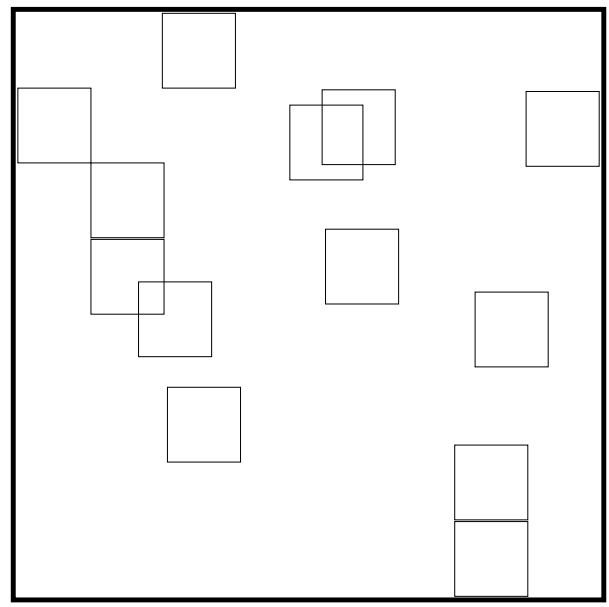

(a)

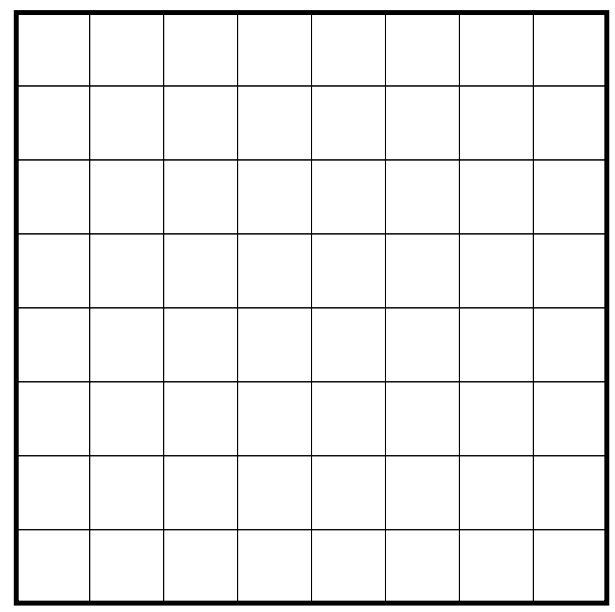

(b)

Figura 5 - Localização dos quadrats para estudos de padrões espaciais. (a) quadrats localizados aleatoriamente; (b) um grid de quadrats contíguos (adaptado de Campbell \& Madden, 1990; Ripley, 1981)

tamanho do quadrat. Xu \& Ridout (2000), considerando a correlação intraclasse e a forma binária da lei de potência, também concluíram que o tamanho do quadrat tem grande influência, bem mais pronunciada do que a forma, sobre as estatísticas espaciais estudadas. Conclusões idênticas também foram obtidas por Xu \& Ridout (2001), que além da correlação intraclasse e lei de potência binária, também estu- 


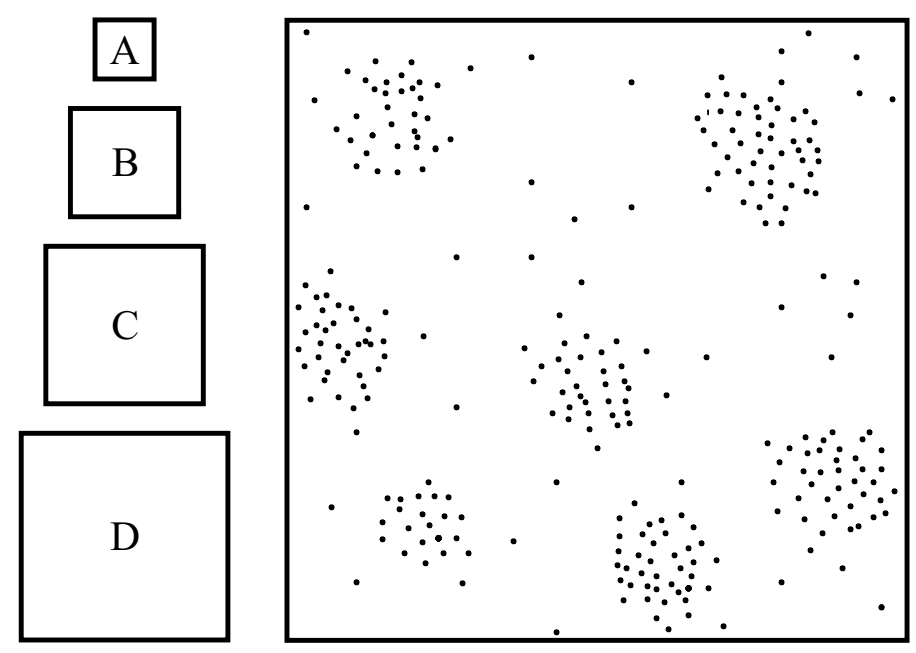

Figura 6 - Quatro tamanhos de quadrats e um padrão agregado de pontos com grupos de indivíduos localizados regularmente (adaptado de Campbell \& Madden, 1990)

daram os efeitos do tamanho e forma do quadrat sobre a autocorrelação espacial. Xu \& Ridout (2000) recomendam que se evite a utilização de quadrats extremamente alongados ou retangulares.

A descrição de padrões espaciais em termos do número de plantas doentes em uma determinada área ou quadrat, assim como em termos da distância entre plantas doentes, parece perder completamente a natureza espacial do padrão (Upton \& Fingleton, 1985), pois pode-se pensar em padrão espacial como algo contínuo dentro de uma área, que na realidade é contínua. Mesmo a utilização de técnicas onde se faz necessária a avaliação da vizinhança, pode parecer estranho considerar plantas vizinhas sabendo que entre elas existe um espaço e que não há uma delimitação exata dos limites de vizinhança. Porém, pode-se utilizar uma técnica chamada de tesselagem, como por exemplo a de Dirichlet e a de Delaunay (Upton \& Fingleton, 1985), que consiste em dividir a área em sub-áreas de tal forma que o centro representa a localização pontual de cada planta. Assim, tem-se uma representação das plantas por pequenas sub-áreas de uma forma contínua, o que possibilita a de- 
terminação exata de sub-áreas ou plantas vizinhas e utilizar técnicas que consideram dados de área, como determinadas técnicas geoestatísticas.

\subsubsection{Algumas técnicas para a avaliação de padrões espaciais}

\subsubsection{Distribuições de probabilidades para a incidência de doenças}

Considere que $Y$ seja uma variável aleatória que corresponda à presença, ou não, de uma doença em uma planta particular. Assim, pode-se definir $Y$ como

$$
Y= \begin{cases}0 & \text { se a planta estiver sadia } \\ 1 & \text { se a planta estiver doente }\end{cases}
$$

Considerando $\pi$ como sendo a probabilidade de a planta estar doente, ou seja, $P(Y=1)=\pi$, obtém-se a distribuição de probabilidades da variável aleatória $Y$ que pode ser representada da seguinte maneira:

\begin{tabular}{c|cc|c}
$y$ & 0 & 1 & \\
\hline$P(Y=y)$ & $(1-\pi)$ & $\pi$ & 1,0
\end{tabular}

Essa distribuição, conhecida como distribuição de Bernoulli, é completamente determinada pelo parâmetro $\pi$ e é a única distribuição de probabilidade possível para uma variável aleatória binária. Com os dados acima pode-se obter, facilmente, a média e a variância de $Y$, que são dadas por $E(Y)=\pi$ e $V(Y)=\pi(1-\pi)$.

Considerando a distribuição de Bernoulli, pode-se definir uma variável aleatória binária $Y_{i}$ para indicar a presença, ou não, da doença em uma planta $i$, localizada em um determinado quadrat, em que $i=1, \ldots, n$. Assim, o número total de plantas doentes no quadrat será $X=\sum_{i=1}^{n} Y_{i}$ e, então, $E(X)=$ $E\left(\sum_{i=1}^{n} Y_{i}\right)=\sum_{i=1}^{n} E\left(Y_{i}\right)=n \pi$. Se a localização de uma planta doente é independente da localização das outras plantas doentes e, como foi dito, toda planta tem a mesma 
probabilidade $\pi$ de estar doente, a variável aleatória $X$ tem distribuição binomial, ou seja,

$$
\begin{array}{r}
P(X=x)=\left(\begin{array}{c}
n \\
x
\end{array}\right) \pi^{x}(1-\pi)^{n-x} I_{\{0,1, \ldots, n\}}(x), \\
\text { e, assim, } V(X)=V\left(\sum_{i=1}^{n} Y_{i}\right)=\sum_{i=1}^{n} V\left(Y_{i}\right)=n \pi(1-\pi) .
\end{array}
$$

Para verificar se os dados observados estão de acordo com a distribuição binomial, o que indica um padrão espacial aleatório, basta aplicar um teste para verificar a concordância entre as freqüências observadas e esperadas, como o teste de aderência de $\chi^{2}$. Na determinação das freqüências observadas e esperadas, considere uma determinada área que é dividida em $N$ quadrats contíguos, com $n$ plantas em cada um, em que as dimensões do quadrat são definidas pelo pesquisador. Em cada um dos quadrats pode-se determinar o número de plantas doentes $x_{j}, j=1,2, \ldots, N$ e obter a estimativa de $\pi$,

$$
\hat{\pi}=\frac{\sum_{j=1}^{N} x_{j}}{n N},
$$

que representa a incidência média da doença (Hughes \& Madden, 1993; Madden \& Hughes, 1995). Substituindo-se $\pi$ na equação 2 por $\hat{\pi}$, pode-se calcular a probabilidade de que um quadrat tenha $x$ plantas doentes, $P(X=x)$. A distribuição de freqüências observada é obtida pela determinação do número de quadrats que contém $x$ plantas doentes e as freqüências esperadas são calculadas por $N \cdot P(X=x)$ (Madden \& Hughes, 1995).

Quando a probabilidade de uma planta estar doente não é constante, a binomial não é apropriada para representar a distribuição das plantas doentes por quadrat. Nessa situação, considera-se que $\pi$ varia de quadrat para quadrat de uma maneira aleatória, devido, por exemplo, à variação do patógeno, do hospedeiro ou das condições ambientais na área plantada. Neste caso, substitui-se $\pi$ por uma variável aleatória $P$, sendo que $0 \leq P \leq 1$. Geralmente, considera-se que a distribuição de $P$ seja a beta e, condicionalmente ao parâmetro $P$, a distribuição de $X$ é binomial, isto é, $X \mid P \sim \operatorname{Bin}(n, P)$. Assim, demonstra-se que $X$ tem distribuição beta-binomial 
generalizada, cuja forma mais simples de se representar sua função de probabilidade é

$$
P(X=x)=\left(\begin{array}{l}
n \\
x
\end{array}\right) \frac{B(\alpha+x, \beta+n-x)}{B(\alpha, \beta)} I_{\{0,1,2, \ldots, n\}}(x)
$$

em que, $B(a, b)=\frac{\Gamma(a) \Gamma(b)}{\Gamma(a+b)}$ é a função Beta.

Sendo $p=\frac{\alpha}{\alpha+\beta}$ e $\theta=\frac{1}{\alpha+\beta}$, demonstra-se que $E(X)=n p$ e $\operatorname{Var}(X)=n p(1-p)[1+(n-1) \rho]$, em que $\rho=\frac{\theta}{1+\theta}=\frac{1}{(\alpha+\beta+1)}$ e $0<\rho<1$ (Collett, 1991; Hinde \& Demétrio,1998; Ridout et al., 1999). De acordo com Hughes \& Madden (1993) e Madden \& Hughes (1995) essa é uma reparametrização mais conveniente e útil, sendo que $p$ representa a incidência média da doença, ou seja, o valor esperado do parâmetro $\pi$, ao invés do $\pi$ constante da distribuição binomial e $\theta$ uma medida da variação de $p$ em relação a $\pi$, ou seja, da heterogeneidade espacial de $X$ (Madden \& Hughes, 1999). O parâmetro $\theta$ é conhecido como um índice de agregação, que varia de 0 a $\infty$, apesar de estar geralmente entre 0 e 1 e pode ser utilizado para indicar o grau de agregação das plantas doentes, quando a distribuição beta-binomial é adequada (Madden \& Hughes, 1995; van Maanen \& Xu, 2003).

A superdispersão ou variação extrabinomial, que está relacionada à ocorrência de um padrão agregado, aumenta à medida que $\theta$ e conseqüentemente $\rho$, aumenta. Pode-se observar que quando $\theta>0$ a variância da distribuição betabinomial é maior do que a da binomial, e quando $\theta=0$ tem-se que a variância é a mesma para as duas distribuições. Assim, quando $\theta \rightarrow 0, V(X)$ tende a $n \pi(1-\pi)$, ou seja, a distribuição beta-binomial se reduz à binomial (Madden \& Hughes, 1995).

$\mathrm{Na}$ verificação se a distribuição beta-binomial se ajusta satisfatoriamente à incidência observada de uma determinada doença, o cálculo das freqüências esperadas é feito de maneira idêntica ao caso da distribuição binomial, precisando apenas das estimativas de $\alpha$ e $\beta$ para o cálculo das probabilidades $P(X=x)$. De acordo com Hughes \& Madden (1993, 1994) e Madden \& Hughes (1995), os esti- 
madores de $p$ e $\theta$, obtidos pelo método dos momentos, são

$$
\hat{p}=\frac{m}{n}=\frac{\sum_{j=1}^{N} x_{j}}{n N} \quad \text { e } \quad \hat{\theta}=\frac{s^{2}-n \hat{p}(1-\hat{p})}{n^{2} \hat{p}(1-\hat{p})-s^{2}},
$$

em que $m=\sum_{j=1}^{N} x_{j} / N$ e $s^{2}=\sum_{j=1}^{N}\left(x_{j}-m\right)^{2} /(N-1)$ são, respectivamente, a média e a variância do número observado de plantas doentes por quadrat. Uma vez

calculados $\hat{p}$ e $\hat{\theta}$, pode-se facilmente obter $\hat{\alpha}$ e $\hat{\beta}$, pois $\hat{p}=\frac{\hat{\alpha}}{\hat{\alpha}+\hat{\beta}}, \hat{\theta}=\frac{1}{\hat{\alpha}+\hat{\beta}}$. Hughes \& Madden (1993) e Madden \& Hughes (1995) utilizaram estimativas de máxima verossimilhança para $p$ e $\theta$ obtidas com a subrotina apresentada por Smith (1993), a qual foi programada em Fortran e utiliza o procedimento iterativo de NewtonRaphson. Madden \& Hughes (1999) dizem que a melhor maneira de se estimarem $p$ e $\theta$ é por máxima verossimilhança, apesar de as estimativas serem mais facilmente obtidas pelo métodos dos momentos e estas serem, muitas vezes, próximas às de máxima verossimilhança.

\subsubsection{2 Índices de dispersão}

Os índices de dispersão são medidas do grau de agregação espacial de uma determinada população. Vários índices de dispersão têm sido propostos e utilizados no estudo de padrões espaciais. Alguns pesquisadores apresentam discussões detalhadas e comparam as similaridades entre as diferentes proposições, como Upton \& Fingleton (1985), Campbell \& Madden (1990), Madden \& Hughes (1995) e Bergamin Filho et al. (2002).

Todos os índices de dispersão têm como princípio básico a característica da distribuição de Poisson de que a média é igual à variância, ou seja, $E(X)=V(X)=\lambda$, em que $X$ é uma variável aleatória referente a algum dado de contagem, como por exemplo o número de plantas doentes em um quadrat e $\lambda$ é o único parâmetro dessa distribuição e representa a intensidade. Assim, para dados de contagem, a relação variância/média ( $V M)$ é usualmente utilizada como uma me- 
dida de agregação, ou seja, assumindo que a localização aleatória de plantas doentes está associada à distribuição de Poisson, conclui-se que $V M=1$ representa um padrão espacial aleatório, enquanto $V M>1$ e $V M<1$ representam padrões espaciais agregado e regular, respectivamente. O teste de $\chi^{2}$ normalmente é utilizado na verificação da hipótese de que o índice de dispersão seja igual a 1.

O índice $V M$ é calculado utilizando dados de contagem, geralmente provenientes de quadrats. Assim, dados $x_{1}, x_{2}, \ldots, x_{N}$ como sendo as contagens de plantas doentes em $N$ quadrats, a média e a variância do número de plantas doentes nos quadrats são, respectivamente,

$$
m=\frac{\sum_{j=1}^{N} x_{j}}{N} \quad \text { e } \quad s^{2}=\frac{\sum_{j=1}^{N}\left(x_{j}-m\right)^{2}}{N-1}
$$

e, portanto, $V M=s^{2} / m$ (Upton \& Fingleton, 1985; Campbell \& Madden, 1990). De acordo com Upton \& Fingleton (1985), Hoel $(1943)^{3}$ demonstrou que a estatística $(N-1) V M$ tem aproximadamente distribuição $\chi_{N-1}^{2}$ sob a pressuposição de aleatoriedade. O índice $V M$ geralmente aumenta à medida que se tem uma maior agregação das plantas doentes, porém este é altamente dependente do tamanho do quadrat e da incidência média da doença (Upton \& Fingleton, 1985; Campbell \& Madden, 1990).

Um outro índice normalmente encontrado na literatura é o de Morisita, $I_{\delta}$ (Upton \& Fingleton, 1985; Campbell \& Madden, 1990; Madden \& Hughes, 1995; Bergamin Filho et al., 2002), definido por

$$
I_{\delta}=\frac{N\left[\sum_{j=1}^{N} x_{j}\left(x_{j}-1\right)\right]}{\sum_{j=1}^{N} x_{j}\left(\sum_{j=1}^{N} x_{j}-1\right)}=\frac{N\left[\sum_{j=1}^{N} x_{j}^{2}-\sum_{j=1}^{N} x_{j}\right]}{\left(\sum_{j=1}^{N} x_{j}\right)^{2}-\sum_{j=1}^{N} x_{j}} .
$$

Campbell \& Madden (1990) dizem que o índice de Morisita foi proposto com o intuito de medir a variabilidade da densidade de grupos de indivíduos

\footnotetext{
${ }^{3}$ HOEL, P.G. On indices of dispersion. Annals of Mathematical Statistics, v.14, p.155-162,
} 1943 
presentes em sub-áreas relativamente grandes, tendo como base a teoria relacionada à diversidade ecológica. Estes autores também apresentam a estatística

$$
I_{\delta}^{*}=I_{\delta}\left(\sum_{j=1}^{N} x_{j}-1\right)+N-\sum_{j=1}^{N} x_{j},
$$

que tem distribuição $\chi_{N-1}^{2}$. Na interpretação do índice de Morisita, um padrão espacial será considerado aleatório se $I_{\delta}=0$.

Os índices de dispersão apresentados, assim como os demais encontrados na literatura, levam em consideração uma propriedade da distribuição de Poisson, a qual está associada a dados de contagem. Madden \& Hughes (1995) afirmam que a utilização de distribuições relacionadas a dados de contagem é válida, porém é uma aproximação aceitável para a incidência de doença apenas quando esta for baixa. Resultados teóricos, obtidos utilizando-se dados simulados, sugerem sua utilização apenas quando a incidência for menor ou igual a 0,20.

A média utilizada no cálculo da relação $V M$ pode ser entendida como a variância esperada (teórica) para a distribuição de Poisson, pois $E(X)=V(X)=\lambda$. Assim, de acordo com van Maanen \& Xu (2003), VM é essencialmente uma relação variância/variância (observada/esperada). Partindo-se dessa consideração, pode-se generalizar a relação $V M$ e definir um índice de dispersão, $D$, como a relação entre a variância observada e a teórica ou esperada no caso de se ter um padrão espacial aleatório. Portanto, $D=1$ para o padrão aleatório, $D>1$ para o agregado e $D<1$ no caso de um padrão espacial regular (Madden \& Hughes, 1995; van Maanen \& Xu, 2003).

Para o caso de dados binários, como é o caso na avaliação da incidência de doenças em plantas, a variância esperada é dada por $n p(1-p)$, assumindo que a distribuição binomial seja adequada para descrever os dados observados. Assim, o estimador de $D$ é dado por

$$
\hat{D}=\frac{s^{2}}{n \hat{p}(1-\hat{p})}
$$

em que $s^{2}$ representa a estimativa da variância do número observado de plantas doentes por quadrat. 
Um teste de $\chi^{2}$ tem sido utilizado para se decidir sobre a aceitação ou rejeição da hipótese nula, de que o padrão espacial seja aleatório $(D=1)$. Se a localização das plantas doentes é independente ou aleatória, o que implica em $p$ constante, segundo Madden \& Hughes (1995), $(N-1) D$ tem distribuição $\chi_{N-1}^{2}$ e para valores altos de $(N-1) D$, a hipótese alternativa de superdispersão é aceita.

\subsubsection{Correlação intraclasse}

A agregação pode ser vista como a tendência de plantas dentro de uma unidade amostral (quadrat) apresentarem o mesmo status, ou seja, de estarem doentes ou sadias (Madden \& Hughes, 1995) e o coeficiente de correlação intraclasse, $\rho$, fornece uma medida de similaridade entre as plantas dentro dos quadrats (Ridout et al., 1999; van Maanen \& Xu, 2003).

Para variáveis aleatórias contínuas, a correlação corresponde a uma medida de associação linear entre duas variáveis. Para variáveis binárias, esta interpretação da correlação não é muito útil porque um par de variáveis binárias, $\left(Y_{1}, Y_{2}\right)$ pode assumir apenas quatro valores distintos: $\left(Y_{1}=0, Y_{2}=0\right),\left(Y_{1}=0, Y_{2}=\right.$ 1), $\left(Y_{1}=1, Y_{2}=0\right)$ e $\left(Y_{1}=1, Y_{2}=1\right)$ (Ridout \& Xu, 2000).

Considere que $Y_{1}$ e $Y_{2}$ são identicamente distribuídas segundo uma Bernoulli com parâmetro $\pi$, ou seja, a probabilidade de estar doente é $\pi$ e é a mesma para ambas as plantas. Assim, tem-se que $E\left(Y_{1}\right)=E\left(Y_{2}\right)=\pi \mathrm{e}$ $\operatorname{Var}\left(Y_{1}\right)=\operatorname{Var}\left(Y_{2}\right)=\pi(1-\pi)$. A correlação entre as duas variáveis aleatórias binárias, $Y_{1}$ e $Y_{2}$, pode ser formalmente definida da mesma maneira do que para qualquer outro par de variáveis aleatórias, ou seja,

$$
\begin{aligned}
\operatorname{Corr}\left(Y_{1}, Y_{2}\right) & =\frac{\operatorname{Cov}\left(Y_{1}, Y_{2}\right)}{\sqrt{V\left(Y_{1}\right) \cdot V\left(Y_{2}\right)}} \\
& =\frac{E\left(Y_{1} Y_{2}\right)-E\left(Y_{1}\right) E\left(Y_{2}\right)}{\sqrt{V\left(Y_{1}\right) \cdot V\left(Y_{2}\right)}} \\
& =\frac{E\left(Y_{1} Y_{2}\right)-\pi^{2}}{\pi(1-\pi)}
\end{aligned}
$$


em que,

$$
\begin{aligned}
E\left(Y_{1} Y_{2}\right)= & \sum_{i=0}^{1} \sum_{j=0}^{1} i j P\left(Y_{1}=i, Y_{2}=j\right) \\
= & 0 \cdot 0 \cdot P\left(Y_{1}=0, Y_{2}=0\right)+0 \cdot 1 \cdot P\left(Y_{1}=0, Y_{2}=1\right)+ \\
& +1 \cdot 0 \cdot P\left(Y_{1}=1, Y_{2}=0\right)+1 \cdot 1 \cdot P\left(Y_{1}=1, Y_{2}=1\right) \\
= & P\left(Y_{1}=1, Y_{2}=1\right) .
\end{aligned}
$$

Substituindo-se (6) em (5) tem-se:

$$
\operatorname{Corr}\left(Y_{1}, Y_{2}\right)=\frac{P\left(Y_{1}=1, Y_{2}=1\right)-\pi^{2}}{\pi(1-\pi)}
$$

e, assim

$$
P\left(Y_{1}=1, Y_{2}=1\right)=\pi^{2}+\pi(1-\pi) \operatorname{Corr}\left(Y_{1}, Y_{2}\right)
$$

Partindo-se da distribuição de probabilidade conjunta de $Y_{1}$ e $Y_{2}$, em que $P\left(Y_{1}=1, Y_{2}=1\right)=\pi^{2}+\pi(1-\pi) \operatorname{Corr}\left(Y_{1}, Y_{2}\right)$ e sabendo-se que as probabilidades marginais $P\left(Y_{1}=1\right)=P\left(Y_{2}=1\right)=\pi$ e $P\left(Y_{1}=0\right)=P\left(Y_{2}=0\right)=1-\pi$, as demais probabilidades conjuntas podem ser facilmente obtidas por:

$$
\begin{aligned}
P\left(Y_{1}=0, Y_{2}=1\right) & =P\left(Y_{2}=1\right)-P\left(Y_{1}=1, Y_{2}=1\right) \\
& =\pi-\left[\pi^{2}+\pi(1-\pi) \operatorname{Corr}\left(Y_{1}, Y_{2}\right)\right] \\
& =\pi(1-\pi)\left(1-\operatorname{Corr}\left(Y_{1}, Y_{2}\right)\right) \\
P\left(Y_{1}=1, Y_{2}=0\right) & =P\left(Y_{1}=1\right)-P\left(Y_{1}=1, Y_{2}=1\right) \\
& =\pi-\left[\pi^{2}+\pi(1-\pi) \operatorname{Corr}\left(Y_{1}, Y_{2}\right)\right] \\
& =\pi(1-\pi)\left(1-\operatorname{Corr}\left(Y_{1}, Y_{2}\right)\right) \\
P\left(Y_{1}=0, Y_{2}=0\right) & =P\left(Y_{1}=0\right)-P\left(Y_{1}=0, Y_{2}=1\right) \\
& =P\left(Y_{2}=0\right)-P\left(Y_{1}=1, Y_{2}=0\right) \\
& =(1-\pi)-\pi(1-\pi)\left(1-\operatorname{Corr}\left(Y_{1}, Y_{2}\right)\right) \\
& =(1-\pi)\left\{1-\pi\left[1-\operatorname{Corr}\left(Y_{1}, Y_{2}\right)\right]\right\} \\
& =(1-\pi)\left\{(1-\pi)+\pi \operatorname{Corr}\left(Y_{1}, Y_{2}\right)\right\} \\
& =(1-\pi)^{2}+\pi(1-\pi) \operatorname{Corr}\left(Y_{1}, Y_{2}\right)
\end{aligned}
$$


Assim, tem-se a distribuição de probabilidade conjunta das variáveis aleatórias $Y_{1}$ e $Y_{2}$, dadas por

\begin{tabular}{c|cc|c} 
& $Y_{2}=0$ & $Y_{2}=1$ & $P\left(Y_{1}=y_{1}\right)$ \\
\hline$Y_{1}=0$ & $(1-\pi)^{2}+\pi(1-\pi) \operatorname{Corr}\left(Y_{1}, Y_{2}\right)$ & $\pi(1-\pi)\left(1-\operatorname{Corr}\left(Y_{1}, Y_{2}\right)\right)$ & $1-\pi$ \\
$Y_{1}=1$ & $\pi(1-\pi)\left(1-\operatorname{Corr}\left(Y_{1}, Y_{2}\right)\right)$ & $\pi^{2}+\pi(1-\pi) \operatorname{Corr}\left(Y_{1}, Y_{2}\right)$ & $\pi$ \\
\hline$P\left(Y_{2}=y_{2}\right)$ & $1-\pi$ & $\pi$ & 1,0
\end{tabular}

Com base nessa distribuição de probabilidade conjunta, pode-se obter uma interpretação interessante da correlação para o caso de variáveis aleatórias binárias. Como se pode observar, para um dado valor de $\pi$, uma correlação positiva aumenta a probabilidade de que ambas as plantas estejam doentes ou sadias e diminui a probabilidade de que uma planta esteja doente e a outra não, quando se compara com o caso de variáveis aleatórias não correlacionadas $\left(\operatorname{Corr}\left(Y_{1}, Y_{2}\right)=0\right)$. Isto significa que, a probabilidade de que duas plantas escolhidas aleatoriamente estejam doentes, ou não, é aumentada quando se tem uma correlação positiva.

De acordo com Ridout \& Xu (2000), a ocorrência de correlações negativas é possível em princípio, mas raramente acontece na prática. Valores negativos de $\operatorname{Corr}\left(Y_{1}, Y_{2}\right)$ devem ser maiores do que ou iguais ao $\max [-\pi /(1-\pi),-(1-\pi) / \pi]$ para assegurar que as probabilidades conjuntas não sejam negativas.

Considere novamente a situação em que $n$ plantas são avaliadas em um quadrat, sendo a variável aleatória $Y_{i}, i=1,2, \ldots, n$, utilizada para representar se a planta $i$ está doente ou não. Sabe-se que $Y_{i} \sim \operatorname{Bernoulli}(\pi)$, em que $\pi$ representa a probabilidade de a planta estar doente e que, sendo $X=\sum_{i=1}^{n} Y_{i}, X \sim \operatorname{Bin}(n, \pi)$ se $\pi$ for constante e $Y_{i}$ for independente de $Y_{j}$, para todo $i, j=1,2, \ldots, n$ e $i<j$. Nesse caso, em que as plantas doentes ocorrem de forma independente, tem-se um padrão espacial aleatório, sendo $V(X)=n \pi(1-\pi)$. Porém, se essa independência não existir, têm-se as situações de padrão espacial agregado ou regular, nas quais a variância seria, respectivamente, maior ou menor do que a variância da distribuição binomial. 
A variância de $X$ pode ser definida considerando que os pares de plantas dentro de um quadrat podem ser correlacionados, ou seja, que $\operatorname{Corr}\left(Y_{i}, Y_{j}\right) \neq 0$. Assim,

$$
\operatorname{Var}(X)=\operatorname{Var}\left(\sum_{i=1}^{n} Y_{i}\right)=\sum_{i=1}^{n} \operatorname{Var}\left(Y_{i}\right)+2 \sum_{i<j} \operatorname{Cov}\left(Y_{i}, Y_{j}\right)
$$

e como $\operatorname{Var}\left(Y_{i}\right)=\pi(1-\pi)$ e $\operatorname{Cov}\left(Y_{i}, Y_{j}\right)=\operatorname{Corr}\left(Y_{i}, Y_{j}\right) \sqrt{\operatorname{Var}\left(Y_{i}\right) \cdot \operatorname{Var}\left(Y_{j}\right)}=$ $\pi(1-\pi) \operatorname{Corr}\left(Y_{i}, Y_{j}\right)$, tem-se

$$
\operatorname{Var}(X)=n \pi(1-\pi)+2 \pi(1-\pi) \sum_{i<j} \operatorname{Corr}\left(Y_{i}, Y_{j}\right) .
$$

De acordo com Ridout \& Xu (2000), uma forma alternativa para a equação (7) é

$$
\begin{aligned}
\operatorname{Var}(X) & =n \pi(1-\pi)\left[1+\frac{2}{n} \sum_{i<j} \operatorname{Corr}\left(Y_{i}, Y_{j}\right)\right] \\
& =n \pi(1-\pi)\left[1+\frac{2(n-1)}{n(n-1)} \sum_{i<j} \operatorname{Corr}\left(Y_{i}, Y_{j}\right)\right] \\
& =n \pi(1-\pi)[1+(n-1) \rho]
\end{aligned}
$$

em que,

$$
\rho=\frac{1}{n(n-1) / 2} \sum_{i<j} \operatorname{Corr}\left(Y_{i}, Y_{j}\right) .
$$

Portanto, para diferentes valores de $\rho$ têm-se interpretações diferentes em termos do padrão espacial da incidência de uma doença. Se $\rho=0$ tem-se um padrão aleatório para a incidência da doença, pois $\operatorname{Var}(X)$ é igual à da distribuição binomial. No caso em que $\rho>0$, tem-se um padrão de agregação espacial, o que implica numa superdispersão de $X$, em relação ao modelo binomial. Valores negativos para $\rho$ raramente ocorrem na prática, mas quando ocorrem tem-se subdispersão de $Y$ em relação ao modelo binomial e, então, um padrão para a incidência da doença indica que a presença de uma planta doente diminui a chance de que as plantas mais próximas a ela também estejam doentes. Vale lembrar que, segundo Prentice (1986),

$$
\left[\frac{-1}{n-1}+\frac{\omega(1-\omega)}{n(n-1) \pi(1-\pi)}\right] \leq \rho \leq 1
$$


em que, $\omega=n \pi-I N T(n \pi)$ onde $I N T(n \pi)$ representa a parte inteira de $n \pi$.

De acordo com Ridout \& Xu (2000), a equação (8) é uma forma padrão para a variância de uma variável binária agrupada, assim como $X$ e pode ser derivada de outras maneiras. Uma delas, que já foi apresentada anteriormente, é o caso em $X \sim \operatorname{Beta-binomial}(\alpha, \beta)$, em que todos os pares de variáveis aleatórias $\left(Y_{i}, Y_{j}\right)$ têm a mesma correlação $\rho$, a qual é denominada de correlação intraclasse. Este modelo é conhecido como modelo de correlação comum (Ridout et al., 1999). Portanto, se ocorre um ajuste aceitável à distribuição beta-binomial, o estimador de $\rho$ é dado por

$$
\hat{\rho}=\frac{\hat{\theta}}{1+\hat{\theta}}=\frac{1}{\hat{\alpha}+\hat{\beta}+1} .
$$

Gibson \& Austin (1996) utilizaram a correlação intraclasse, previamente utilizada por Fleiss (1971), na caracterização de padrões espaciais e na comparação de padrões espaciais da incidência de tristeza dos citros (CTV) com padrões simulados a partir de um modelo. Este estimador é definido por

$$
\hat{\rho}=\frac{\hat{p}_{s}-\hat{p}_{0}}{1-\hat{p}_{0}}
$$

em que, $\hat{p}_{s}=1-\frac{2}{N} \sum_{j=1}^{N} \frac{x_{j}\left(n-x_{j}\right)}{n(n-1)}, \quad \hat{p}_{0}=1-2 \hat{\pi}(1-\hat{\pi}), \quad x_{j}$ é o número de plantas doentes no quadrat $j$, com $j=1,2, \ldots, N$ e $\hat{\pi}=\frac{1}{n N} \sum_{j=1}^{N} x_{j}$. Segundo Gibson \& Austin (1996), valores altos de $\hat{\rho}$ indicam um alto grau de agregação das plantas doentes. van Maanen \& Xu (2003) apresentam esse mesmo estimador, mas de uma forma um pouco diferente, ou seja,

$$
\hat{\rho}=1-\frac{1}{\hat{\pi}(1-\hat{\pi}) n N(n-1)} \sum_{j=1}^{N} x_{j}\left(n-x_{j}\right) .
$$

A equação (10) é obtida substituindo $\hat{p}_{s}$ e $\hat{p}_{0}$, conforme definido anteriormente, na equação (9).

van Maaen \& Xu (2003) ainda apresentam um outro estimador da correlação intraclasse, ou seja, $\hat{\rho}=(\hat{D}-1) /(n-1)$. Este estimador, que relaciona 
$\rho$ com o índice de dispersão $D$, é obtido a partir da equação (8), considerando-se a definição de $D$, apresentada em (4). Assim, tem-se

$$
\begin{aligned}
s^{2}=\hat{V}(X) & =n \hat{\pi}(1-\hat{\pi})[1+(n-1) \hat{\rho}] \\
\frac{s^{2}}{n \hat{\pi}(1-\hat{\pi})} & =1+(n-1) \hat{\rho} \\
\hat{D} & =1+(n-1) \hat{\rho} \\
\hat{\rho} & =\frac{\hat{D}-1}{n-1} .
\end{aligned}
$$

\subsubsection{Lei de potência binária}

Hughes \& Madden (1992), tendo como base a lei de potência de Taylor, propuseram a lei de potência binária para a descrição de padrões espaciais de doenças em plantas.

Taylor (1961), avaliando dados de contagem de animais de espécies diferentes, em vários locais diferentes, de tal maneira que se tinham repetições de grupos de unidades amostrais, observou que a variância das populações desses animais, geralmente, é proporcional a uma potência da média. Este modelo pode ser representado da seguinte maneira

$$
v=a \cdot m^{b}
$$

em que, $v$ e $m$ são, respectivamente, a variância e a média da densidade populacional de uma espécie animal e $a$ e $b$ são parâmetros a serem estimados. Esse modelo, conhecido como lei de potência de Taylor, pode ser escrito na forma

$$
\ln (v)=\ln (a)+b \cdot \ln (m)
$$

que descreve uma relação linear entre os logaritmos da variância e da média da densidade populacional de uma espécie (Taylor, 1961; Taylor et al., 1978).

Taylor (1961) definiu o parâmetro b como sendo um índice de agregação, sendo este importante em estudos ecológicos, pois é um indicativo do comportamento espacial de espécies animais e o parâmetro $a$, dependente do procedimento 
de amostragem, é considerado como de menor interesse imediato. Se $a=b=1$ nas equações (11) ou (12), tem-se que os dados de contagem seguem uma distribuição Poisson, pois tem-se que $v=m$ e, portanto, o padrão de distribuição da espécie é aleatório, enquanto que $b>1$ sugere agregação.

De acordo com Hughes \& Madden (1992), seguindo o raciocínio de Patil \& Stiteler (1974), pode-se entender esta lei de potência como a relação entre a variância observada $(v)$ e a variância de uma população cuja contagem dos animais siga a distribuição de Poisson $\left(v_{r}\right)$, uma vez que neste caso a média é igual à variância, ou seja, $m=v_{r}$. Assim, pode-se escrever a equação (12) da seguinte maneira

$$
\ln (v)=\ln (a)+b \cdot \ln \left(v_{r}\right),
$$

em que $v$ é a variância observada, $v_{r}$ é a variância teórica para uma distribuição aleatória dos animais na área, $a$ e $b$ são parâmetros.

Para se caracterizar o padrão espacial utilizando o modelo apresentado em (13) é necessário que se tenha uma amostra de variâncias observadas e esperadas, ou seja, repetições das variâncias. Para isso, diferentes áreas são avaliadas e, para cada uma dessas áreas, que são consideradas como independentes, as variâncias são calculadas. O cálculo das variâncias observada e esperada é possível, uma vez que cada área é dividida em unidades amostrais, nas quais são contados os números de animais, ou seja, em cada área se têm repetições da variável número de animais. Com estas informações, utiliza-se a análise de regressão para se estimarem os parâmetros $a$ e $b$, assim como testes de hipóteses para verificar se os parâmetros podem ser considerados iguais a 1 .

Na avaliação da incidência de uma doença em plantas, a equação (13) pode ser representada de duas maneiras diferentes, dependendo de como os dados são considerados. Para que se possa utilizar a lei de potência, seguindo o mesmo raciocínio da coleta de dados no caso do estudo de padrões espaciais de espécies animais, é necessário que a incidência da doença seja avaliada em diferentes áreas independentes, como por exemplo diferentes talhões, os quais são divididos em unidades amostrais ou quadrats, nos quais é contado o número de plantas doentes. Esta in- 
formação pode ser apresentada como um dado de contagem propriamente dito ou de proporção de plantas doentes no quadrat, o que implica em definições diferentes para a variância esperada. Como existem vários quadrats em cada talhão, pode-se calcular a variância esperada sob condição de aleatoriedade das plantas doentes, $v_{r}$ e a variância observada, $v$. Assim, têm-se repetições de $v$ e $v_{r}$, pois vários talhões são avaliados, podendo-se utilizar a análise de regressão para se estimarem $a$ e $b$.

Considere um determinado talhão, dividido em $N$ quadrats, com $n$ plantas em cada um e que o número de plantas doentes em cada quadrat seja obtido. Se o dado de contagem for considerado, tem-se que a variável aleatória $X$ representa essa contagem e, sob a condição de que as plantas doentes sejam independentes e que a probabilidade da planta estar doente seja a mesma para todas as plantas, $X \sim \operatorname{Bin}(n, \pi)$. Assim, a variância esperada é definida por $v_{r}=V(X)=n \pi(1-\pi)$ e a equação (13) será

$$
\ln (v)=\ln (a)+b \cdot \ln [n \pi(1-\pi)] .
$$

Caso a incidência da doença seja avaliada utilizando-se a proporção de plantas doentes no quadrat, ou seja, $X / n$, a variância esperada é dada por $v_{r}=$ $V\left(\frac{X}{n}\right)=\frac{1}{n^{2}} V(X)=\frac{\pi(1-\pi)}{n}$ e da equação (13) tem-se

$$
\ln (v)=\ln (a)+b \cdot \ln \left[\frac{\pi(1-\pi)}{n}\right] .
$$

De acordo com Madden \& Hughes (1995), Turechek \& Madden (1999b, 2001) e Turechek et al. (2001), quando $a=b=1$ tem-se um padrão aleatório para a incidência da doença, pois $\ln (v)=\ln \left(v_{r}\right)$, o que implica em igualdade da variância esperada, sob condição de aleatoriedade das plantas doentes, com a variância observada. Caso $a>1$ e $b=1$, ocorre um padrão de agregação espacial, o que implica em superdispersão, ou seja, a variância observada é maior do que a esperada, porém o grau de superdispersão em cada talhão não depende de $\pi$. Outro caso que indica agregação é quando $a$ e $b$ são maiores do que 1, porém a superdispersão varia com os valores de $\pi$. Comentários sobre valores de $a$ e $b$ diferentes destes não foram encontrados na literatura, talvez devido ao fato de que no estudo da incidência de doenças 
em plantas, em condições naturais, apenas os padrões espaciais aleatório e agregado são encontrados, como afirma Bergamin Filho et al. (2002). A grande maioria dos resultados obtidos e apresentados nos artigos, como pode ser visto em Bassanezi et al. (2003a), Hughes \& Madden (1992), Madden \& Hughes (1995), Turechek \& Madden (1999b, 2001) e Turechek et al. (2001), indicam valores de $\hat{a}$ e $\hat{b}$ maiores do que 1, o que dá suporte à afirmação de Bergamin Filho et al. (2002).

As equações (14) e (15) são denominadas lei de potência binária, por Hughes \& Madden (1992). No caso em que se tem $n$ constante, ou seja, quando os quadrats têm o mesmo número de plantas, essas equações podem ser representadas por

$$
\ln (v)=\ln (A)+b \cdot \ln [\pi(1-\pi)]
$$

em que $A=a n^{b}$ para o caso de dados de contagem e $A=a n^{-b}$ para o caso de proporções de plantas doentes.

Uma outra forma de se apresentar a lei de potência binária é a forma estendida, que de acordo com Madden \& Hughes (1995) é dada por

$$
\ln (v)=\ln (a)+b_{1} \ln (\pi)+b_{2} \ln (1-\pi)
$$

em que $a, b_{1}$ e $b_{2}$ são os parâmetros a serem estimados. A interpretação dos parâmetros na equação (17) é um pouco mais complexa e menos direta do que as formas mais simples apresentadas em (14), (15) e (16). Além disso, segundo Ridout \& Xu (2000), geralmente, as formas mais simples para a lei de potência binária, têm se ajustado muito bem a vários conjuntos de dados.

Para a estimação dos parâmetros $a$ e $b$ (ou $b_{1}$ e $b_{2}$ ) através da análise de regressão, primeiro é necessário que se tenham estimativas de $\pi$ e $v$. O estimador da variância observada é definido de duas maneiras diferentes, ambas pelo método dos momentos, dependendo do tipo de dado que será analisado, ou seja, número ou proporção de plantas doentes por quadrat. O estimador da variância observada do 
número de plantas doentes é dado por

$$
\hat{v}=s^{2}=\hat{V}(X)=\frac{\sum_{j=1}^{N}\left(x_{j}-m\right)^{2}}{N-1},
$$

em que $x_{j}$ é o número de plantas doentes no quadrat j e $m=\frac{\sum_{j=1}^{N} x_{j}}{N}$, que representa o número médio de plantas doentes no talhão, o qual contém $N$ quadrats. No caso de se considerar a proporção de plantas doentes por quadrat, tem-se

$$
\hat{v}=s^{2}=\hat{V}\left(\frac{X}{n}\right)=\frac{1}{n^{2}} \hat{V}(X)=\frac{\sum_{j=1}^{N}\left(x_{j}-m\right)^{2}}{n^{2}(N-1)},
$$

em que o número de plantas nos quadrats é constante e igual a $n$.

O estimador de $\pi$, pelo método dos momentos, dado na eq. (3), como dito anteriormente, representa a incidência média da doença. Outra maneira de se estimar $\pi$, assim como foi utilizado por Turechek \& Madden (1999b), é considerar $\hat{\pi}=\hat{p}$, em que $\hat{p}$ é o estimador de máxima verossimilhança para $p$, obtido a partir da distribuição beta-binomial.

De acordo com Madden \& Hughes (1995) e Turechek \& Madden (1999b), o parâmetro $\theta$ da distribuição beta-binomial pode ser representado como uma função dos parâmetros $A$ (ou $a$ ) e $b$ da lei de potência binária, ou seja,

$$
\theta=\frac{A-\frac{f(\pi)}{n}}{f(\pi)-A}
$$

em que $f(\pi)=[\pi(1-\pi)]^{1-b}$ e $A=a n^{-b}$, quando for utilizada a proporção de plantas doentes nas análises (Madden \& Hughes, 1995) ou $A=a n^{b-2}$, quando se utilizar a contagem de plantas doentes nos quadrats (Turechek \& Madden, 1999b).

A vantagem de se utilizar a lei de potência binária na caracterização de padrões espaciais é que a agregação de todo o de conjunto dados é descrita por um número menor de parâmetros, ou seja, $a$ (ou $A$ ) e $b$ (Bergamin Filho et al., 2002). Esta se torna realmente uma grande vantagem principalmente quando se têm muitos talhões para serem avaliados e, como a grande maioria dos métodos propostos para 
a descrição de padrões espaciais fornecem estimativas de parâmetros ou medidas de agregação para cada talhão, tem-se um número muito grande de estimativas, o que pode dificultar muito a obtenção de uma conclusão geral para todo o conjunto dos dados. Porém, segundo recomendação de Bergamin Filho et al. (2002), quando se utiliza a lei de potência binária na comparação de diferentes doenças ou da mesma doença, mas em condições diferentes, deve-se considerar um conjunto de dados com intensidades semelhantes da doença, pois, caso contrário, podem-se obter resultados conflitantes.

\subsubsection{Métodos de classes de distâncias}

Proctor $(1984)^{4}$, citado por Gray et al. (1986), descreveu o padrão espacial de plantas doentes considerando uma área retangular com 4 linhas e 5 colunas, na qual o espaçamento entre linhas e dentro da linha era constante. Os pares de plantas doentes dessa área, conhecida como látice regular 4x5, foram contados e separados em grupos de acordo com classes de distância e orientação. A distância era dada pelo comprimento da hipotenusa de um triângulo retângulo em que os comprimentos dos catetos correspondiam às distâncias entre linhas e dentro das linhas, definidas como abscissa e ordenada, respectivamente. A direção era dada pelo ângulo formado entre a hipotenusa e a abscissa. Segundo Gray et al. (1986), os números de pares em cada uma das classes eram então analisados estatisticamente através de um modelo log-linear, buscando caracterizar o padrão espacial.

Gray et al. (1986) dizem que o modelo log-linear utilizado por Proctor (1984) é complexo e foi aplicado especificamente para o caso de um látice 4x5, apesar de que a técnica pode ser estendida para látices com outras dimensões. Assim, Gray et al. (1986) propuseram uma nova técnica baseda em classes de distâncias, na qual os números de pares de plantas doentes em cada uma das classes são comparados com

\footnotetext{
${ }^{4}$ PROCTOR, C.H. On the detectionof clustering and anisotrophy using binary data from a lattice patch. Commun. Statist. - Theor. Meth., v.13, p.617-638, 1984.
} 
os números esperados de pares, obtidos por simulação sob a condição de distribuição aleatória das plantas doentes no látice.

Nesta nova metodologia, a distância entre duas plantas doentes é definida em termos das distâncias horizontal $(X)$ e vertical $(Y)$ e não mais em termos do comprimento da hipotenusa e os pares de plantas doentes são separados em classes de distâncias bidimensionais $[X, Y]$. As coordenadas $X$ e $Y$ representam as distâncias absolutas, dadas em unidades de espaçamento entre as linhas de plantio e entre as plantas dentro das linhas de plantio, respectivamente. Portanto, se uma planta doente está localizada na linha 2 e na coluna 3 e uma outra está na linha 4 e na coluna 2, a classe desse par de plantas doentes será $[2,1]$. Em um látice 4x5, que é o mesmo que um talhão com 4 linhas de plantio e 5 plantas em cada linha, têm-se as seguintes classes de distâncias:

\begin{tabular}{ccccc}
\hline & \multicolumn{4}{c}{$X$} \\
\cline { 2 - 4 }$Y$ & 0 & 1 & 2 & 3 \\
\hline 0 & - & {$[1,0]$} & {$[2,0]$} & {$[3,0]$} \\
1 & {$[0,1]$} & {$[1,1]$} & {$[2,1]$} & {$[3,1]$} \\
2 & {$[0,2]$} & {$[1,2]$} & {$[2,2]$} & {$[3,2]$} \\
3 & {$[0,3]$} & {$[1,3]$} & {$[2,3]$} & {$[3,3]$} \\
4 & {$[0,4]$} & {$[1,4]$} & {$[2,4]$} & {$[3,4]$} \\
\hline
\end{tabular}

Todos os pares de plantas doentes são identificados e classificados de acordo com as suas respectivas classes de distância, obtendo-se o número de pares em cada uma das classes. Porém, de acordo com Gray et al. (1986), os números de pares de plantas doentes não podem ser diretamente comparados, pois o número máximo possível de pares em cada uma das classes varia. Por exemplo, em um látice $4 \times 5$, a classe $[0,1]$ pode conter no máximo 16 pares, enquanto a classe $[1,1]$ pode ter até 24 pares. Para que esse problema seja contornado, Gray et al. (1986) padronizam as contagens e utilizam as freqüências das contagens padronizadas ou SCF (standardized count frequencies), que consistem da divisão dos números de 
pares em cada classe pelo número total de pares de plantas doentes em toda a área estudada.

Gray et al. (1986) comparam as $S C F$ observadas com as esperadas, para verificar se o padrão observado difere significativamente do padrão aleatório. As freqüências esperadas foram obtidas a partir de dados simulados, considerando as mesmas dimensões do látice e o mesmo número de plantas doentes, porém as posições das plantas doentes eram definidas aleatoriamente, ou seja, na simulação qualquer planta tinha a mesma chance de estar doente. Foram simulados 400 látices e, para cada um deles, as $S C F$ foram calculadas, juntamente com a média e o desvio-padrão das $S C F$ para cada uma das classes.

Níveis de significância, para cada uma das classes de distâncias $[X, Y]$, podem ser determinados calculando-se a porcentagem de vezes que as $S C F$ observadas excedem as $S C F$ obtidas nas simulações. Para uma determinada classe $[X, Y]$, se a $S C F$ observada é maior em $95 \%$ ou mais das simulações, ela é considerada significativamente maior do que a esperada $(P \leq 0,05)$, no caso de um padrão espacial aleatório. Utilizando o mesmo raciocínio, se a $S C F$ observada é menor em $95 \%$ ou mais das simulações, então esta é considerada significativamente menor do que a esperada, se as plantas estivessem localizadas aleatoriamente dentro da área em estudo $(P \geq 0,95)$. Caso contrário, a $S C F$ não é considerada significativamente diferente da esperada.

Os resultados obtidos para a significância das $S C F$ são resumidos na forma de uma matrix ou tabela, como apresentado na Tabela 1, em que • indica a classe de distância $[X, Y]$ com $S C F$ observada significativamente maior do que a esperada $(P \leq 0,05)$, o indica $S C F$ significativamente menor do que a esperada $(P \geq 0,95)$ e - indica diferenças não significativas entre $S C F$ observadas e esperadas.

A proporção, em relação ao número total, de classes de distâncias que apresentam diferenças significativas entre as $S C F$ observadas e esperadas pode ser facilmente vista quando os resultados são apresentados na forma da Tabela 1. Esta 
Tabela 1. Tabela com a representação dos resultados das significâncias das $S C F$ para um látice $4 \times 5$

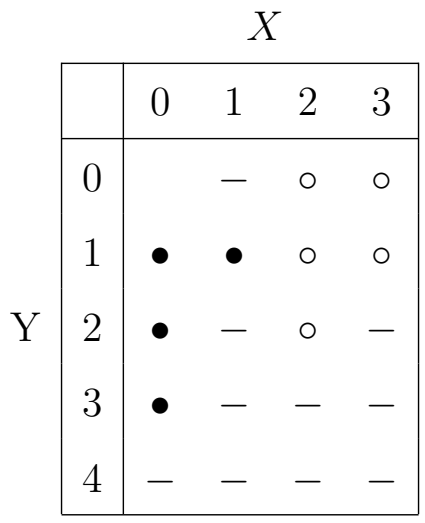

proporção está diretamente relacionada ao grau de desvio do padrão espacial avaliado em relação a um padrão espacial aleatório. Segundo Nelson (1995), o tamanho, a forma e a posição de grupos agregados das $S C F$ observadas, significativamente diferentes das esperadas, são características utilizadas para descrever e quantificar atributos do padrão espacial agregado, como a presença de pequenos ou grandes grupos (ou agregados) de plantas doentes na parte central ou nas bordas do látice. Nelson et al. (1992) dizem que um grande atrativo da metodologia proposta por Gray et al. (1986) é a possibilidade de se identificar a localização dos agregados dentro do látice e se ter uma idéia do tamanho desses agregados.

Gray et al. (1986), analisando dados de doenças em melão e lúpulo, Nelson et al. (1992), utilizando dados simulados e Nelson (1995), com dados simulados e de doenças em citros e mamão, apresentam uma descrição detalhada sobre a interpretação dos resultados obtidos com a aplicação da metodologia proposta por Gray et al. (1986).

De acordo com Nelson et al. (1992), esta metodologia de classes de distância bidimensional pode ser inapropriada quando o número de plantas doentes no látice é muito pequeno ou muito grande. Portanto, existem restrições à utilização dessa técnica. Nelson (1995) apresenta as seguintes restrições à sua utilização, 
semelhantes às apresentadas por Nelson et al. (1992):

- ter de 10 a 90\% de plantas doentes na área ou talhão (látice) em estudo;

- ter no mínimo $1 \%$ de plantas doentes na primeira avaliação, quando a doença for avaliada em dois tempos diferentes;

- ter no máximo $20 \%$ de plantas ausentes no talhão;

- utilizar no mínimo 400 conjuntos de dados simulados.

Ferrandino (1996) critica a metodologia proposta por Gray et al. (1986) e apresenta soluções para os problemas levantados. A aproximação original, que envolve a comparação de valores observados e esperados, apresenta os mesmos problemas associados a todos os testes de comparações múltiplas, pois envolve a comparação de valores observados e esperados para um número grande de classes de distâncias. De acordo com Ferrandino (1996), estes problemas podem ser solucionados apenas com a utilização de testes estatísticos de significância mais conservadores, o que implicaria em um aumento no número de simulações utilizadas nas análises, indicando que, ao invés de se utilizar apenas 400 simulações, seriam necessárias $4 \times 10^{5}$ simulações aproximadamente. Assim, um método analítico para se calcular a média do número esperado de pares de plantas doentes em cada classe $[X, Y]$, juntamente com os respectivos limites de confiança, é proposto, utilizando-se apenas da teoria de análise combinatória.

Ferrandino (1998) propôs uma outra metodologia, também baseada em classes de distâncias, que, segundo o autor, corrige o viés causado pela heterogeneidade dos dados e que está presente na metodologia original de Gray et al. (1986). Nesta nova técnica, denominada de 2DCORR, as freqüências esperadas em cada uma das classes de distâncias $[X, Y]$ são calculadas analiticamente e as diferenças entre as freqüências observadas e esperadas são testadas através de um teste de comparação de $\chi^{2}$. De acordo com Ferrandino (1998), a metodologia original é sensitiva a efeitos de bordas, ou seja, à deteç̧ão de agregados nas bordas e às vezes acusa a presença de 
falsos grupos agregados de plantas doentes, sendo que, com 2DCORR esse problema é contornado. O autor faz a descrição detalhada, juntamente com a comparação dos resultados obtidos pela 2DCLASS e 2DCORR, considerando dados de uma doença do lúpulo.

\subsubsection{Autocorrelação espacial}

Autocorrelação espacial é utilizada para caracterizar a dependência espacial da incidência de uma doença, considerando diferentes distâncias e padrões de proximidade das plantas ou das unidades amostrais, como por exemplo os quadrats (Campbell \& Madden, 1990; Cliff \& Ord, 1981; Upton \& Fingleton, 1985; Xu \& Ridout, 2000). A análise de autocorrelação espacial é uma técnica muito útil e versátil, pois pode ser utilizada para o caso de dados contínuos, como por exemplo a avaliação da área foliar afetada por uma doença e discretos, como contagens de plantas doentes em quadrats ou dados binários, em que cada planta é classificada como doente ou sadia.

$\mathrm{Na}$ análise de autocorrelação espacial, a idéia é verificar se as plantas próximas a uma determinada planta doente estão doentes ou sadias ou comparar o número de plantas doentes de cada quadrat com o número de plantas doentes dos quadrats mais próximos, obedecendo a padrões de proximidade pré-estabelecidos. Esses padrões de proximidade são determinados pelo tipo de conexão e pela distância entre as plantas ou quadrats. Comparações de primeira ordem envolvem plantas ou quadrats adjacentes e de segunda ordem envolve a comparação de plantas ou quadrats separados por uma unidade. Comparações de ordens superiores também podem ser consideradas. Campbell \& Madden (1990) e Reynolds \& Madden (1988) apresentam uma classificação dos padrões de proximidade de primeira e segunda ordens, considerando a terminologia utilizada no jogo de xadrez. Esta classificação, considerando a vizinhança de plantas, é apresentada na Figura 7. A definição dos padrões de proximidade ou esquema de vizinhança é muito flexível e pode ser adap- 
tada a uma situação particular. Gumpertz et al. (1997) apresenta os padrões de proximidade de uma maneira diferente, conforme pode ser visto na Figura 8, para o caso de se considerar a comparação em nível de plantas. Se o interesse é comparar o número de plantas doentes presentes nos quadrats, o esquema de vizinhança é definido da mesma maneira, apenas consideram-se os quadrats ao invés das plantas, conforme pode ser visto na Figura 9, que corresponde aos padrões de proximidade definidos por Gumpertz et al. (1997). Os padrões apresentados por Campbell \& Madden (1990) e Reynolds \& Madden (1988), considerando quadrats, são definidos de maneira idêntica.

Uma estatística utilizada para se determinar o grau de autocorrelação espacial é a estatística do produto cruzado, a qual é apresentada por Campbell \& Madden (1990), Cliff \& Ord (1981) e Upton \& Fingleton (1985). Esta estatística é definida por:

$$
r=\sum_{i} \sum_{j} W_{i j} Y_{i j}
$$

em que, $W_{i j}$ é uma medida da proximidade espacial e $Y_{i j}$ é uma medida da semelhança das unidades amostrais $i$ e $j$.

No caso em que se deseja calcular o coeficiente de autocorrelação em nível de planta, ou seja, quando se compara o status (doente ou sadia) de uma planta com o de suas vizinhas, pode-se considerar, na equação (19), $Y_{i j}=1$, quando as plantas $i$ e $j$ estiverem doentes ou $Y_{i j}=0$, caso contrário e $W_{i j}$ assume valores 0 ou 1 , ou seja, se as plantas $i$ e $j$ estiverem nas posições definidas pelo padrão de proximidade considerado, $W_{i j}=1$, caso contrário, $W_{i j}=0$. Assim, obtém-se a estatística join-count, $J$, a qual corresponde ao número de conexões entre plantas doentes, para um dado esquema de vizinhança ou padrão de proximidade, em uma determinada área. Esta estatística é discutida com mais detalhes por Cliff \& Ord (1981) e Upton \& Fingleton (1985) e foi utilizada por Gibson \& Austin (1996) na caracterização de padrões espaciais e na comparação de padrões espaciais da incidência de tristeza dos citros com padrões simulados. 


\begin{tabular}{|c|c|c|c|c|c|c|c|c|c|c|}
\hline \multirow{3}{*}{$\begin{array}{c}\text { Padrão de } \\
\text { proximidade }\end{array}$} & \multicolumn{10}{|c|}{ Ordem } \\
\hline & \multicolumn{5}{|c|}{ Primeira } & \multicolumn{5}{|c|}{ Segunda } \\
\hline & . & . & $\cdot$ & . & . & . & . & $*$ & & . \\
\hline & . & . & $*$ & . & . & . & . & . & . & . \\
\hline \multirow[t]{5}{*}{ Torre } & . & * & $x$ & * & . & * & . & $x$ & . & * \\
\hline & . & . & $*$ & . & . & . & . & . & . & . \\
\hline & . & . & . & . & . & . & . & * & . & . \\
\hline & . & . & $\cdot$ & . & . & * & . & . & . & * \\
\hline & . & * & . & * & . & . & . & . & . & . \\
\hline \multirow[t]{5}{*}{ Bispo } & . & . & $x$ & . & . & . & . & $x$ & . & . \\
\hline & . & * & . & * & . & . & . & . & . & . \\
\hline & . & . & . & . & . & * & . & . & . & * \\
\hline & . & . & . & . & . & * & . & * & . & * \\
\hline & . & * & * & * & . & . & . & . & . & . \\
\hline \multirow[t]{5}{*}{ Rainha } & . & * & $x$ & * & . & * & . & $x$ & . & * \\
\hline & . & * & $*$ & $*$ & . & . & . & . & . & . \\
\hline & . & . & . & . & . & * & . & * & . & * \\
\hline & . & . & & . & . & * & * & * & * & * \\
\hline & . & * & * & * & . & * & . & . & . & * \\
\hline \multirow[t]{5}{*}{ Quadrado } & . & * & $x$ & $*$ & . & * & . & $x$ & rat & * \\
\hline & . & * & $*$ & * & · & * & . & . & . & * \\
\hline & . & . & . & . & . & * & * & * & * & * \\
\hline & . & · & . & . & . & . & . & * & r & . \\
\hline & . & . & $*$ & . & . & . & . & . & rat & . \\
\hline \multirow[t]{5}{*}{ Entre linhas } & . & . & $x$ & . & . & . & . & $x$ & rat & . \\
\hline & . & . & * & . & . & . & . & . & the & . \\
\hline & . & . & . & . & . & . & . & $*$ & rat & . \\
\hline & . & . & . & . & . & . & . & . & ra & . \\
\hline & . & . & . & . & . & . & . & . & rat & . \\
\hline \multirow[t]{3}{*}{ Dentro da linha } & . & * & $x$ & $*$ & . & * & . & $x$ & trat & $*$ \\
\hline & . & . & . & . & . & . & . & . & 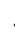 & . \\
\hline & . & . & . & . & . & . & . & . & 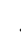 & . \\
\hline
\end{tabular}

Figura 7 - Padrões de proximidade típicos utilizados na análise de autocorrelação espacial, em que $\times$ representa uma planta de referência, $*$ representa as plantas vizinhas consideradas na comparação e · representa as demais plantas 
Figura 8 - Padrões de proximidade apresentados por Gumpertz et al. (1997), em que $\times$ representa uma planta de referência, $*$ representa as plantas vizinhas consideradas na comparação e · representa as demais plantas

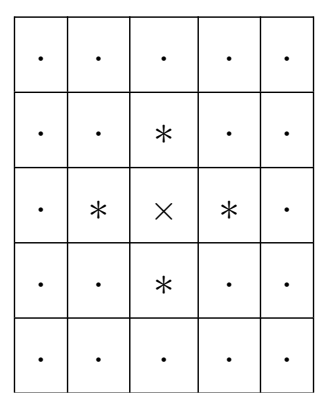

Primeira ordem

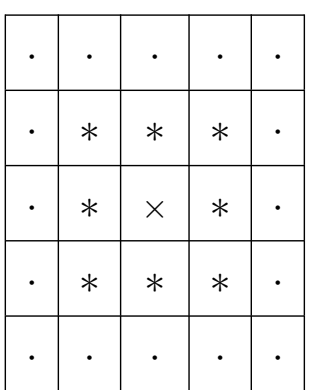

Segunda ordem

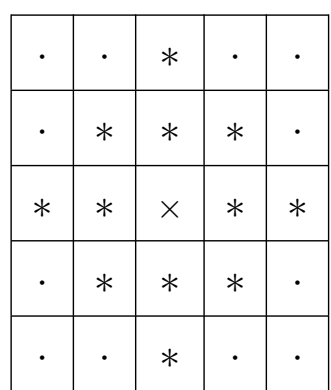

Terceira ordem

Figura 9 - Padrões de proximidade apresentados por Gumpertz et al. (1997), em que $\times$ representa um quadrat de referência, $*$ representa os quadrats considerados na comparação e $\cdot \cdot$ representa os demais quadrats

Segundo Upton \& Fingleton (1985), a estatística join-count considera a informação obtida de um conjunto de dados na sua forma mais simples, ou seja, quando cada planta é classificada como doente ou sadia. Generalizações para o caso de outros tipos de dados, contínuos ou discretos, como por exemplo a contagem do número de plantas doentes nos quadrats, são encontradas na literatura. Ripley (1981) e Upton \& Fingleton (1985) apresentam outras duas formas relacionadas de se estimar a autocorrelação espacial: a estatística $I$ de Moran e a estatística $C$, 
proposta por Geary $(1954)^{5}$. Estas estatísticas são definidas por

$$
I=\frac{N}{\sum_{i} \sum_{j} W_{i j}} \frac{\sum_{i} \sum_{j} W_{i j}\left(x_{i}-\bar{x}\right)\left(x_{j}-\bar{x}\right)}{\sum_{i}\left(x_{i}-\bar{x}\right)^{2}}
$$

e

$$
C=\frac{(N-1)}{2 \sum_{i} \sum_{j} W_{i j}} \frac{\sum_{i} \sum_{j} W_{i j}\left(x_{i}-x_{j}\right)^{2}}{\sum_{i}\left(x_{i}-x_{j}\right)^{2}},
$$

em que $x_{i}$ e $x_{j}$ são os valores observados nas unidades amostrais $i$ e $j$ respectivamente, como por exemplo o número de plantas doentes nos quadrats $i$ e $j$, sendo $i, j=1,2, \ldots, N$ e $i \neq j$ e $W_{i j}=1$ ou 0 , conforme definido anteriormente. Valores de $I$ próximos de 0 e de $C$ próximos de 1 é uma característica de padrões espaciais aleatórios, enquanto que valores próximos de 0 para $I$ e próximos de 1 para $C$, indicam uma autocorrelação positiva entre as unidades amostrais, o que está associado a padrões espaciais agregados.

Testes de hipóteses podem ser utilizados para verificar se os valores de $r, I$ ou $C$ são significativamente diferentes dos valores esperados no caso de padrões espaciais aleatórios. Aproximações da distribuição Normal usualmente são acuradas e têm grande valor prático para se verificar se valores observados da autocorrelação espacial diferem significativamente dos esperados sob uma determinada condição, o que corresponde à hipótese nula (Upton \& Fingleton, 1985). Pressupondo que $r$, I e $C$ são normalmente distribuídos assintoticamente (Campbell \& Madden, 1990; Ripley, 1981; Upton \& Fingleton, 1985) pode-se utilizar o teste $Z$, por exemplo. De acordo com Campbell \& Madden (1990), se o número de quadrats é pequeno, o teste $t$ é mais apropriado. Discussões detalhadas sobre a aplicação de diferentes testes de hipóteses, assim como a definição dos valores esperados e das variâncias de $r, I$ e $C$ são apresentadas por Ripley (1981) e Upton \& Fingleton (1985).

\footnotetext{
${ }^{5}$ GEARY, R.C. The contiguity ratio and statistical mapping. The Incorporated Statistician, v.5, p.115-145, 1954.
} 
Campbell \& Madden (1990) definem a autocorrelação espacial considerando dados provenientes de quadrats e afirmam que, usualmente, $W_{i j}$ assume valores 0 ou 1 , conforme definido anteriormente e $Y_{i j}=\left(x_{i}-\bar{x}\right)\left(x_{j}-\bar{x}\right)$, em que $x_{i}$ e $x_{j}$ são os números de plantas doentes nos quadrats $i$ e $j$, respectivamente. De acordo com esses autores, se os quadrats vizinhos apresentarem quantidades similares de plantas doentes, então $r$ de primeira ordem será alto, enquanto que, no caso de se terem quadrats muito diferentes, valores mais baixos de $r$ serão obtidos. Upton \& Fingleton (1985) definem $Y_{i j}$ como o quadrado da diferença entre $x_{i}$ e $x_{j}$, ou seja,

$$
Y_{i j}=\left(x_{i}-x_{j}\right)^{2}
$$

que corresponde a uma outra forma de quantificar a diferença ou desvio entre $x_{i}$ e $x_{j}$.

Campbel \& Madden (1990) alertam para o problema de que a estatística $r$ não está limitada a um intervalo, como ocorre com a correlação intraclasse e sua magnitude está diretamente relacionada ao número de quadrats considerado no cálculo. Portanto, não se podem comparar diretamente r's calculados para diferentes conjuntos de dados, nos quais as dimensões e/ou número de quadrats são diferentes. Porém, pode-se multiplicar $r$ por um fator de escala apropriado e, assim, obter um valor que esteja entre -1,0 e 1,0. Assim a estatística I de Moran, conforme Campbell \& Madden (1990), pode ser calculada a partir de $r$, ou seja,

$$
I=\frac{r}{T s^{2}}
$$

em que, $T=\sum_{i} \sum_{j} W_{i j}$ e $s^{2}=\sum_{i=1}^{N}\left(x_{i}-\bar{x}\right) /(N-1)$ é a variância e $\bar{x}=\sum_{i=1}^{N} x_{i} / N$ é a média do número de plantas doentes dos $N$ quadrats .

Ridout \& Xu (2000) dizem que sendo a autocorrelação espacial conhecida, várias outras medidas obtidas a partir de dados provenientes de quadrats e utilizadas na caracterização de padrões espaciais, como correlação intraclasse, índices de dispersão e lei de potência binária, podem ser obtidas. Esses autores ainda afirmam que a autocorrelação espacial é a medida mais importante na caracterização da estrutura espacial para dados de incidência de doenças. 


\subsubsection{Modelos estocásticos espaço-temporais}

Gibson \& Austin (1996) propuseram um método, baseado na verossimilhança, para ajustar modelos estocásticos espaço-temporais, a dados de doenças de plantas. Esses autores utilizaram dois modelos diferentes, nos quais a transmissão da doença ocorria apenas entre plantas do mesmo látice e era descrita por um único parâmetro. Na estimação desse parâmetro foi utilizada uma técnica de integração estocástica que, segundo Gibson (1997b), apresentava problemas. Assim, Gibson (1997b) propôs uma nova metodologia para a estimação dos parâmetros, com a utilização de métodos de Monte Carlo baseado em cadeias de Markov (MCMC). Posteriormente, Gibson (1997a) propôs um modelo mais complexo, com dois parâmetros, que descreve tanto a infecção de plantas sadias por plantas doentes do mesmo látice, como os modelos utilizados por Gibson \& Austin (1996) e Gibson (1997b), quanto a infecção por fontes de fora do látice.

Os modelos considerados são estocásticos, o que significa que eles quantificam a chance ou probabilidade de que qualquer planta sadia se torne infectada (Gibson, 1997b), e procuram descrever como uma determinada doença é disseminada entre a população de plantas, as quais ocupam os vértices de um látice retangular bidimensional finito, $L$. Em condições de campo, esse látice corresponde a uma área ou um talhão retangular, onde as plantas estão dispostas em linhas e colunas de uma forma regular, ou seja, em que os espaçamentos entre linhas e entre plantas dentro de cada linha (colunas) são constantes. Cada vértice, que correponde ao cruzamento das linhas e colunas, contém uma planta que pode ser identificada pelas coordenadas desse vértice. Por exemplo, a terceira planta da segunda linha tem coordenada $(2,3)$, ou seja, linha 2 e coluna 3. Para facilitar a notação, $x, y$ e $z$ representam três plantas diferentes do mesmo látice e suas coordenadas espaciais. O tempo é considerado como uma variável contínua e, num determinado tempo $t$, a planta pode ser classificada como doente ou sadia. O conjunto de todas as plantas doentes do látice, nesse tempo $t$, é representado pelo conjunto $D(t)$. 
A infecção de plantas sadias por plantas doentes é tratada como um processo estocástico (Gibson, 1997b). Se, no tempo $t$, a planta $x \in L$ é sadia e $y \in L$ está doente então, para $\mathrm{d} t \rightarrow 0$,

$$
P(y \text { infectar } x \text { em }[t, t+\mathrm{d} t])=k(t) F_{\boldsymbol{\alpha}}(y-x) \mathrm{d} t
$$

em que $k(t)$ é uma constante no tempo $t$ e $F_{\boldsymbol{\alpha}}(y-x)$ é uma função da distância entre as plantas $x$ e $y$, aqui representada por $(y-x)$. A função $F_{\boldsymbol{\alpha}}(y-x)$, que caracteriza a relação entre a pressão infectiva e as posições das plantas doentes e sadias, é nãonegativa e, geralmente, decresce monotonicamente com a distância. Os parâmetros de $F_{\boldsymbol{\alpha}}(y-x)$ são representados pelo vetor de parâmetros $\boldsymbol{\alpha}$. O termo $k(t)$, que deve ser não-negativo e que pode variar com $t$, representa o efeito de fatores secundários importantes, que podem favorecer ou prejudicar a infecção de plantas sadias em um determinado tempo $t$, como por exemplo a quantidade de chuvas ou velocidade do vento.

Gibson \& Austin (1996) e Gibson (1997b) consideraram duas funções $F_{\boldsymbol{\alpha}}(y-x)$ diferentes, com um único parâmetro $\alpha$. Nestes casos o vetor de parâmetros $\boldsymbol{\alpha}$ é um escalar, ou seja, $\boldsymbol{\alpha}=[\alpha]$ ou simplesmente $\alpha$, em que $\alpha \geq 0$. No primeiro deles, a pressão infectiva, que corresponde à pressão exercida pela planta doente $y$ sobre a sadia $x$, diminui exponencialmente com a distância, ou seja,

$$
F_{\alpha}(y-x)=e^{-\alpha|y-x|}
$$

enquanto que no segundo, esta é inversamente proporcional a uma potência da distância,

$$
F_{\alpha}(y-x)=|y-x|^{-2 \alpha},
$$

em que $|y-x|$ representa a distância entre $y$ e $x$ no látice. Dado que as plantas $y$ e $x$ estejam nas coordenadas $\left(y_{1}, y_{2}\right)$ e $\left(x_{1}, x_{2}\right)$ respectivamente, o que significa que $y$ está localizada na linha $y_{1}$ e coluna $y_{2}$ e $x$ está na linha $x_{1}$ e coluna $x_{2}$, a distância entre $y$ e $x$ é dada por

$$
|y-x|=\sqrt{\left(y_{1}-x_{1}\right)^{2}+\left(y_{2}-x_{2}\right)^{2}} .
$$


Gibson \& Austin (1996) e Gibson (1997b), utilizando técnicas diferentes, compararam os ajustes das duas funções, apresentados em (21) e (22), considerando dados de tristeza dos citros. Gibson (1997b) utilizou um teste baseado na verossimilhança e Gibson \& Austin (1996), utilizando simulação, consideraram as distribuições de três medidas de agregação: a estatística join-count, o parâmetro de agregação da distribuição beta-binomial e o coeficiente de correlação intraclasse. Em ambos os trabalhos, a função (22) apresentou um melhor ajuste aos dados de tristeza dos citros.

A função utilizada por Gibson (1997a) contém dois parâmetros, ou seja, $\boldsymbol{\alpha}^{\prime}=\left[\begin{array}{ll}\alpha_{1} & \alpha_{2}\end{array}\right]$ e é dada por

$$
F_{\boldsymbol{\alpha}}(y-x)=\alpha_{1}+|y-x|^{-2 \alpha_{2}}
$$

em que $\alpha_{1}$ e $\alpha_{2} \geq 0$.

O parâmetro $\alpha_{1}$, no modelo apresentado em (23), representa uma fonte primária de infecção, ou seja, está relacionado à chance de que uma planta sadia seja infectada por fontes fora de sua área ou talhão. Os parâmetros $\alpha$, em (21) e (22) e $\alpha_{2}$, na função apresentada em (23), estão associados à transmissão local da doença, ou seja, de uma planta doente para uma sadia presentes na mesma área ou talhão. Os termos $e^{-\alpha|y-x|},|y-x|^{-2 \alpha}$ e $|y-x|^{-2 \alpha_{2}}$, em (21), (22) e (23), respectivamente, representam a chance de que uma planta sadia seja infectada por uma planta doente do mesmo talhão e pode-se observar que, para um determinado valor de $\alpha$ ou $\alpha_{2}$, esta chance diminui à medida que a distância entre $x$ e $y$, dada por $|y-x|$, aumenta.

Gibson \& Austin (1996) e Gibson (1997a, 1997b) não consideraram nenhum período latente, ou seja, a partir do momento em que uma planta se torna infectada, ela está apta a infectar outras plantas. Também consideraram que as plantas infectadas podem infectar plantas sadias independentemente, dentro da mesma área ou talhão. Assim, considerando a definição apresentada em (20) e as funções 
apresentadas em (21), (22) e (23), têm-se, respectivamente,

$$
\begin{gathered}
P(x \text { se torne infectada em }[t, t+\mathrm{d} t])=k(t)\left[\sum_{y \in D(t)} e^{-\alpha|y-x|}\right] \mathrm{d} t, \\
P(x \text { se torne infectada em }[t, t+\mathrm{d} t])=k(t)\left[\sum_{y \in D(t)}|y-x|^{-2 \alpha}\right] \mathrm{d} t \quad \mathrm{e} \\
P(x \text { se torne infectada em }[t, t+\mathrm{d} t])=k(t)\left[\alpha_{1}+\sum_{y \in D(t)}|y-x|^{-2 \alpha_{2}}\right] \mathrm{d} t,
\end{gathered}
$$

em que o termo do somatório representa a soma das pressões infectivas exercidas por todas as plantas doentes do talhão sobre a planta sadia $x$. Utiliza-se esse somatório pois é assumido que cada uma das plantas doentes do conjunto $D(t)$ afeta a planta sadia de forma independente.

Nos dois modelos definidos em (24) e (25) pode-se observar que a probabilidade de que qualquer planta sadia do talhão se torne doente é a mesma quando $\alpha=0$, pois o termo que leva em consideração a distância das plantas infectadas assumirá sempre um peso igual a 1, independente da localização das plantas sadias em relação às doentes. Nessa situação, qualquer planta sadia terá a mesma probabilidade de se tornar doente, o que caracteriza um padrão espacial aleatório. Valores altos de $\alpha$ representam uma forte pressão infectiva local que diminui rapidamente com a distância, caracterizando uma transmissão local predominantemente para plantas vizinhas mais próximas. Nessa situação, tem-se um padrão espacial agregado, caracterizado por um único grupo de plantas agregadas em torno da fonte inicial de infecção.

A interpretação dos parâmetros do modelo apresentado em (26) é um pouco mais complexa, pois nesse caso têm-se dois parâmetros, apesar da interpretação do parâmetro $\alpha_{2}$ ser exatamente a mesma de $\alpha$, nos modelos (24) e (25). Mesmo com dois parâmetros, o modelo (26) é simples e fácil de se trabalhar e, de acordo com Gibson (1997a), esse modelo permite que sejam estudados aspectos importantes, como a transmissão primária e secundária da doença. Dependendo dos valores dos 
parâmetros $\alpha_{1}$ e $\alpha_{2}$, o modelo (26) especifica mecanismos de dispersão da doença ou padrões espaciais muito diferentes. Para $\alpha_{1}=0$, tem-se um modelo idêntico ao apresentado em (25), portanto a interpretação do parâmetro $\alpha_{2}$ é a mesma de $\alpha$. Quando $\alpha_{1} \rightarrow \infty$, o efeito da transmissão local, para qualquer valor de $\alpha_{2}$, é dominado pelo efeito da fonte externa de infecção, ou seja, $\alpha_{1}$ muito alto impede que o efeito descrito pelo parâmetro $\alpha_{2}$ apareça e, novamente têm-se padrões espaciais aleatórios. Se $\alpha_{1}$ é pequeno e $\alpha_{2}$ é grande, tem-se um padrão espacial agregado, porém, na presença de uma fonte de infecção externa ou que não é proveniente de plantas doentes próximas, o que altera o comportamento da dispersão da doença. Nesse caso, a transmissão local para plantas mais próximas predomina mas, devido à outra fonte de infecção, representada por $\alpha_{1}$, ocorre a formação de vários grupos agregados de plantas doentes. Portanto, o modelo apresentado em (26) permite não só a discriminação de padrões aleatórios e agregados, como os modelos (24) e (25), mas também possibilita a identificação de diferentes formas do padrão espacial agregado: o padrão espacial com um único grupo de plantas doentes agregadas e o padrão espacial com a formação de alguns pequenos grupos agregados. De acordo com Pethybridge \& Madden (2003), apesar de $\alpha_{1}$ e $\alpha_{2}$ não apresentarem limite superior, valores iguais a 3, 0, para ambos, são extremamente altos.

\subsection{Métodos de Monte Carlo baseado em cadeias de Markov (MCMC)}

Os métodos MCMC, que são métodos iterativos de simulação, representam na realidade uma alternativa aos métodos de simulação de uma amostra a partir de uma distribuição de interesse $\pi(x)$. Quando se conhece $\pi(x)$ e é possível simular diretamente de $\pi(x)$, os valores da amostra são gerados de forma independente e a partir dessa amostra podem-se fazer inferências sobre tal distribuição, desde que o tamanho da amostra seja suficientemente grande. Esses métodos de simulação 
são conhecidos como não-iterativos.

A idéia principal dos métodos MCMC continua sendo a de se obter uma amostra da distribuição de interesse $\pi(x)$, com o intuito de fazer inferências sobre esta distribuição. Esses métodos podem ser utilizados quando $\pi(x)$ é muito complexa ou é conhecida apenas parcialmente, isto é, $\pi(x)$ é conhecida desconsiderando-se uma constante de proporcionalidade, o que impede a simulação de valores para a variável aleatória $X$ diretamente a partir de $\pi(x)$. Assim, pode-se construir uma cadeia de Markov, que é um tipo particular de processo estocástico, tal que a distribuição estacionária seja $\pi(x)$.

Um processo estocástico pode ser definido como uma coleção de variáveis aleatórias $\left\{X^{(t)}: \quad t \in T\right\}$, isto é, para cada $t \in T, X^{(t)}$ é uma variável aleatória que assume valores $x^{(t)} \in S$, em que $S$ é o espaço de estados, que representa o conjunto de todos os valores que $X^{(t)}$ pode assumir e $T$ é um conjunto de índices (Gamerman, 1997; Ross, 1993). O espaço de estados $S$ pode ser discreto ou contínuo e, geralmente, assume-se o índice $t$ como sendo um tempo e assim, $X^{(t)}$ é definido como o estado do processo no tempo $t$. Se $T$ representa um conjunto enumerável, o processo estocástico é um processo de tempo discreto e se $T$ corresponde a um intervalo tal que $T \in \Re$, ou seja, um conjunto não-enumerável, o processo é dito de tempo contínuo.

Uma cadeia de Markov é um processo estocástico associado a uma seqüência de variáveis aleatórias $\left\{X^{(0)}, X^{(1)}, X^{(2)}, \ldots\right\}$ em que, dado o estado presente, os estados passados e futuros são independentes, isto é, a distribuição de $X^{(t+1)}$ dado todos os valores anteriores $X^{(0)}, X^{(1)}, \ldots, X^{(t)}$ depende apenas de $X^{(t)}$. Essa propriedade pode ser mais formalmente descrita por

$$
P\left(X^{(t+1)} \in A \mid X^{(t)}=a, X^{(t-1)} \in A_{t-1}, \ldots, X^{(0)} \in A_{0}\right)=P\left(X^{(t+1)} \in A \mid X^{(t)}=a\right)
$$

para todos os conjuntos $A_{0}, \ldots, A_{t-1}, A \subset S$ e $a \in S$ (Gamerman, 1997). Portanto, pode-se pensar na cadeia de Markov como um modelo para um sistema que se move aleatoriamente através de uma série de estados sem ter qualquer "lembrança" de onde esteve (Leandro, 2001), isto é, o valor que $X^{(t+1)}$ assumirá depende apenas do 
valor $a$, uma vez que $X^{(t)}=a$.

Pode-se observar que a probabilidade definida em (27) depende de $t$, $A$ e $a$. Caso não dependa de $t$, a cadeia de Markov é definida como homogênea e

$$
P\left(X^{(t+1)} \in A \mid X^{(t)}=a\right)=P(a, A), \quad \forall \quad t,
$$

que significa que as probabilidades de transição de um estado para outro são invariantes e $P(a, A)$ é definida como função ou kernel de transição. O kernel de transição não é único e representa a distribuição a partir da qual será gerado o valor de $X^{t+1}$, dado que $X^{(t)}=a$. Assim, podem-se utilizar diferentes funções de transição $P(a, A)$, conforme pode ser visto em Smith \& Roberts (1993), Chib \& Geenberg (1995), Gamerman (1997) e Morgan (2000).

No caso de espaço de estados discretos, Gamerman (1997) define a função de transição $P(a, A)$ como

1. $P(a, \cdot)$ é uma distribuição de probabilidade sobre $S$, para todo $a \in S$;

2. a função $a \longmapsto P(a, A)$ pode ser avaliada, para todo $A \subset S$

e utiliza $P(a,\{b\})=P(a, b)$, que é chamada de probabilidade de transição e satisfaz às seguintes condições:

i. $P(a, b) \geq 0, \forall \quad a, b \in S$;

ii. $\sum_{b \in S} P(a, b)=1, \forall \quad a \in S$;

de maneira idêntica a qualquer distribuição de probabilidade.

Para o caso de espaço de estados contínuos, a forma como foi definida a probabilidade de transição, não é mais conveniente dentro do contexto utilizado para a definição de cadeias de Markov, pois $P(a, b)$ é sempre igual a zero. Porém, de acordo com Gamerman (1997), dado que $P(a, \cdot)$ define uma distribuição de probabilidade, pode-se considerar

$$
P(a, b)=P\left(X^{(t+1)} \leq b \mid X^{(t)}=a\right)
$$


para $a, b \in S$, quando $P$ é absolutamente contínuo em relação a $b$. A partir dessa função de distribuição acumulada condicional $P(a, b)$, pode-se obter a densidade condicional correspondente

$$
p(a, b)=\frac{\partial P(a, b)}{\partial b}, \quad \forall \quad a, b \in S,
$$

que pode ser utilizada para definir o kernel de transição da cadeia, ao invés de $P(a, A)$.

Já foi dito que nos métodos MCMC, a idéia básica é obter uma amostra de uma distribuição de interesse construindo uma cadeia de Markov com distribuição estacionária dada por $\pi(x)$. De acordo com Gamerman (1997), uma distribuição $\pi$ é uma distribuição estacionária de uma cadeia de Markov, com probabilidades de transição $P(a, b)$ ou $p(a, b)$, se

$$
\pi(b)=\sum_{a \in S} \pi(a) P(a, b), \quad \forall \quad b \in S,
$$

no caso da variável aleatória ser discreta ou

$$
\pi(b)=\int_{-\infty}^{\infty} \pi(x) p(a, b) \mathrm{d} x
$$

no caso de uma variável aleatória contínua.

Entretanto, não basta que $\pi(x)$ seja a distribuição estacionária da cadeia de Markov obtida. Também é necessário que a cadeia de Markov seja ergódica, isto é, que convirja para essa mesma distribuição $\pi(x)$ independente de qual seja a distribuição inicialmente escolhida. Esta distribuição inicialmente escolhida é a que define a função de transição da cadeia, que não é única. Assim, uma cadeia de Markov ergódica terá uma única distribuição estacionária, conhecida como distribuição de equilíbrio. Gamerman (1997) diz que a condição de uma cadeia ergódica é satisfeita quando a cadeia é irredutível e aperiódica. Uma cadeia é irredutível quando cada estado pode ser atingido a partir de qualquer outro estado, em um número finito de iterações e ela é aperiódica quando não há estados absorventes. Um estado é dito absorvente, quando, uma vez atingido esse estado, é impossível sair dele (Jones \& 
Smith, 2001). Por exemplo, no caso de um espaço de estados discretos, se $a \in S$ é absorvente então $P(a, a)=1$ e, conseqüentemente, $P(a, b)=0$ para todo valor de $b \in S$, em que $b \neq a$. Assim, uma vez que $X$ assuma valor igual a $a$, isto é, que se esteja no estado $a$, a probabilidade que $X$ assuma um valor diferente, ou que a cadeia mude de estado, é nula.

\subsubsection{Cadeias de passeios aleatórios (random walk chains)}

Um passeio aleatório ou random walk é uma cadeia de Markov na qual a mudança de estado para outro é definida por $X^{(t+1)}=X^{(t)}+W_{t+1}$, em que $W_{t+1}$ são variáveis aleatórias independentes e identicamente distribuídas, com distribuição independente da cadeia (Gamerman, 1997).

Segundo Jones \& Smith (2001), um passeio aleatório irrestrito simples, em uma linha ou uma dimensão, ocorre quando um passo a frente $(+1)$ tem probabilidade $p$ e um passo atrás $(-1)$ tem probabilidade $q=1-p$. Assim, a posição da cadeia no tempo $t+1$ pode ser definida por $X^{(t+1)}=X^{(t)}+W_{t+1}$, em que $W_{t+1}$ pode ser definida como uma variável aleatória Bernoulli modificada, uma vez que pode assumir valores $\{-1,+1\}$ ao invés de $\{0,1\}$. Portanto, o valor assumido por $X^{(t+1)}$ é definido pela soma do valor de $X^{(t)}$ com o valor de $W_{t+1}$, tal que o valor assumido por $W_{t+1}$ é simulado a partir da distribuição de probabilidade definida pela Bernoulli modificada. Esse passeio aleatório pode ser generalizado para qualquer função de probabilidade de uma variável aleatória discreta, como pode ser visto no Exemplo 4.1 de Gamerman (1997).

No caso de espaço de estados contínuos, $W_{t+1}$ são variáveis aleatórias contínuas independentes e identicamente distribuídas, com função densidade de probabilidade dada por $f_{W}(w)$. Assim, simula-se um valor para $W_{t+1}$ e o estado da cadeia em $(t+1)$, ou valor que $X^{(t+1)}$ assume, é dado por $x^{(t+1)}=x^{(t)}+w_{t+1}$. Nesse caso, o kernel de transição é dado por $p(a, b)=f_{W}(b-a)$, conforme é demonstrado a seguir. Considerando a definição das probabilidades de transição, dada em (28) e 
que $X^{(t+1)}=X^{(t)}+W_{t+1}$ tem-se

$$
\begin{aligned}
P(a, b) & =P\left(X^{(t+1)} \leq b \mid X^{(t)}=a\right) \\
& =P\left(X^{(t)}+W_{t+1} \leq b \mid X^{(t)}=a\right) \\
& =P\left(W_{t+1} \leq b-a\right) \\
& =\int_{-\infty}^{b-a} f_{W}(w) \mathrm{d} w \\
& =F(b-a) .
\end{aligned}
$$

Assim, de acordo com a definição apresentada em (29), tem-se

$$
p(a, b)=\frac{\partial P(a, b)}{\partial b}=f_{W}(b-a) .
$$

\subsubsection{Algoritmo de Metropolis-Hastings}

O algoritmo de Metropolis-Hastings é um método de simulação baseado em cadeias de Markov e foi descrito pela primeira vez por Hastings (1970) como uma generalização do algoritmo de Metropolis, que foi desenvolvido por Metropolis et al. (1953).

Segundo Morgan (2000), dada uma variável aleatória $X$, com distribuição $\pi(x)$, no algoritmo de Metropolis-Hastings constrói-se uma série de variáveis aleatórias $X^{(t)}$ as quais assumem valores $x^{(t)}$ de tal maneira que, quando $t \rightarrow \infty$, a distribuição de $X^{(t)}$ tende a $\pi(x)$, ou seja, $\pi(x)$ é a distribuição estacionária. As possíveis alterações em $X^{(t)}$ são determinadas pela função de transição $q(a, b)$, que pode ser interpretada como: quando se está no ponto $a$, um novo ponto $b$ é gerado ou simulado a partir de $q(a, b)$, que representa a densidade $p(a, b)$ no caso de variáveis aleatórias contínuas ou $P(a, b)$ para o caso discreto. Assim, se $X^{(t)}=a$, então o valor $b$, gerado com probabilidade $q(a, b)$, é um valor candidato para $X^{(t+1)}$ e será aceito com probabilidade $\delta(a, b)$. A forma padrão para esta função $\delta(a, b)$, como pode ser visto em Chib \& Greenberg (1995), Gamerman (1997), Gelman et al. (1995) e 
Morgan (2000), é dada por:

$$
\delta(a, b)= \begin{cases}\min \left\{\frac{\pi(b) q(b, a)}{\pi(a) q(a, b)}, 1\right\}, & \text { se } \pi(a) q(a, b)>0 \\ 1, & \text { se } \pi(a) q(a, b)=0 .\end{cases}
$$

Pode-se notar que a distribuição de interesse, $\pi(x)$, é levada em consideração no processo de simulação apenas através da razão $\pi(b) / \pi(a)$, em que $x, a, b \in S$. Assim, o fato de se conhecer $\pi(x)$, desconsiderando-se uma constante de proporcionalidade, é suficiente para que o processo de simulação seja implementado, pois na razão $\pi(b) / \pi(a)$, esta constante de proporcionalidade seria cancelada.

Smith \& Roberts (1993) e Mengersen \& Tweedie (1996) demonstram que, para $q(a, b)$ qualquer, a cadeia obtida é irredutível e aperiódica, as quais são condições suficientes para que $\pi(\cdot)$ seja a distribuição de equilíbrio da cadeia. Porém, essas condições não determinam a grau de convergência de uma cadeia particular gerada.

Leandro (2001) diz que é necessário examinar a cadeia ou cadeias geradas e verificar certas características, que indicam se houve a convergência. Podem-se utilizar testes de diagnósticos, analisar visualmente se o traço (gráfico dos valores gerados) da cadeia gerada se mantém dentro de uma amplitude de valores plausíveis e quantificar a porcentagem de aceitação da cadeia, que representa a porcentagem de vezes que um valor candidato é aceito (Borgatto, 2003). Uma recomendação prática é de que a aceitação deve estar entre 30\% e 40\%. O pacote CODA do R apresenta diferentes testes de convergência da cadeia.

Na utilização do algoritmo de Metropolis-Hastings, assim como de outros métodos MCMC, recomenda-se descartar a parte inicial da cadeia, chamada de burn-in, que representa um período de aquecimento da cadeia e utilizar o restante da cadeia para os testes de diagnósticos e para inferir sobre a distribuição de interesse. A justificativa para o burn-in se baseia nos fatos de que à medida que o número de iterações aumenta, a cadeia "esquece" os valores iniciais e converge para a distribuição de equilíbrio. Assim, tem-se a garantia de que a amostra obtida seja da distribuição de interesse. 


\subsection{Estimação dos parâmetros nos modelos estocásticos espaço-temporais utilizando métodos MCMC}

Gibson (1997b) propôs uma maneira de se estimar o parâmetro $\alpha$ dos modelos (24) e (25), utilizando métodos MCMC e mostrou que foi consideravelmente melhor do que o método utilizado por Gibson \& Austin (1996). Gibson (1997a) também utilizou a mesma técnica, considerando métodos MCMC, porém ajustou o modelo com dois parâmetros, apresentado em (26). A extensão da técnica para a estimação dos dois parâmetros é direta, basta repetir para um parâmetro, o que foi feito para o outro. Assim, $\alpha_{1}$ e $\alpha_{2}$ são estimados independentemente, que é uma característica destes dois parâmetros. A seguir será descrita a técnica proposta por Gibson (1997b), considerando apenas um único parâmetro $\alpha$.

Considere que $S_{0}$ e $S_{1} \subset L$ são dois conjuntos de plantas doentes observados nos tempos $t_{0}$ e $t_{1}$ respectivamente, em que $L$ corresponde ao conjunto de todas as plantas do látice, $t_{1}>t_{0}$ e $S_{0} \subseteq S_{1}$, para que o modelo seja coerente. Assim, o conjunto das novas infecções, ou seja, aquelas que ocorreram entre os tempos $t_{0}$ e $t_{1}$, pode ser representado pela diferença entre os conjuntos $S_{1}$ e $S_{0}$ ou $S_{1}-S_{0}=S_{1} \backslash S_{0}$ e o conjunto das plantas sadias no tempo $t_{1}$ pode ser definido como $L \backslash S_{1}$. Para reforçar as definições dos conjuntos $S_{0}, S_{1}, S_{1} \backslash S_{0}, L \backslash S_{1}$ e apresentar a definição de $\omega$, a ordem na qual as infecções ocorrem, considere uma situação na qual um talhão $5 \times 5$ é avaliado em dois tempos, $t_{0}$ e $t_{1}$, de tal forma que no primeiro tempo tem-se apenas a planta central doente e no segundo, três novas plantas se tornaram doentes na seguinte ordem: $1^{\underline{O}}$. planta $(3,2), 2^{\underline{O}}$. planta $(2,2)$ e $3^{\underline{O}}$. planta $(3,4)$. Essa situação pode ser representada da maneira que se segue: 
Talhão no tempo $t_{0}$

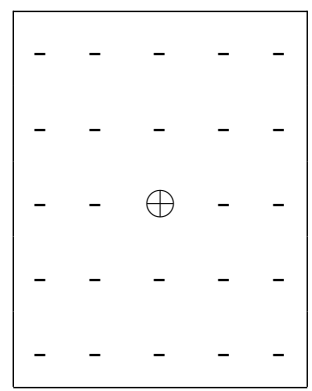

Talhão no tempo $t_{1}$

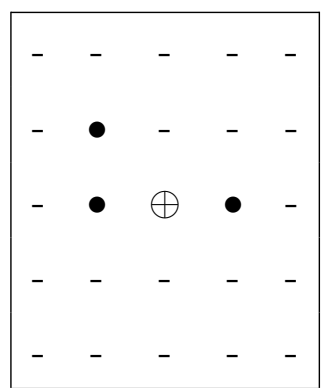

em que $\oplus$ representa a planta doente inicialmente, - são as plantas sadias e $\bullet$ são as novas infecções, que ocorreram entre $t_{0}$ e $t_{1}$.

Para facilitar a notação, considere que cada planta e sua coordenada seja identificada por $x_{i}$, tal que $i=1,2, \ldots, 25$, ou seja,

\begin{tabular}{lllll}
$(1,1)$ & $(1,2)$ & $(1,3)$ & $(1,4)$ & $(1,5)$ \\
$(2,1)$ & $(2,2)$ & $(2,3)$ & $(2,4)$ & $(2,5)$ \\
$(3,1)$ & $(3,2)$ & $(3,3)$ & $(3,4)$ & $(3,5)$ \\
$(4,1)$ & $(4,2)$ & $(4,3)$ & $(4,4)$ & $(4,5)$ \\
$(5,1)$ & $(5,2)$ & $(5,3)$ & $(5,4)$ & $(5,5)$ \\
\hline
\end{tabular}

$\equiv \quad \begin{array}{ccccc}x_{1} & x_{2} & x_{3} & x_{4} & x_{5} \\ x_{6} & x_{7} & x_{8} & x_{9} & x_{10} \\ x_{11} & x_{12} & x_{13} & x_{14} & x_{15} \\ x_{16} & x_{17} & x_{18} & x_{19} & x_{20} \\ x_{21} & x_{22} & x_{23} & x_{24} & x_{25}\end{array}$.

Assim podem-se definir os conjuntos:

$$
\begin{aligned}
S_{0}= & \left\{x_{13}\right\} \\
S_{1}= & \left\{x_{7}, x_{12}, x_{13}, x_{14}\right\} \\
S_{1} \backslash S_{0}= & \left\{x_{7}, x_{12}, x_{14}\right\} \\
L \backslash S_{1}= & \left\{x_{1}, x_{2}, x_{3}, x_{4}, x_{5}, x_{6}, x_{8}, x_{9}, x_{10}, x_{11}, x_{15},\right. \\
& \left.x_{16}, x_{17}, x_{18}, x_{19}, x_{20}, x_{21}, x_{22}, x_{23}, x_{24}, x_{25}\right\}
\end{aligned}
$$

A ordem de ocorrência das novas infecções, $\omega$, nada mais é do que uma seqüência de números que identificam as plantas que foram infectadas entre os tempos $t_{0}$ e $t_{1}$ e, pode ser representada na forma de conjunto, porém, obedecendo a ordem de ocorrência das infecções. Neste exemplo, tem-se que $\omega=\{12,7,14\}$, de tal forma que $\omega_{(1)}=12$, indicando que $x_{12}$ foi a primeira das três plantas que se 
tornou doente, $\omega_{(2)}=7$ indica que a segunda foi a planta $x_{7}$ e a terceira foi $x_{14}$, pois $\omega_{(3)}=14$.

Considere a situação ideal, semelhante à anterior, na qual o látice é avaliado no tempo $t_{0}$, tendo-se que o conjunto de plantas doentes é $S_{0}$ e, então, continuamente e intensivamente avaliado até o tempo $t_{1}$, quando se tem o conjunto $S_{1}$ de plantas doentes. Nessa situação, sabe-se quais são as $N$ novas infecções ocorridas no intervalo entre $t_{0}$ e $t_{1}$, as suas coordenadas e a ordem precisa de ocorrência dessas novas infecções, $\omega$. De acordo com Gibson (1997a), nesse caso uma verossimilhança $G(\alpha)=P(\alpha \mid \omega)$ poderia ser calculada e utilizada para se comparar o ajuste do modelo proposto aos dados, considerando diferentes valores de $\alpha$. O valor de $\alpha$ que apresentasse $G(\alpha)$ máximo seria a estimativa de máxima verossimilhança. Sendo $t_{\alpha}(x)$ uma variável aleatória que representa o tempo em que $x$ se torna infectada, Gibson \& Austin (1996) e Gibson (1997b) definem G( $\alpha$ ) como

$$
\begin{aligned}
G(\alpha) & =P\left[t_{\alpha}(x)<t_{\alpha}(z) \text { para todo } x \in S_{1} \backslash S_{0}, z \in L \backslash S_{1}\right] \\
& =P\left[t_{\alpha}\left(x_{\omega(1)}\right)<t_{\alpha}\left(x_{\omega(2)}\right)<\ldots<t_{\alpha}\left(x_{\omega(N)}\right)<\min \left\{t_{\alpha}(z) \mid z \in L \backslash S_{1}\right\}\right] .
\end{aligned}
$$

Porém essa situação ideal é praticamente impossível de acontecer, pois a avaliação de campos experimentais e pomares comerciais é feita em determinados intervalos de tempo, de tal forma que se têm as avaliações nos tempos $t_{0}$ e $t_{1}$, mas sem observar o que acontece entre essas duas épocas. Assim, tem-se uma observação ou evento, que pode ser definida por $\mathcal{E}$, que consiste do conjunto das plantas doentes inicialmente ou no tempo $t_{0}, S_{0}$, das localizações das novas infecções ocorridas entre $t_{0}$ e $t_{1}$ e, conseqüentemente, $S_{1}$, mas não se sabe a ordem, $\omega$, em que essas novas infecções ocorreram.

A estratégia de Gibson (1997b), diante dessa situação, foi considerar a verossimilhança de que todas as plantas do conjunto $S_{1} \backslash S_{0}=\left\{x_{1}, x_{2}, \ldots, x_{N}\right\}$, se tornem infectadas antes de qualquer outra planta sadia da população no tempo $t_{1}$, ou seja, do conjunto $L \backslash S_{1}$ e utilizá-la para fazer inferências sobre os parâmetros do 
modelo. Assim, considera-se a verossimilhança

$$
\begin{aligned}
G(\alpha) & =P\left[t_{\alpha}(x)<t_{\alpha}(z) \text { para todo } x \in S_{1} \backslash S_{0}, z \in L \backslash S_{1}\right] \\
& =\sum_{\omega \in \Omega} P\left[t_{\alpha}\left(x_{\omega(1)}\right)<t_{\alpha}\left(x_{\omega(2)}\right)<\ldots<t_{\alpha}\left(x_{\omega(N)}\right)<\min \left\{t_{\alpha}(z) \mid z \in L \backslash S_{1}\right\}\right] \\
& =\sum_{\omega \in \Omega} P_{\omega}(\alpha) .
\end{aligned}
$$

em que, $\Omega$ é o conjunto de todos os possíveis $\omega^{\prime}$ s, isto é, o somatório em relação a $\omega \in \Omega$ abrange todas as $N$ ! possíveis maneiras diferentes de se representar a ordem de ocorrência das $N$ novas infecções. No Apêndice 1, demonstra-se como calcular $P_{\omega}(\alpha)$, para o caso particular de uma ordem de infecção $\omega$.

Gibson \& Austin (1996) e Gibson (1997b) afirmam que a utilização de $G(\alpha)$, como apresentada em (31), representa uma simplificação, pois algumas informações dos dados são ignoradas, uma vez que $G(\alpha)$ representa a probabilidade de que todas as plantas em $S_{1} \backslash S_{0}$ se tornem infectadas antes de qualquer outra planta em $L \backslash S_{1}$, sem considerar os tempos precisos de ocorrência das infecções. Porém, com esta definição de $G(\alpha)$, tem-se o benefício de que o termo referente aos fatores secundários, $k(t)$, que aparece nas equações $(24)$, (25) e (26), pode ser considerado igual a um, sem perda de generalidade, o que simplifica consideravelmente as análises.

A determinação da verossimilhança $G(\alpha)$ exige a soma de $P_{\omega}(\alpha)$ em relação a todas as possíveis ordens $\omega$, o que é praticamente impossível, a não ser que o número de novas infecções, $N$, seja pequeno (aproximadamente, menor do que 12). Contudo, de acordo com Gibson (1997b), é possível estimarem-se os valores relativos de $G(\alpha)$, utilizando métodos MCMC o que permite a estimação dos parâmetros do modelo.

Na descrição a seguir, apresentada por Gibson (1997b), $\omega$ representa a ordem ou permutação de $1,2, \ldots, N$ e o evento correspondente

$$
t_{\alpha}\left(x_{\omega(1)}\right)<t_{\alpha}\left(x_{\omega(2)}\right)<\ldots<t_{\alpha}\left(x_{\omega(N)}\right)<t_{\alpha}(z) \text { para todo } z \in L \mid S_{1} .
$$

Gibson (1997a, 1997b) assumiu um número finito de valores discretos para $\alpha$, definidos por $\alpha_{j}, 1 \leq j \leq a$, os quais são equiprováveis a priori. Um exemplo 
deste conjunto finito de $\alpha$ 's seria subdividir o intervalo $0 \leq \alpha \leq 2,0$ em 6 valores discretos com passo 0,4. Assim, tem-se o conjunto de $a=6$ valores, em que $\alpha_{1}=0,0$, $\alpha_{2}=0,4, \alpha_{3}=0,8, \alpha_{4}=1,2, \alpha_{5}=1,6$ e $\alpha_{6}=2,0$.

Dado $\mathcal{E}$ como sendo o evento $t_{\alpha}(x)<t_{\alpha}(z)$ para todo $x \in S_{1} \backslash S_{0}, z \in$ $L \backslash S_{1}$, a distribuição marginal a posteriori de $\alpha$,

$$
\pi(\alpha \mid \mathcal{E})=\sum_{\omega \in \Omega} \pi(\alpha, \omega \mid \mathcal{E})
$$

é proporcional à verossimilhança $G(\alpha)$ e fornece seus valores relativos sobre o espaço paramétrico. Para se estudar $\pi(\alpha \mid \mathcal{E})$, Gibson (1997a e 1997b) considerou a densidade conjunta a posteriori $\pi(\alpha, \omega \mid \mathcal{E})$. Esta densidade é proporcional à quantidade $P_{\omega}(\alpha)$, cujo cálculo está descrito no Apêndice 1 e é bastante adequada ao estudo utilizando métodos MCMC.

Suponha que se tenha uma sequência de pares de parâmetro e permutação $\left\{\left(\alpha_{i}, \omega_{i}\right) ; 1 \leq i \leq m\right\}$ obtida a partir de uma cadeia de Markov cuja distribuição estacionária seja $\pi(\alpha, \omega \mid \mathcal{E})$, a densidade conjunta a posteriori de parâmetros e permutações. Uma estimativa da densidade a posteriori do parâmetro $\alpha$ pode então, ser calculada a partir de

$$
\hat{\pi}(\alpha \mid \mathcal{E})=\frac{1}{m} \sum_{i=1}^{m} \pi\left(\alpha \mid \omega_{i}, \mathcal{E}\right)
$$

Nesse cálculo, tira-se proveito do fato de que a densidade condicional $\pi(\alpha \mid \omega, \mathcal{E})$ pode ser facilmente calculada a partir de

$$
\pi\left(\alpha_{j} \mid \omega, \mathcal{E}\right)=\frac{P_{\omega}\left(\alpha_{j}\right)}{\sum_{k=1}^{a} P_{\omega}\left(\alpha_{k}\right)}
$$

isto é, calcula-se $P_{\omega}\left(\alpha_{j}\right)$, conforme apresentado no Apêndice 1, para cada um dos valores discretos assumidos para $\alpha, \alpha_{j}$, com $j=1,2, \ldots, a$ e dividindo cada um deles por $\sum_{k=1}^{a} P_{\omega}\left(\alpha_{k}\right)$, tem-se a distribuição de probabilidade

\begin{tabular}{c|cccc|c}
$\alpha_{j}$ & $\alpha_{1}$ & $\alpha_{2}$ & $\cdots$ & $\alpha_{a}$ & \\
\hline$\pi\left(\alpha_{j} \mid \omega, \mathcal{E}\right)$ & $\pi\left(\alpha_{1} \mid \omega, \mathcal{E}\right)$ & $\pi\left(\alpha_{2} \mid \omega, \mathcal{E}\right)$ & $\cdots$ & $\pi\left(\alpha_{a} \mid \omega, \mathcal{E}\right)$ & 1,0
\end{tabular}


Na cadeia de Markov utilizada para se estudar $\pi(\alpha, \omega \mid \mathcal{E})$, cada novo par $\left(\alpha_{i+1}, \omega_{i+1}\right)$ é obtido a partir do par $\left(\alpha_{i}, \omega_{i}\right)$. Primeiro, obtém-se um valor aleatório $\alpha_{i+1}$ a partir da distribuição $\pi\left(\alpha_{j} \mid \omega_{i}, \mathcal{E}\right)$, a qual foi definida em (33). Para isso, gera-se um valor $u$, a partir de uma distribuição $U(0,1)$, determina-se a função de distribuição acumulada, $F\left(\alpha_{k}\right)=\sum_{j=1}^{k} \pi\left(\alpha_{j} \mid \omega, \mathcal{E}\right)$ e, a partir de $j=1$ até $j=a$, o primeiro valor de $\alpha_{j}$, tal que $F\left(\alpha_{j}\right)>u$, corresponde ao valor de $\alpha_{j}$ simulado a partir da distribuição definida em (33).

A nova permutação $\omega_{i+1}$ é gerada, aplicando-se o processo de mutação, que será apresentado a seguir. Este processo é aplicado à permutação $\omega_{i}$, considerando os pares adjacentes $\left(\omega_{i(j)}, \omega_{i(j+1)}\right)$, que serão revertidos ou não, dependendo do efeito desta reversão sobre $P_{\omega}\left(\alpha_{i+1}\right)$. Especificamente, a geração de uma nova permutação a partir de $\omega_{i}$, com algumas mutações ou troca de pares, consiste dos seguintes passos:

(a) Simular um valor $k \in\{0,1\}$ com probabilidades iguais. As possíveis reversões serão aplicadas primeiro aos pares $\left\{\left(\omega_{(1)}, \omega_{(2)}\right),\left(\omega_{(3)}, \omega_{(4)}\right), \ldots\right\}$, se $k=0$ ou aos pares $\left\{\left(\omega_{(2)}, \omega_{(3)}\right),\left(\omega_{(4)}, \omega_{(5)}\right), \ldots\right\}$, se $k=1$;

(b) Considere $J$ como sendo o maior inteiro tal que $2 J+k<N-1$. $J$ nada mais é do que o número total de pares. Então, para cada $j, 0 \leq j \leq J$, considere os dois conjuntos de plantas doentes $S_{0}^{j} \subset S_{1}^{j}$, em que

$$
S_{0}^{j}=S_{0} \cup\left\{x_{\omega(1)}, \ldots, x_{\omega(2 j+k)}\right\} \text { e } S_{1}^{j}=S_{0}^{j} \cup\left\{x_{\omega(2 j+k+1)}, x_{\omega(2 j+k+2)}\right\} .
$$

Para um dado subevento $\mathcal{E}_{j}$, a transição de $S_{0}^{j}$ para $S_{1}^{j}$, seleciona aleatoriamente uma de duas possíveis ordens de infecções, $\omega^{j}=(\omega(2 j+k+1), \omega(2 j+k+2))$ e $\omega_{r}^{j}=(\omega(2 j+k+2), \omega(2 j+k+1))$, escolhendo $\omega_{r}^{j}$ com probabilidade

$$
p=\frac{P_{\omega_{r}^{j}}(\alpha)}{P_{\omega^{j}}(\alpha)+P_{\omega_{r}^{j}}(\alpha)} .
$$

Se $\omega_{r}^{j}$ é selecionado, então foi efetuada uma mutação em $\omega$ através da reversão das ordens de $\omega(2 j+k+1)$ e $\omega(2 j+k+2)$. A aplicação deste procedimento 
para cada valor de $j, 0 \leq j \leq J$, produz uma permutação intermediária $\omega_{I}$, obtida a partir de $\omega$, com a reversão da ordem de alguns pares de infecções temporariamente adjacentes;

(c) Aplicar o procedimento descrito em (b) para a permutação intermediária, substituindo $k$ por $k^{\prime}=1-k$.

Os passos (a)-(c) são repetidos $K$ vezes, partindo-se de $\omega_{i}$, para que $\omega_{i+1}$ seja obtida. Gibson (1997b) demonstra que a cadeia de Markov definida tem $\pi(\alpha, \omega \mid \mathcal{E})$ como distribuição estacionária e afirma que esse esquema utilizado na obtenção da cadeia pode ser modificado para melhorar sua eficiência. De acordo com o autor, a regra de aceitação de Barker, apresentada na equação (34), poderia ser substituída por uma regra mais usual, como Metropolis. Além disso, esta nova regra de aceitação também poderia ser utilizada na atualização do parâmetro $\alpha$, evitando a utilização de valores discretos para esse parâmetro e a necessidade de se calcularem as probabilidades definidas na equação (33), toda vez que $\alpha$ é atualizado. 


\section{MATERIAL E MÉTODOS}

\subsection{Material}

Neste estudo são utilizados quatro conjuntos de dados, referentes à avaliação da incidência de doenças em plantas, em que o interesse está na caracterização dos padrões espaciais. Dois deles, cancro cítrico e morte súbita dos citros, foram a motivação inicial, por se tratarem de duas das mais importantes doenças dos citros, no Brasil. Os outros dois, tristeza dos citros e viroses do lúpulo, previamente analisados em diferentes artigos, são utilizados para verificar se os programas implementados estão corretos, através da reprodução dos resultados obtidos anteriormente. Além disso, foram simulados dois conjuntos de dados para entendimento dos modelos utilizados.

\subsubsection{Dados simulados}

No ajuste de modelos estocásticos espaço-temporais, em que o interesse principal está na estimação de parâmetros que descrevem o padrão espacial de uma doença, a simulação pode ser utilizada para verificar a acurácia das estimativas obtidas. Na obtenção de dados simulados, os valores dos parâmetros são fixados e, portanto, conhecidos. Assim, pode-se utilizar uma metodologia para a estimação dos parâmetros a partir dos dados simulados e comparar as estimativas obtidas com os valores conhecidos dos parâmetros.

Na simulação de doenças em plantas, as quais são classificadas como doentes ou sadias e são representadas na forma de um látice $l$ xc, em que $l$ é o número 
de linhas e $c$ é o número de colunas ou de plantas/linha, parte-se de uma infecção inicial, calculam-se as probabilidades de cada planta sadia tornar-se doente e simulase uma nova infeç̧ão. A partir do momento em que mais uma infecção ocorreu, isto é, tem-se mais uma planta doente, todas as probabilidades devem ser atualizadas, pois estas probabilidades são calculadas com base na pressão infectiva exercida pelas plantas doentes sobre as sadias. Essa pressão infectiva é definida através de modelos matemáticos, como por exemplo as funções apresentadas em (21), (22) e (23). Assim, cada nova infecção é simulada com base em uma distribuição de probabilidades que as plantas sadias têm de serem infectadas. Esse procedimento nada mais é do que a simulação estocástica através do método de Monte Carlo, que, tipicamente envolve a simulação de observações a partir de uma distribuição de probabilidades.

A infecção inicial pode ser uma única planta ou um grupo de plantas doentes. A localização dessa infecção inicial (da planta ou das plantas que estão doentes inicialmente) pode ser definida e fixada pelo pesquisador ou pode ser determinada aleatoriamente no látice.

Para facilitar o entendimento e explicar o procedimento utilizado nas simulações, será utilizado um pequeno exemplo. Seja um látice 5x5, tal que a infecção inicial seja a planta central, na coordenada $(3,3)$ e que a função que descreve a pressão infectiva seja a mesma que está apresentada na eq. (23), ou seja,

$$
F_{\boldsymbol{\alpha}}(y-x)=\alpha_{1}+|y-x|^{-2 \alpha_{2}} .
$$

Os parâmetros utilizados na simulação são: $\alpha_{1}=1,0$ e $\alpha_{2}=1,0$, para facilitar os cálculos. A extensão do procedimento de simulação para o caso de outros modelos, que expressam a pressão infectiva, é direta. O procedimento de simulação consiste nos seguintes passos:

(i) calcula-se um peso ou taxa para cada uma das plantas sadias, $r_{\boldsymbol{\alpha}}(x)$, com base na função que descreve a pressão infectiva, isto é, $r_{\boldsymbol{\alpha}}(x)=\alpha_{1}+\sum_{y \in D(t)}|y-x|^{-2 \alpha_{2}}$, em que $x$ representa uma planta sadia, $y$ representa uma planta doente e $D(t)$ é o conjunto de todas as plantas doentes num determinado tempo $t$. Assumindo 
que neste tempo $t$, tem-se apenas a planta na coordenada $(3,3)$ doente, o valor de $r_{\boldsymbol{\alpha}}(x)$ para a primeira planta, cuja coordenada é $(1,1)$, será

$$
r_{\boldsymbol{\alpha}}\left(x_{(1)}\right)=1,0+\left[\sqrt{(1-3)^{2}+(1-3)^{2}}\right]^{-2 \cdot 1,0}=1,125 .
$$

Para a segunda planta, de coordenadas $(1,2)$ tem-se

$$
r_{\boldsymbol{\alpha}}\left(x_{(2)}\right)=1,0+\left[\sqrt{(1-3)^{2}+(1-2)^{2}}\right]^{-2 \cdot 1,0}=1,200
$$

e assim por diante, até a última planta. Vale lembrar que a planta $x_{(13)}$, na coordenada $(3,3)$, recebe $r_{\boldsymbol{\alpha}}\left(x_{(13)}\right)=0$, pois esta já está doente. Os valores de $r_{\boldsymbol{\alpha}}(x)$, para todas as 25 plantas do látice podem ser representados em uma matriz, ou seja,

$$
\left[\begin{array}{ccccc}
1,125 & 1,200 & 1,250 & 1,200 & 1,125 \\
1,200 & 1,500 & 2,000 & 1,500 & 1,200 \\
1,250 & 2,000 & 0 & 2,000 & 1,250 \\
1,200 & 1,500 & 2,000 & 1,500 & 1,200 \\
1,125 & 1,200 & 1,250 & 1,200 & 1,125
\end{array}\right] .
$$

(ii) A partir dos valores de $r_{\boldsymbol{\alpha}}(x)$, as probabilidades de as plantas sadias serem infectadas, $P\left(x_{(i)}\right)$, para $i=1,2, \ldots, 25$, podem ser facilmente calculadas, bastando dividir cada um dos $r_{\boldsymbol{\alpha}}(x)$ pela soma de todos, $\sum_{i=1}^{25} r_{\boldsymbol{\alpha}}\left(x_{(i)}\right)=33,100$. Assim, uma matriz com as probabilidades das plantas serem infectadas é dada por:

$$
\left[\begin{array}{ccccc}
0,034 & 0,036 & 0,038 & 0,036 & 0,034 \\
0,036 & 0,046 & 0,060 & 0,046 & 0,036 \\
0,038 & 0,060 & 0 & 0,060 & 0,038 \\
0,036 & 0,046 & 0,060 & 0,046 & 0,036 \\
0,034 & 0,036 & 0,038 & 0,036 & 0,034
\end{array}\right] .
$$

(iii) Para simular uma nova infecção, basta gerar um valor $u$, a partir de uma distribuição $U(0,1)$, determinar a função de distribuição acumulada, dada por 
$F\left(x_{(k)}\right)=\sum_{j=1}^{k} P\left(x_{(k)}\right)$ e, a partir de $i=1$ até 25 , a primeira planta $x_{(i)}$, tal que $F\left(x_{(i)}\right)>u$, corresponde à planta que se tornará infectada. Assim, sendo $u=0,3079$ e a matriz com os valores de $F\left(x_{(k)}\right)$ dada por

$$
\left[\begin{array}{cccccc}
0,034 & 0,070 & 0,108 & 0,144 & 0,178 \\
0,214 & 0,260 & \mathbf{0 , 3 2 0} & 0,366 & 0,402 \\
0,440 & 0,500 & 0,500 & 0,560 & 0,598 \\
0,634 & 0,680 & 0,740 & 0,786 & 0,822 \\
0,856 & 0,892 & 0,930 & 0,966 & 1,000
\end{array}\right],
$$

a planta 8 ou da coordenada $(2,3)$ será a nova planta infectada.

Para se determinar uma nova infecção, repetir os passos (i)-(iii), porém, considerando as duas plantas, $x_{(8)}$ e $x_{(13)}$, que já estão doentes e, portanto $P\left(x_{(8)}\right)=$ $P\left(x_{(13)}\right)=0$. Neste caso, a matriz com as probabilidades será

$$
\left[\begin{array}{ccccc}
0,038 & 0,044 & 0,053 & 0,044 & 0,038 \\
0,040 & 0,056 & 0 & 0,056 & 0,040 \\
0,040 & 0,056 & 0 & 0,056 & 0,040 \\
0,038 & 0,044 & 0,053 & 0,044 & 0,038 \\
0,035 & 0,037 & 0,038 & 0,037 & 0,035
\end{array}\right] .
$$

Supondo $u=0,5214$, a nova infecção seria a planta localizada na coordenada $(3,4)$. Assim, o látice 5x5 com uma planta inicialmente infectada e duas novas infecções simuladas seria

$$
\begin{array}{lllll}
- & - & - & - & - \\
- & - & \bullet & - & - \\
- & - & \oplus & \bullet & - \\
- & - & - & - & - \\
- & - & - & - & - \\
\hline
\end{array}
$$

em que $\oplus$ representa a planta doente inicialmente, -, as plantas sadias e $\bullet$, as novas infecções. 
Todo o procedimento de simulação apresentado foi implementado em Fortran 90, para cada um dos modelos apresentados nas eq. (24), (25) e (26).

\subsubsection{Conjunto 1. simulado a partir de um modelo com um parâmetro}

O primeiro conjunto de dados simulados consiste de quatro látices 11x11 (121 plantas), isto é, com 11 linhas e 11 plantas/linha, que diferem entre si pelo parâmetro utilizado na simulação. Em cada um desses látices, o espaçamento considerado foi igual a 1, tanto entre linhas, como entre plantas dentro da mesma linha, a planta central, localizada na coordenada $(6,6)$, foi considerada como infecção inicial e foram simuladas mais nove infecções. O modelo utilizado nesta simulação está apresentado na eq. (25), contém um único parâmetro e a pressão infectiva exercida pelas plantas infectadas sobre as sadias, é inversamente proporcional a uma potência da distância. Os valores utilizados para o parâmetro $\alpha$, nas quatro simulações foram: 0,$5 ; 1,0 ; 2,0$ e 3,0. Estes valores estão associados a diferentes padrões espaciais, de tal maneira que, à medida que $\alpha$ aumenta, tem-se um padrão espacial mais agregado.

A utilização de látices com pequenas dimensões e com poucas plantas infectadas, nesse primeiro conjunto de dados simulados, se justifica pelo interesse em se calcular $G(\alpha)$ exata, conforme definida na eq. (31). $G(\alpha)$, que é proporcional a $\pi(\alpha \mid \mathcal{E})$, será comparada com as verossimilhanças aproximadas, $\hat{\pi}(\alpha \mid \mathcal{E})$, utilizando-se a metodologia original, proposta por Gibson (1997b) e a metodologia proposta neste trabalho. Como pode ser observado na definição (31), considera-se o $\sum_{\omega \in \Omega} P_{\omega}(\alpha)$ no cálculo de $G(\alpha)$, em que se têm $N$ ! termos no somatório. Portanto, a utilização de um exemplo com um número maior de plantas doentes seria inviável, se o interesse for determinar a verossimilhança exata. Neste exemplo, em que se tem apenas nove novas infecções, para cada valor discreto assumido para o parâmetro $\alpha$, devem-se considerar $9 !=362880 \omega$ 's diferentes. 


\subsubsection{Conjunto 2. simulado a partir de modelo com dois parâmetros}

O segundo conjunto de dados simulados foi obtido a partir do modelo apresentado na eq. (26), em que se têm dois parâmetros, ou seja, tem-se o vetor de parâmetros $\boldsymbol{\alpha}^{\prime}=\left[\begin{array}{ll}\alpha_{1} & \alpha_{2}\end{array}\right]$. Este conjunto consiste de quatro látices 25x25, que é uma representação de talhões com 25 linhas de 25 plantas/linha de plantio, espaçadas de uma unidade. Em cada simulação foi considerado, como foco de infecção inicial, a planta central, localizada na coordenada $(13,13)$ e foram simuladas 50 novas infecções ou plantas doentes. Nas simulações foram considerados diferentes valores para os parâmetros $\alpha_{1}$ e $\alpha_{2}$, buscando representar diferentes mecanismos de dispersão da doença. Os quatro látices foram simulados com os seguintes parâmetros: A. $\alpha_{1}=0$ e $\alpha_{2}=2,0$; B. $\alpha_{1}=0,1$ e $\alpha_{2}=2,0$; C. $\alpha_{1}=0,1$ e $\alpha_{2}=1,0$ e D. $\alpha_{1}=0,1$ e $\alpha_{2}=0$.

O interesse principal com a análise desse conjunto de dados simulados, também é a comparação das estimativas dos parâmetros, obtidas através da metodologia proposta por Gibson (1997b) e da metodologia proposta neste trabalho. Neste caso, é impossível se calcular a verossimilhança exata, $\pi(\boldsymbol{\alpha} \mid \mathcal{E})$, pois envolveria a soma de 50! termos, conforme pode ser visto na sua definição, na eq. (31). Porém, a comparação é válida, uma vez que se conhecem os verdadeiros parâmetros, utilizados na simulação.

Com a utilização do modelo com dois parâmetros, a verossimilhança corresponde a uma superfície que, se este modelo fosse determinístico, teria um valor máximo, localizado na coordenada $\left(\alpha_{1}, \alpha_{2}\right)$. Porém, na simulação estocástica, isso dificilmente ocorre, pois o fator do acaso está sempre presente. Assim, espera-se que o máximo da verossimilhança esteja localizado próximo à coordenada $\left(\alpha_{1}, \alpha_{2}\right)$. Se forem realizadas várias simulações, com os mesmos parâmetros, espera-se que, em média, o máximo esteja localizado na coordenada $\left(\alpha_{1}, \alpha_{2}\right)$. Este raciocínio também é válido para o caso dos modelos com um único parâmetro, porém, tem-se uma curva, representando a verossimilhança, ao invés de uma superfície. 


\subsubsection{Dados de incidência de doenças em plantas}

\subsubsection{Dados de cancro cítrico}

Os dados utilizados neste trabalho fazem parte de um conjunto de dados coletados pelo Fundecitrus - Fundo de Defesa da Citricultura, para se avaliar a incidência de cancro cítrico na região norte do Estado de São Paulo. São provenientes de 292 talhões, em que a idade das árvores varia de 1 a 20 anos, avaliados em 30 municípios diferentes no período de 1996 a 2000. O número de plantas em cada talhão varia de 192 a 8640, variando também a incidência da doença entre os diferentes talhões. Em determinados talhões ocorrem falhas, ou seja, faltam algumas plantas.

Os talhões avaliados foram de laranjas (Citrus sinensis: 'Charmut', 'Hamlin', 'Natal', 'Valência', 'Pera' e 'Westin'), limas ácidas (C. latifolia: 'Lima da Pérsia' e 'Lima Taiti') e tangerinas ( $C$. reticulata: 'Ponkan' e $C$. reticulata x C. sinensis: 'Murcote'). A incidência do cancro cítrico foi avaliada por inspeção visual de todas as árvores em cada talhão, anotando-se a localização das plantas sadias e infectadas, isto é, em qual linha e coluna estavam localizadas. Depois de confirmado o diagnóstico, as plantas doentes e 'expostas' foram eliminadas, de acordo com a legislação vigente no Estado de São Paulo.

Nesse trabalho, especificamente, são analisados apenas três talhões, que apresentam padrões espaciais bem diferentes, visualmente. Esses talhões, cujos mapas estão apresentados na Figura 10, têm as seguintes características:

\begin{tabular}{ccccccccc}
\hline & & & \multicolumn{2}{c}{ Ano de } & \multirow{2}{*}{ \% plantas } & \multicolumn{2}{c}{ Dimensões } \\
Talhão & Variedade & Espaçamento & plantio & inspeção & doentes & linhas & colunas \\
\hline C02 & Murcote & $3,0 \times 7,0 \mathrm{~m}$ & 1997 & 1998 & 17,08 & & 12 & 40 \\
K026 & Pera & $4,0 \times 7,0 \mathrm{~m}$ & 1994 & 1998 & 2,77 & 28 & 40 \\
K097 & Valência & $5,0 \times 7,0 \mathrm{~m}$ & 1992 & 1998 & 9,52 & 20 & 52 \\
\hline
\end{tabular}



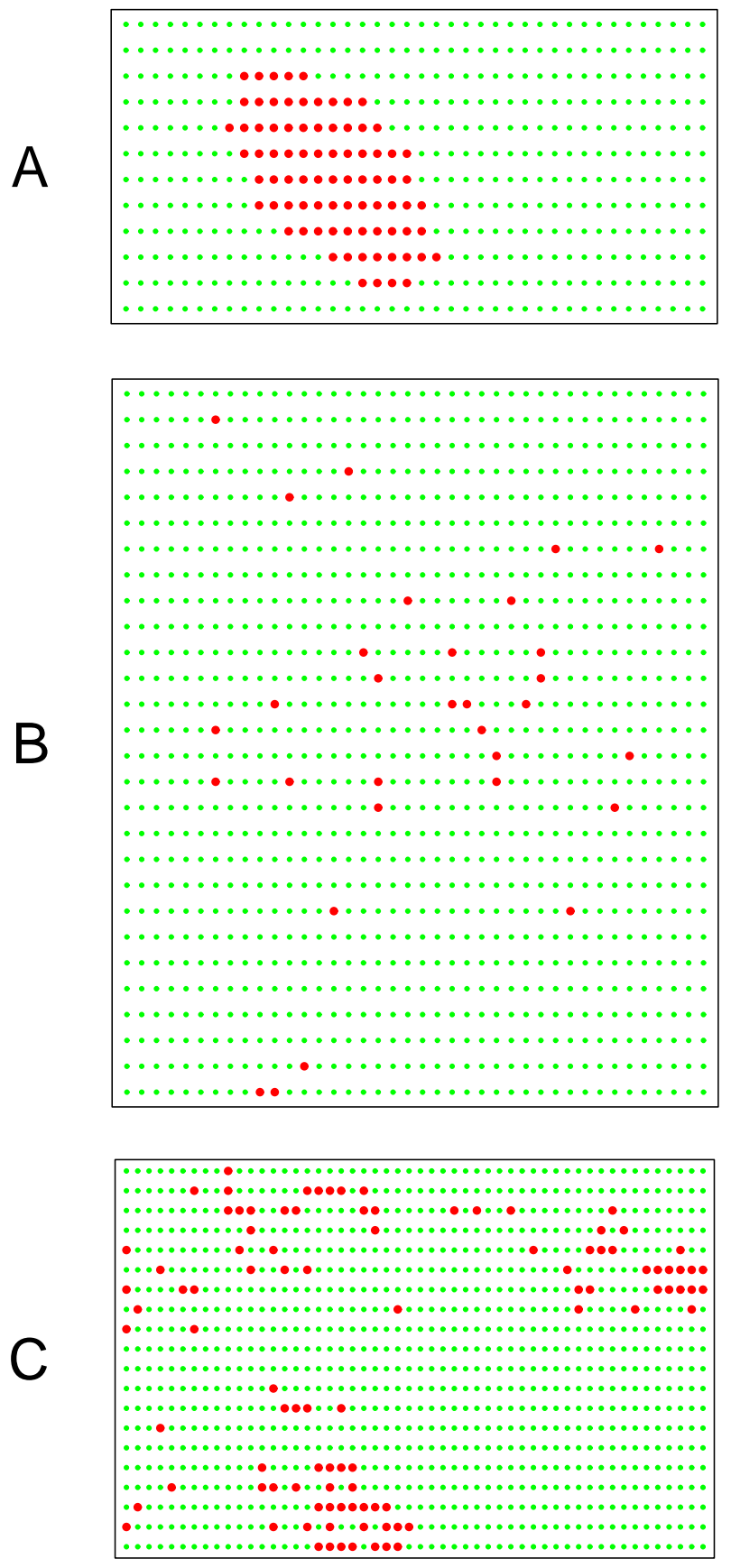

Figura 10 - Mapas representando as posições espaciais das plantas sadias e infectadas por cancro cítrico, em que • são as plantas infectadas e •, as plantas sadias. A. Talhão C02, B. Talhão K026 e C. Talhão K097 


\subsubsection{Dados de morte súbita dos citros}

Os dados da incidência de morte súbita dos citros, também fazem parte de um conjunto de dados coletados pelo Fundecitrus. Referem-se à avaliação, no período de março de 2001 a março de 2004, de 41 talhões localizados nos Estados de Minas Gerais e São Paulo. Esses talhões são os mesmos considerados nas análises feitas por Bassanezi et al. (2003) que utilizaram diferentes metodologias para se avaliarem padrões espaciais e temporais da doença. Porém, tem-se um número maior de avaliações ao longo do tempo, pois as inspeções foram realizadas em um período

maior. Os talhões foram fiscalizados em até 23 tempos diferentes e sucessivos e o número de plantas nos talhões varia de 360 a 5952, sendo que a proporção de plantas doentes é variável.

Os talhões foram de laranjas ('Hamlin', 'Natal', 'Valência', 'Pera' e 'Westin') enxertadas sobre limão 'Cravo', sendo que as plantas foram avaliadas por inspeção visual de suas copas. Quando necessária, a confirmação do diagnóstico era realizada através da observação do sintoma característico da doença, que é o aparecimento de coloração amarela na parte interna da casca do porta-enxerto. As localizações das plantas doentes e sadias foram registradas para permitir que planilhas, nas quais as plantas sadias são identificadas por 0 e as doentes por 1, pudessem ser construídas. Assim, mapas representando os talhões podem ser facilmente construídos a partir dessas planilhas.

São analisados os dados de dois talhões: 107C e 303. Estes talhões apresentam característica diferentes e foram vistoriados em 10 e 16 tempos diferentes. Mapas, representando as plantas infectadas e sadias, em três tempos escolhidos apenas para ilustrar os dados dos talhões 107C e 303, estão apresentados na Figura 11. Os detalhes sobre cada um desses mapas estão apresentados na Tabela 2. 

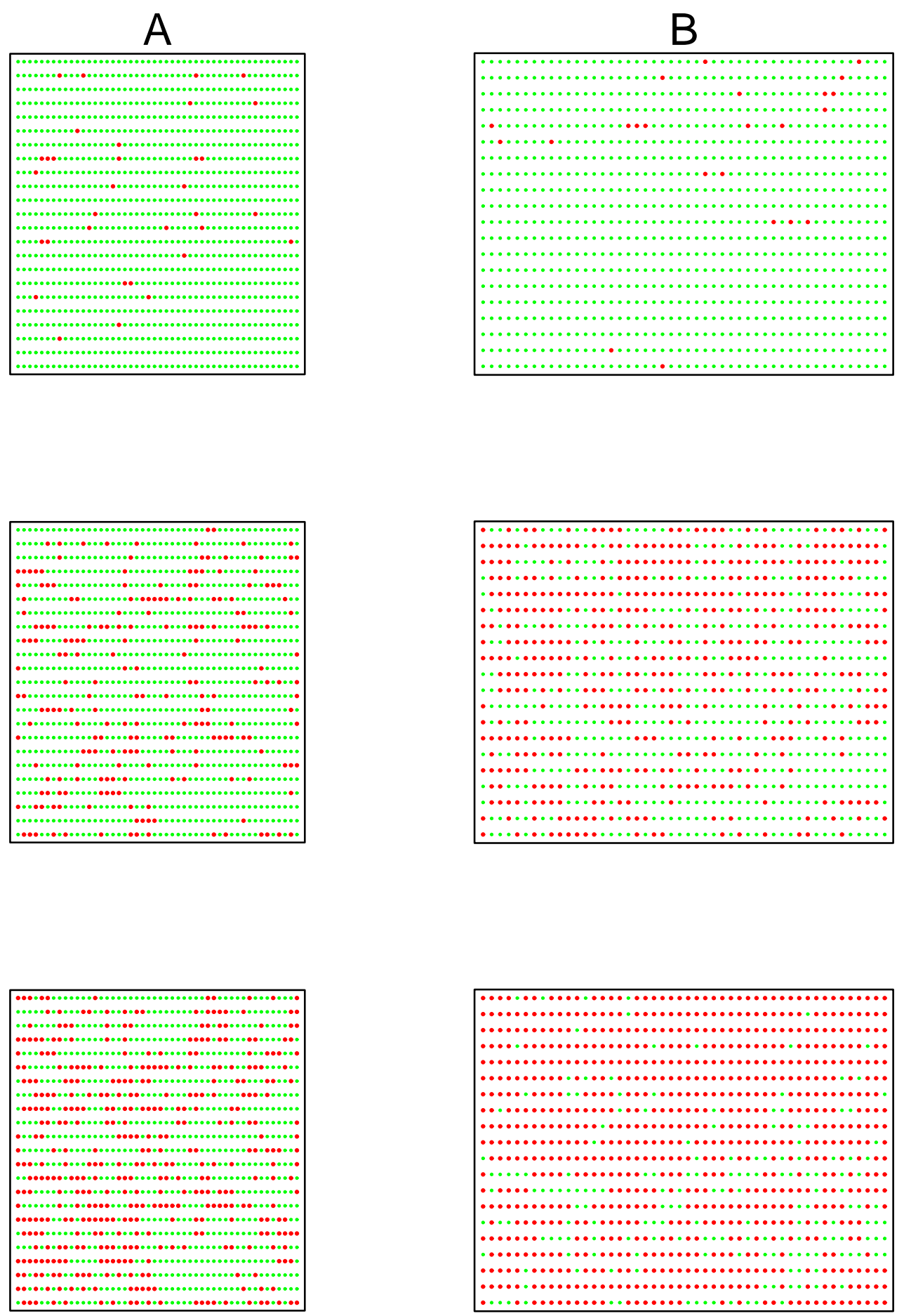

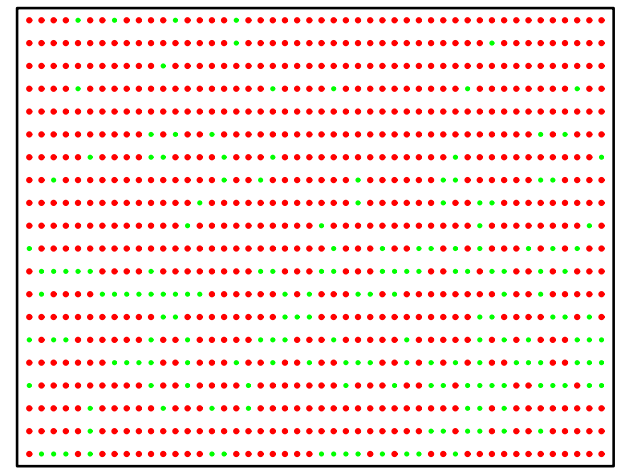

Figura 11 - Mapas representando as posições espaciais das plantas sadias e infectadas por morte súbita dos citros, em que • são as plantas infectadas e •, as plantas sadias. A. Talhão 107C, vistoriado em 27/08/01, 31/12/01 e 10/05/02, B. Talhão 303, vistoriado em 01/08/01, 07/11/01 e 08/05/02 
Tabela 2. Descrição dos talhões 107C e 303, infectados com morte súbita dos citros

\begin{tabular}{|c|c|c|c|c|c|c|}
\hline Talhão & Cultivar & Espaçamento & $\begin{array}{l}\text { Ano de } \\
\text { plantio }\end{array}$ & $\begin{array}{l}\text { Data da } \\
\text { inspeção }\end{array}$ & $\begin{array}{c}\text { № plantas } \\
\text { doentes }\end{array}$ & $\begin{array}{l}\text { № novas } \\
\text { infecções }\end{array}$ \\
\hline \multirow[t]{10}{*}{$107 \mathrm{C}$} & \multirow[t]{10}{*}{ Pera } & \multirow[t]{10}{*}{$3,0 \times 7,0 \mathrm{~m}$} & \multirow[t]{10}{*}{1990} & $27 / 08 / 01$ & 32 & 32 \\
\hline & & & & $24 / 09 / 01$ & 123 & 91 \\
\hline & & & & $25 / 10 / 01$ & 132 & 9 \\
\hline & & & & $20 / 11 / 01$ & 199 & 67 \\
\hline & & & & $31 / 12 / 01$ & 215 & 16 \\
\hline & & & & $22 / 01 / 02$ & 250 & 35 \\
\hline & & & & $22 / 02 / 02$ & 280 & 30 \\
\hline & & & & $22 / 03 / 02$ & 319 & 39 \\
\hline & & & & $24 / 04 / 02$ & 337 & 18 \\
\hline & & & & $10 / 05 / 02$ & 417 & 80 \\
\hline \multirow[t]{16}{*}{303} & \multirow[t]{16}{*}{ Valência } & \multirow[t]{16}{*}{$4,0 \times 7,5 \mathrm{~m}$} & \multirow[t]{16}{*}{1991} & 01/08/01 & 22 & 22 \\
\hline & & & & 08/08/01 & 26 & 4 \\
\hline & & & & $16 / 08 / 01$ & 73 & 47 \\
\hline & & & & $22 / 08 / 01$ & 89 & 16 \\
\hline & & & & 06/09/01 & 151 & 62 \\
\hline & & & & $12 / 09 / 01$ & 239 & 88 \\
\hline & & & & 06/10/01 & 301 & 62 \\
\hline & & & & $10 / 10 / 01$ & 319 & 18 \\
\hline & & & & $07 / 11 / 01$ & 467 & 148 \\
\hline & & & & 06/12/01 & 524 & 57 \\
\hline & & & & 08/01/02 & 578 & 54 \\
\hline & & & & $12 / 02 / 02$ & 591 & 13 \\
\hline & & & & $15 / 03 / 02$ & 622 & 31 \\
\hline & & & & 05/04/02 & 640 & 18 \\
\hline & & & & $24 / 04 / 02$ & 721 & 81 \\
\hline & & & & 08/05/02 & 779 & 58 \\
\hline
\end{tabular}




\subsubsection{Dados de tristeza dos citros}

Os dados de tristeza dos citros, citados em Gibson (1997b), Gibson \& Austin (1996), Hughes \& Madden (1993) e Marcus et al. (1984), foram coletados em uma área experimental e consistem de uma única área retangular com 28 linhas de plantio e 36 plantas/linha, com espaçamento de 5,5m entre linhas e de $4 \mathrm{~m}$ entre plantas dentro da linha, que foi avaliada em dois anos consecutivos, 1981 e 1982. Assim, tem-se um látice 28x36 que está apresentado na Figura 12, sendo que em 1981 tinha-se um total de 131 plantas infectadas e em 1982, mais 45 novas infecções foram identificadas.

Marcus et al. (1984) foram os primeiros a analisar esses dados, ajustando a distribuição gama ao conjunto das distâncias entre a planta doente e suas vizinhas mais próximas. Posteriormente, Hughes \& Madden (1993) utilizaram este mesmo conjunto de dados no ajuste da distribuição beta-binomial. Gibson (1997b) e Gibson \& Austin (1996) também utilizaram esses dados, mas para ilustrar o ajuste de modelos estocásticos espaço-temporais.

\subsubsection{Dados de viroses do lúpulo}

Esses dados são referentes a três viroses que, de acordo com Pethybridge \& Madden (2003), são os três patógenos do lúpulo (Humulus lupulus L.; Família Canabidaceae) mais comuns e importantes na Austrália: o Hop latent virus (HpLV), o Hop mosaic virus (HpMV) e o Apple mosaic virus (ApMV).

São provenientes de uma lavoura comercial, estabelecida em 1989, utilizando-se plantas testadas e não infectadas pelos três tipos de vírus. A área é retangular com 25 linhas de plantio e 51 plantas/linha e espaçamento de 2,1m entre linhas e 1,8m entre plantas dentro da linha. Portanto, tem-se um látice 25x51 que foi avaliado em 1996 e 1997, sendo que, para a detecção dos vírus foram utilizadas 


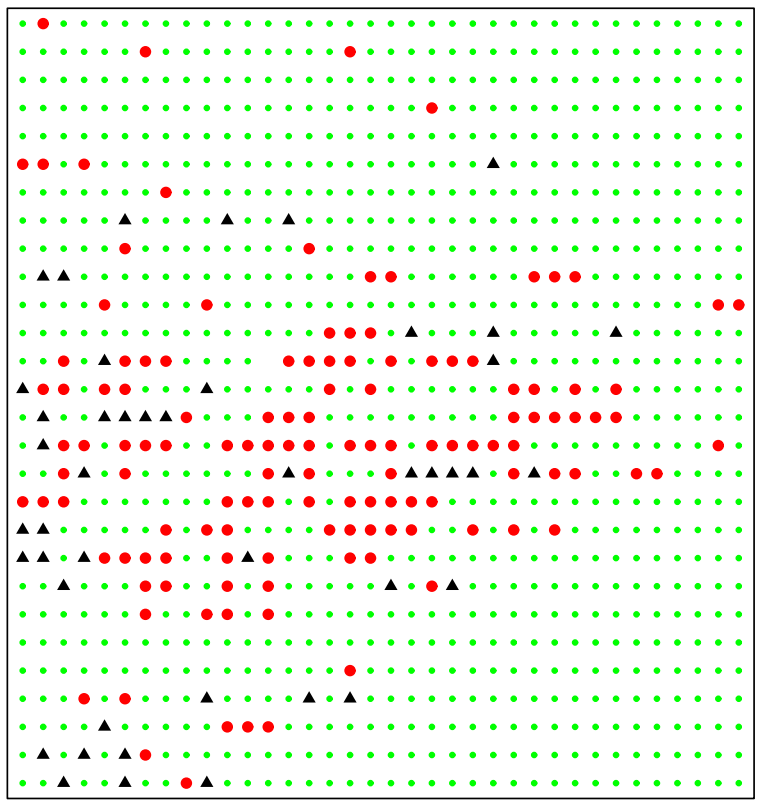

Figura 12 - Mapa representando as posições espaciais das plantas sadias e infectadas com tristeza dos citros, em que • são as infecções identificadas em 1981, $\triangle$, as infecções identificadas em 1982 e •, as plantas sadias

análises laboratoriais. Os três mapas representando as plantas infectadas com os três diferentes vírus e as plantas sadias estão apresentados na Figura 13.

\subsection{Métodos}

Para o estudo e a caracterização de padrões espaciais de doenças em plantas foi utilizado o método baseado na verossimilhança para o ajuste de modelos estocásticos espaço-temporais, inicialmente proposto por Gibson \& Austin (1996). Esses autores utilizaram uma técnica de integração estocástica no processo de estimação dos parâmetros dos modelos, que foi posteriormente criticada por Gibson (1997b), que apresentou melhorias no processo de estimação dos parâmetros, utilizando métodos MCMC. Nesse novo processo de estimação, obtém-se uma seqüência 
A

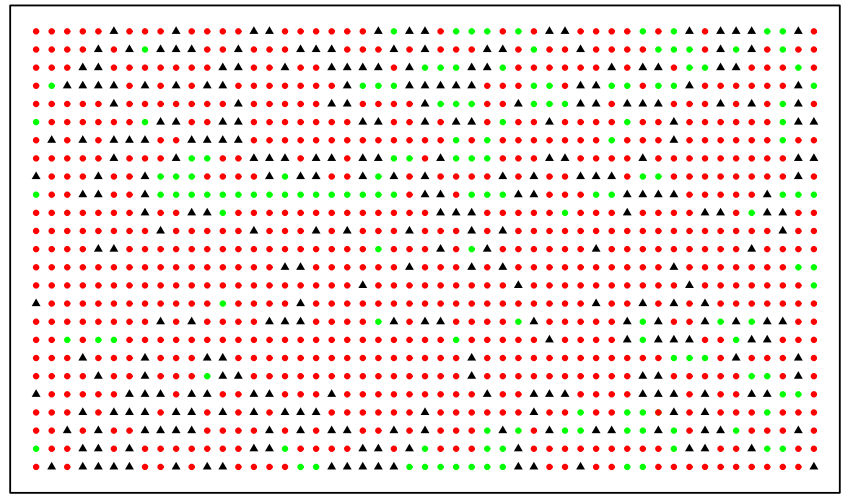

B

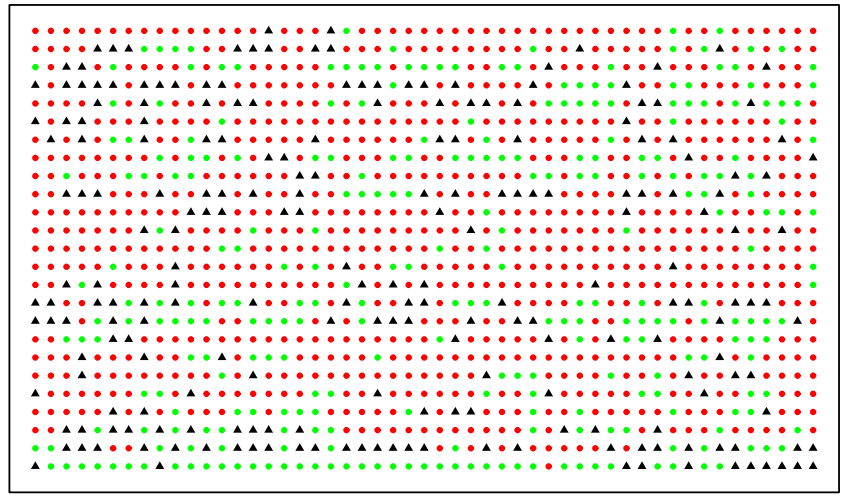

C

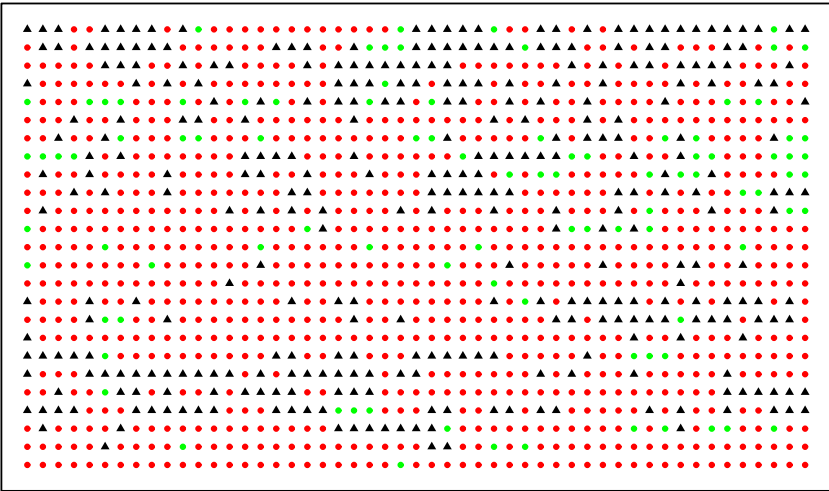

Figura 13 - Mapa representando as posições espaciais das plantas sadias e infectadas por A. Hop latent virus, B. Hop mosaic virus e C. Apple mosaic virus, em que • são as infecções identificadas em 1996, $\triangle$, as infecções identificadas em 1997 e $\cdot$, as plantas sadias 
de pares de parâmetro e permutação $\left\{\left(\alpha_{i}, \omega_{i}\right) \mid 1 \leq i \leq m\right\}$ a partir de uma cadeia de Markov, conforme definido anteriormente em 2.3.3.7.

Gibson (1997b) utilizou um esquema para criar mutações na permutação $\omega_{i}$, a fim de obter uma nova permutação $\omega_{i+1}$, que é bastante complexo. Conforme pode ser visto em 2.5, as alterações em $\omega_{i}$, para a obtenção de $\omega_{i+1}$, são realizadas em nível de par de elementos de $\omega_{i}$, o que exige que os pares sejam percorridos um a um e que consome muito tempo computacional. Além disso, no processo de estimação proposto por Gibson (1997b), consideram-se valores discretos para $\alpha$ dentro de um intervalo pré-definido, sendo que na realidade este parâmetro é contínuo. Portanto, modificações na metodologia original de Gibson (1997b), podem trazer grandes benefícios.

Neste trabalho, são implementadas modificações no processo original de estimação de Gibson (1997b), com o intuito de diminuir o tempo computacional gasto nas análises. Duas modificações significativas foram implementadas:

(i) modificações no processo de obtenção de $\omega_{i+1}$ a partir de $\omega_{i}$ : altera-se completamente a forma de se obter a nova permutação, $\omega_{i+1}$, eliminando-se o processo de mutação, proposto originalmente, que é o componente que demanda o maior tempo computacional e utiliza-se Metropolis-Hastings como critério de aceitação dessa nova permutação proposta, ao invés do critério de Barker que é utilizado por Gibson (1997b);

(ii) modificações no processo de obtenção de $\alpha_{i+1}$ a partir de $\alpha_{i}$ : considera-se o parâmetro $\alpha$, dos modelos $(24)$ e $(25)$ e os parâmetros $\boldsymbol{\alpha}^{\prime}=\left[\alpha_{1}, \alpha_{2}\right]$, do modelo (26), como contínuos, ao invés de utilizar valores discretos, como Gibson (1997b), obtendo-se os valores propostos para $\alpha_{i+1}$ ou $\boldsymbol{\alpha}_{i+1}$ através de cadeias de passeios aleatórios (random walk chains), conforme definido por Gamerman (1997) e utiliza-se o critério de Metropolis-Hastings para verificar a aceitação dos valores propostos para $\alpha_{i+1}$ e $\boldsymbol{\alpha}_{i+1}$. 


\subsubsection{Processo proposto para a estimação dos parâmetros nos modelos estocásticos espaço-temporais utilizando métodos MCMC}

\subsubsection{Processo de estimação para o caso de modelos com um parâmetro}

O processo de estimação do parâmetro $\alpha$, dos modelos (24) e (25), é baseado na verossimilhança $G(\alpha)$, conforme descrito no item 2.5. Porém, é praticamente impossível obter-se $G(\alpha)$, definida na eq. (31), pois envolve um somatório de dimensões intratáveis. Entretanto, podem-se utilizar métodos MCMC para se estimar $G(\alpha)$.

Como foi visto no item 2.5, $G(\alpha) \propto \pi(\alpha \mid \mathcal{E})$, sob a pressuposição de que todos os valores de $\alpha$ sejam, a priori, equiprováveis, em que $\mathcal{E}$ é o evento que representa as informações obtidas dos dados, isto é, as plantas inicialmente infectadas e as novas infecções que ocorreram em um determinado intervalo de tempo, como por exemplo, entre $t_{0}$ e $t_{1}$. Portanto, utilizando o mesmo raciocínio apresentado por Gibson (1997b), o interesse é estimar $\pi(\alpha \mid \mathcal{E})$, considerando a densidade conjunta a posteriori $\pi(\alpha, \omega \mid \mathcal{E})$, em que $\omega$ representa a ordem na qual as novas infecções aconteceram. Como definido anteriormente, $\pi(\alpha, \omega \mid \mathcal{E})$ é proporcional a $P_{\omega}(\boldsymbol{\alpha})$ cujo cálculo está apresentado no Apêndice 1. Assim, considerando estas definições, podese concluir que uma boa opção para este processo de estimação é utilizar os métodos MCMC, uma vez que a densidade de interesse é conhecida apenas parcialmente, sem uma constante de proporcionalidade.

O interesse principal é obter uma amostra de $\alpha$ para que se possa estimar $\pi(\alpha \mid \mathcal{E})$ e, conseqüentemente estimar o parâmetro do modelo considerado. Para isso, foi utilizado o algoritmo de Metropolis-Hastings, considerando cadeias de passeios aleatórios (random walk chains) na definição da função de transição (kernel de transição). Assim, gerou-se uma sequência de parâmetros e ordens $\left\{\left(\alpha_{i}, \omega_{i}\right) \mid 1 \leq\right.$ $i \leq m\}$ a partir de uma cadeia de Markov, na qual $m$ é o tamanho da amostra ou

o número de pares $(\alpha, \omega)$ gerados. Um novo par $\left(\alpha_{i+1}, \omega_{i+1}\right)$ foi gerado a partir de 
$\left(\alpha_{i}, \omega_{i}\right)$, como se segue.

\section{Atualização de $\alpha$}

Na obtenção de um valor candidato a $\alpha_{i+1}, \alpha^{*}$, a partir de $\alpha_{i}$, são utilizadas cadeias de passeios aleatórios, conforme definição apresentada em 2.4.1. De acordo com esta definição, $x^{(t+1)}=x^{(t)}+w_{t+1}$, o que significa que um novo valor para a variável aleatória, $x^{(t+1)}$, é gerado a partir do valor atual, somando-se um valor $w_{t+1}$, que representa um distúrbio ou alteração acrescentada em $x_{t}$, e que é gerado a partir de uma outra distribuição, a de $W$.

O novo valor, $\alpha^{*}$, é gerado a partir de $\alpha_{i}$, utilizando-se

$$
\operatorname{logit}\left(\frac{\alpha^{*}}{C}\right)=\operatorname{logit}\left(\frac{\alpha_{i}}{C}\right)+w
$$

em que $\operatorname{logit}\left(\frac{\alpha}{C}\right)=\log \left(\frac{\alpha / C}{1-\alpha / C}\right)=\log \left(\frac{\alpha}{C-\alpha}\right)$ e $w$ é um valor simulado da variável aleatória $W$, em que $W \sim N\left(0, \sigma^{2}\right)$. Essa transformação de variável na geração de $\alpha^{*}$ é necessária pois $\alpha \in[0, \infty)$ e $w \in(-\infty, \infty)$ e assim, os valores simulados para $\alpha$ mantêm-se restritos a um intervalo pré-definido, isto é, $\alpha \in[0, C]$, em que $C$ é definido pelo pesquisador.

A determinação de um limite superior para os valores do parâmetro $\alpha$ foi implementada na simulação porque valores em torno de 3,0 já podem ser considerados extremamente altos, apesar de, teoricamente, $\alpha$ poder assumir qualquer valor positivo. Assim, a partir da eq. (36), tem-se

$$
\alpha^{*}=C\left[1+\frac{C-\alpha_{i}}{\alpha_{i} e^{w}}\right]^{-1} .
$$

Uma vez gerado $\alpha^{*}$, deve-se verificar se este será aceito ou não. Sabe-se que $\pi\left(\alpha, \omega_{i} \mid \mathcal{E}\right) \propto P_{\omega_{i}}(\alpha)$ e, de acordo com o algoritmo de Metropolis-Hastings, o valor proposto, $\alpha^{*}$, será aceito com probabilidade $\delta\left(\alpha_{i}, \alpha^{*}\right)$ dada por

$$
\begin{aligned}
\delta\left(\alpha_{i}, \alpha^{*}\right) & =\min \left\{1, \frac{P_{\omega_{i}}\left(\alpha^{*}\right) q\left(\alpha^{*}, \alpha_{i}\right)}{P_{\omega_{i}}\left(\alpha_{i}\right) q\left(\alpha_{i}, \alpha^{*}\right)}\right\} \\
& =\min \left\{1, \frac{P_{\omega_{i}}\left(\alpha^{*}\right) \alpha^{*}\left(C-\alpha^{*}\right)}{P_{\omega_{i}}\left(\alpha_{i}\right) \alpha_{i}\left(C-\alpha_{i}\right)}\right\}
\end{aligned}
$$


em que $q\left(\alpha_{i}, \alpha^{*}\right)$ é a função de transição, que é obtida utilizando-se o conceito de transformação de variáveis aleatórias (Mood et al., 1974), ou seja,

$$
q\left(\alpha_{i}, \alpha^{*}\right)=\frac{C}{\alpha^{*}\left(C-\alpha^{*}\right)} \cdot \frac{1}{\sqrt{2 \pi} \sigma} \cdot \exp \left\{-\frac{1}{2 \sigma^{2}}\left[\log \left(\frac{\alpha^{*}}{C-\alpha^{*}}\right)-\mu\right]^{2}\right\} I_{(0, C)}\left(\alpha^{*}\right),
$$

em que $\mu=\log \left(\frac{\alpha_{i}}{C-\alpha_{i}}\right)$. Vale lembrar que, $q\left(\alpha^{*}, \alpha_{i}\right)$ é definido da mesma maneira, bastando substituir $\alpha^{*}$ por $\alpha_{i}$ e vice-versa.

A variância de $W, \sigma^{2}$, interfere diretamente na porcentagem de aceitação dos valores propostos, $\alpha^{*}$. Valores altos de $\sigma^{2}$ levam a alterações maiores, isto é, a diferenças maiores entre $\alpha^{*}$ e $\alpha_{i}$. Porém, a porcentagem de aceitação dos valores propostos é bem pequena. Por outro lado, quando se utilizam valores menores de $\sigma^{2}$, o valor proposto de $\alpha^{*}$ está mais próximo do valor anterior, $\alpha_{i}$, e assim, a porcentagem de aceitação dos valores propostos é maior. Portanto, a definição do valor de $\sigma^{2}$, a ser utilizado nas simulações, é um aspecto importante. Segundo uma recomendação prática, devem-se utilizar valores que garantam uma aceitação de $30 \%$ a $40 \%$ dos valores propostos. Após a obtenção do parâmetro atualizado, $\alpha_{i+1}$, deve-se atualizar $\omega_{i}$, isto é, obter $\omega_{i+1}$ a partir de $\omega_{i}$.

\section{Atualização de $\omega$}

Na obtenção de $\omega_{i+1}$ a partir de $\omega_{i}$, uma nova ordem de ocorrência das novas infecções ou permutação candidata, $\omega^{*}$, é obtida efetuando-se a troca das posições dos elementos de $H$ pares escolhidos aleatoriamente, obedecendo a determinadas regras. Suponha que se tenham $N$ novas infecções, ou seja, que $S_{1} \backslash S_{0}$ é o conjunto dessas $N$ plantas. A ordem de infecção $\omega_{i}$ corresponde a uma das $N$ ! possíveis maneiras de se representar a ordem em que as $N$ infecções ocorreram. Assim, pode-se definir $\omega_{i}$ por

$$
\omega_{i}=\left(\omega_{i(1)}, \omega_{i(2)}, \ldots, \omega_{i(N)}\right)
$$

Para a obtenção de $\omega^{*}$ são efetuadas $H$ trocas de posições, em pares escolhidos aleatoriamente, na permutação $\omega_{i}$. $H$ é obtido a partir do coeficiente de 
correlação de Kendall ou $\tau$ de Kendall (Sprent \& Smeeton, 2001). Esse coeficiente fornece uma medida de concordância entre as permutações $\omega_{i}$ e $\omega^{*}$ e assume valores de $-1,0$ a 1,0. Se todas as posições são concordantes, $\tau=1,0$ e se as duas permutações são completamente diferentes, $\tau=-1,0$. O número de pares, a serem trocados, é dado por

$$
H=n_{d}=\frac{N(N-1)(1-\tau)}{4},
$$

em que $n_{d}$ é o número de discordâncias, $N$ é número de novas infecções ou número de elementos da permutação $\omega$ e $\tau$ é o coeficiente de correlação de Kendall.

Cada troca é realizada de acordo com os seguintes passos:

(a) Um elemento de $\omega_{i}, \omega_{i(j)}$, é selecionado aleatoriamente;

(b) Um outro elemento de $\omega_{i}, \omega_{i(k)}$, o qual será trocado por $\omega_{i(j)}$, a menos que $i=k$, é escolhido da seguinte maneira:

(b.1) define-se aleatoriamente, com igual probabilidade, a direção de $\omega_{i(k)}$ em relação a $\omega_{i(j)}$, ou seja, esquerda $(j>k)$ ou direita $(j<k)$;

(b.2) a distância $d$, entre $\omega_{i(j)}$ e $\omega_{i(k)}$, é aleatoriamente definida considerando que a variável aleatória $D \sim \operatorname{Bin}(n, \pi)$, em que $n=1, \ldots, d_{\max }$, com $d_{\max }=j-1$, se a direção escolhida foi esquerda ou $d_{\max }=N-j$, caso contrário;

(b.3) $k$ é obtido por:

$$
k= \begin{cases}j-d, & \text { se a direção escolhida foi esquerda } \\ j+d, & \text { se a direção escolhida foi direita; }\end{cases}
$$

(c) Troca-se $\omega_{i(j)}$ e $\omega_{i(k)}$ de posições. Note que pode não haver troca, quando $d=0$ e, assim, $j=k$;

(d) Repetir os passos (a)-(c) $H$ vezes. O resultado final será a nova permutação, $\omega^{*}$. 
O critério de aceitação da nova permutação também é o de MetropolisHastings e a permutação $\omega^{*}$ será aceita com probabilidade

$$
\delta\left(\omega_{i}, \omega^{*}\right)=\min \left\{1, \frac{P_{\omega^{*}}\left(\alpha_{i+1}\right)}{P_{\omega_{i}}\left(\alpha_{i+1}\right)}\right\} .
$$

O cálculo de $\delta\left(\omega_{i}, \omega^{*}\right)$, apresentado em (40), é mais simples do que o de $\delta\left(\alpha_{i}, \alpha^{*}\right)$, apresentado em (38), porém o algoritmo em ambos é o mesmo, ou seja, o de Metropolis-Hastings. A diferença é que na obtenção da nova permutação $\omega^{*}$ a função de transição $q$ é simétrica, isto é, $q\left(\omega_{i}, \omega^{*}\right)=q\left(\omega^{*}, \omega_{i}\right)$ e, portanto, cancelam-se. Na realidade, este último é o critério de aceitação do algoritmo de Metropolis, que é um caso especial do algoritmo de Metropolis-Hastings, quando a função de transição é simétrica.

\section{Obtenção dos valores iniciais, $\alpha^{(0)}$ e $\omega^{(0)}$}

$\mathrm{Na}$ construção de qualquer cadeia de Markov, valores iniciais são necessários. Assim, nesse processo de simulação utilizando métodos MCMC, necessita-se de valores iniciais dos parâmetros e da ordem de infecção. Esses são definidos, respectivamente, por $\alpha^{(0)}$ e $\omega^{(0)}$.

O valor de $\alpha^{(0)}$ é facilmente obtido, considerando que os parâmetros tenham distribuição uniforme, a priori, que foi a condição assumida antes de se iniciar o processo de simulação. Assim, $\alpha^{(0)}$ é obtido simulando-se um valor a partir da distribuição $U(0, C)$.

$\mathrm{Na}$ determinação de $\omega^{(0)}$, leva-se em consideração a pressão infectiva sofrida pelas plantas pertencentes ao conjunto das plantas infectadas entre os tempos $t_{0}$ e $t_{1}$, exercida pelo conjunto de plantas inicialmente infectadas. Já foi visto que $S_{0}$ e $S_{1}$ são os conjuntos de plantas doentes nos tempos $t_{0}$ e $t_{1}$, respectivamente. Conseqüentemente, tem-se o conjunto $S_{1} \backslash S_{0}$ das plantas infectadas entre $t_{0}$ e $t_{1}$. Assim, para cada uma das plantas $x \in S_{1} \backslash S_{0}$, calcula-se um peso, $r_{\alpha}(x)$, da mesma maneira que no item (i) do processo de simulação de um conjunto de dados, apresentado em 3.1.1. Esse peso representa a pressão infectiva exercida pelas plantas infectadas sobre as plantas sadias e envolve um somatório em relação a todas as plantas doentes 
num determinado tempo $t$. No caso da determinação de $\omega^{(0)}$, o somatório é em relação a todas as plantas infectadas $y \in S_{0}$. O valor inicial $\omega^{(0)}$ representa as plantas $x \in S_{1} \backslash S_{0}$ colocadas em ordem decrescente, de acordo com os valores de $r_{\alpha}(x)$.

Para ilustrar a determinação de $\omega^{(0)}$, considere o mesmo exemplo utilizado para exemplificar o processo de simulação, em que se tem um látice 5x5, a infecção inicial era a planta central e a matriz com os valores de $r_{\alpha}(x)$ calculados para todas as plantas do látice é dada em (35). Neste exemplo tem-se que $S_{0}=\left\{x_{(13)}\right\}$, isto é, a infecção inicial corresponde a uma única planta: a planta 13, na coordenada $(3,3)$. Suponha que o conjunto das novas infecções seja $S_{1} \backslash S_{0}=\left\{x_{(17)}, x_{(18)}, x_{(22)}, x_{(23)}\right\}$ ou as plantas que estão nas coordenadas $(4,2),(4,3),(5,2)$ e $(5,3)$, respectivamente. O valor de $r_{\alpha}(x)$ para cada uma dessas plantas é: $r_{\alpha}\left(x_{(17)}\right)=1,50, r_{\alpha}\left(x_{(18)}\right)=2,00$, $r_{\alpha}\left(x_{(22)}\right)=1,20$ e $r_{\alpha}\left(x_{(23)}\right)=1,25$. Assim, o valor inicial para a ordem de infecção seria $\omega^{(0)}=\{18,17,23,22\}$.

\section{Resumo do algoritmo de estimação}

De uma forma resumida, o algoritmo segue os seguintes passos:

(a) obtêm-se os valores iniciais da cadeia: $\alpha^{(0)}$ e $\omega^{(0)}$;

(b) atualiza-se $\alpha_{i}$, através dos passos:

b.1. calcula-se $\alpha^{*}$, a partir de $\alpha_{i}$, conforme definido em (37);

b.2. calcula-se, $\delta\left(\alpha_{i}, \alpha^{*}\right)$, a partir de (38);

b.3. gera-se um valor $u$, tal que $U \sim(0,1)$;

b.4. obtém-se $\alpha_{i+1}$, através da seguinte regra:

$$
\alpha_{i+1}= \begin{cases}\alpha^{*}, & \text { se } \delta\left(\alpha_{i}, \alpha^{*}\right) \geq u \\ \alpha_{i}, & \text { se } \delta\left(\alpha_{i}, \alpha^{*}\right)<u\end{cases}
$$

(c) atualiza-se $\omega_{i}$, através dos passos:

c.1. obtém-se $\omega^{*}$, a partir de $\omega_{i}$; 
c.2. calcula-se, $\delta\left(\omega_{i}, \omega^{*}\right)$, a partir de $(40)$;

c.3. gera-se um valor $u$, tal que $U \sim(0,1)$;

c.4. obtém-se $\omega_{i+1}$, através da seguinte regra:

$$
\omega_{i+1}= \begin{cases}\omega^{*}, & \text { se } \delta\left(\omega_{i}, \omega^{*}\right) \geq u \\ \omega_{i}, & \text { se } \delta\left(\omega_{i}, \omega^{*}\right)<u\end{cases}
$$

(d) repetem-se os passos (b)-(c) até que se tenha uma cadeia do tamanho desejado.

Ao final de todo o processo tem-se uma amostra do parâmetro, que é utilizada para se estimar a densidade de interesse $\pi(\alpha \mid \mathcal{E})$ e, conseqüentemente a verossimilhança $G(\alpha)$. Para isso, é utilizada a função density, desenvolvida em $\mathrm{R}$ e presente no próprio programa.

Para exemplificar a aplicação desse processo de estimação, assim como comparar as estimativas com as obtidas através da verossimilhança exata e através da metodologia proposta por Gibson (1997b), são analisados os dados simulados a partir do modelo (25) e os dados de tristeza dos citros, já descritos.

\section{Definição dos intervalos de $\alpha$ e das características da cadeia}

$\mathrm{Na}$ análise dos dados simulados, a verossimilhança exata, $\pi(\alpha \mid \mathcal{E})$ é calculada considerando-se todas as $9 !$ permutações $(\omega)$ possíveis, a partir da eq. (31). Na obtenção de $\hat{\pi}(\alpha \mid \mathcal{E})$ através das duas aproximações, os valores iniciais de $\alpha$ e $\omega$ são obtidos, conforme já descrito. Na aproximação de Gibson (1997b), $\alpha^{(0)}$ é simulado a partir de uma distribuição uniforme discreta, definida para valores do conjunto $\{0,0,1,0,2, \ldots, C\}$, em que $C$ representa o valor máximo de $\alpha$, assumido a priori. Nas análises dos dados simulados com $\alpha$ igual a 0,5 e 1,0, assume-se $C=2,0$, enquanto $C=5,0$, nos casos em que os dados simulados foram obtidos com $\alpha=2,0$ e 3,0. Na aproximação proposta neste trabalho, em que o parâmetro $\alpha$ é considerado como contínuo, $\alpha^{(0)}$ foi simulado a partir de uma $U(0,2)$ ou uma $U(0,5)$, obedecendo os mesmos intervalos que no caso da aproximação de Gibson. 
$\mathrm{Na}$ análise dos dados de tristeza dos citros, os quais foram analisados por Gibson (1997b), foram considerados os valores discretos $\{0,9,0,925, \ldots, 1,5\}$ e $\{0,8,0,85, \ldots, 2,0\}$, nas análises considerando infecções identificadas, respectivamente, em 1981 e 1982. Assim, os valores iniciais de $\alpha$, em cada uma das análises, foi escolhido aleatoriamente dentro dos conjuntos de valores discretos definidos. Estes valores discretos foram os mesmos utilizados por Gibson (1997b).

O valor inicial de $\omega, \omega^{(0)}$ é obtido conforme descrito anteriormente, sendo que, na análise para o ano de 1981, a infecção inicial corresponde a uma única planta, escolhida aleatoriamente entre as 131 doentes. Já na análise de 1982, as 131 plantas doentes identificadas em 1981, são consideradas como infecção inicial.

As definições do tamanho da cadeia e burn-in são as mesmas nas análises dos dados simulados e dos dados de tristeza dos citros. Na utilização da metodologia original, de Gibson (1997b), são geradas 1020 distribuições e as últimas 1000 são utilizadas na obtenção de $\hat{\pi}(\alpha \mid \mathcal{E})$, a partir da eq. (32) e, assim, tem-se $m=1000$. Na geração de cada uma dessas distribuições, $\omega_{i+1}$ é obtido a partir de $\omega_{i}$, aplicando-se o processo de mutação, apresentado em 2.5, 500 vezes, isto é, os passos (a)-(c) do processo de mutação é repetido 500 vezes em cada uma das 1000 simulações. Na metodologia proposta, obtém-se uma cadeia com 11000 iterações, sendo que as primeiras 1000 iterações são descartadas, como burn-in. Assim, tem-se uma amostra de tamanho 10000 do parâmetro $\alpha$, a qual é considerada na obtenção de $\hat{\pi}(\alpha \mid \mathcal{E})$, utilizando-se a função density do R.

Todos os cálculos envolvidos na obtenção de $\pi(\alpha \mid \mathcal{E})$ exata e aproximadas, foram executados utilizando-se programas computacionais implementados em Fortran 90. Os programas desenvolvidos são muito extensos, o que impossibilita a apresentação desses códigos. 


\subsubsection{Processo de estimação para o caso do modelo com dois parâme- $\operatorname{tros}$}

O processo de estimação para o caso do modelo com dois parâmetros é basicamente o mesmo dos modelos com um parâmetro. A diferença está apenas na atualização dos parâmetros, pois, neste caso tem-se um vetor de parâmetros $\boldsymbol{\alpha}^{\prime}=$ $\left[\begin{array}{ll}\alpha_{1} & \alpha_{2}\end{array}\right]$, ao invés de um único $\alpha$.

\section{Atualização de $\alpha$}

No caso dos modelos com um parâmetro, a simulação de um novo valor é direta, pois trata-se de um único parâmetro e assim, basta calcular $\alpha^{*}$ a partir de $\alpha_{i}$, considerando uma outra variável aleatória $W \sim\left(0, \sigma^{2}\right)$ e verificar sua aceitação. Porém, no modelo com dois parâmetros, a atualização de $\boldsymbol{\alpha}_{i}$ envolve a simulação de dois novos valores, $\alpha_{1}^{*}$ e $\alpha_{2}^{*}$. Neste caso, as simulações são realizadas independentemente, ou seja, simula-se o valor de $\alpha_{1}^{*}$ a partir de $\alpha_{i 1}$, considerando a variável aleatória $W_{1} \sim\left(0, \sigma_{1}^{2}\right)$, posteriormente simula-se $\alpha_{2}^{*}$ a partir de $\alpha_{i 2}$, com um distúrbio definido através da variável aleatória $W_{2} \sim\left(0, \sigma_{2}^{2}\right)$ e, assim, gera-se o novo vetor $\boldsymbol{\alpha}^{*}$, tal que $\left(\boldsymbol{\alpha}^{*}\right)^{\prime}=\left[\begin{array}{ll}\alpha_{1}^{*} & \alpha_{2}^{*}\end{array}\right]$. Cada um dos valores do vetor $\boldsymbol{\alpha}^{*}$ é obtido da mesma maneira que o único parâmetro, em 3.2.1.1.

No entanto, a probabilidade de aceitação, do valor proposto para $\boldsymbol{\alpha}_{i+1}$, é um pouco mais complexa do que no caso de um único parâmetro. Sabe-se que os parâmetros $\alpha_{1}$ e $\alpha_{2}$, tal que $\boldsymbol{\alpha}^{\prime}=\left[\begin{array}{ll}\alpha_{1} & \alpha_{2}\end{array}\right]$, são independentes. Partindo-se deste princípio e da eq. (39), a função de transição conjunta pode ser definida como o produto das funções de transição de cada um dos parâmetros, isto é, 


$$
\begin{aligned}
q\left(\boldsymbol{\alpha}_{i}, \boldsymbol{\alpha}^{*}\right)= & q\left(\alpha_{i 1}, \alpha_{1}^{*}\right) q\left(\alpha_{i 2}, \alpha_{2}^{*}\right) \\
= & \frac{C_{1}}{\alpha_{1}^{*}\left(C_{1}-\alpha_{1}^{*}\right)} \cdot \frac{C_{2}}{\alpha_{2}^{*}\left(C_{2}-\alpha_{2}^{*}\right)} \\
& \frac{1}{\sqrt{2 \pi} \sigma_{1}} \cdot \frac{1}{\sqrt{2 \pi} \sigma_{2}} \cdot \exp \left\{-\frac{1}{2 \sigma_{1}^{2}}\left[\log \left(\frac{\alpha_{1}^{*}}{C_{1}-\alpha_{1}^{*}}\right)-\mu_{1}\right]^{2}\right\} \\
& \cdot \exp \left\{-\frac{1}{2 \sigma_{2}^{2}}\left[\log \left(\frac{\alpha_{2}^{*}}{C_{2}-\alpha_{2}^{*}}\right)-\mu_{2}\right]^{2}\right\} I_{\left(0, C_{1}\right)}\left(\alpha_{1}^{*}\right) I_{\left(0, C_{2}\right)}\left(\alpha_{2}^{*}\right),
\end{aligned}
$$

em que, $C_{1}$ e $C_{2}$ são os limites superiores para $\alpha_{1}$ e $\alpha_{2}$, respectivamente, $\mu_{1}=$ $\log \left(\frac{\alpha_{i 1}}{C_{1}-\alpha_{i 1}}\right)$ e $\mu_{2}=\log \left(\frac{\alpha_{i 2}}{C_{2}-\alpha_{i 2}}\right)$. Assim, a probabilidade de aceitação de $\alpha^{*}$ proposto é definida por

$$
\begin{aligned}
\delta\left(\boldsymbol{\alpha}_{i}, \boldsymbol{\alpha}^{*}\right) & =\min \left\{1, \frac{P_{\omega_{i}}\left(\boldsymbol{\alpha}^{*}\right) q\left(\boldsymbol{\alpha}^{*}, \boldsymbol{\alpha}_{i}\right)}{P_{\omega_{i}}\left(\boldsymbol{\alpha}_{i}\right) q\left(\boldsymbol{\alpha}_{i}, \boldsymbol{\alpha}^{*}\right)}\right\} \\
& =\min \left\{1, \frac{P_{\omega_{i}}\left(\boldsymbol{\alpha}^{*}\right) \alpha_{1}^{*}\left(C_{1}-\alpha_{1}^{*}\right) \alpha_{2}^{*}\left(C_{2}-\alpha_{2}^{*}\right)}{P_{\omega_{i}}\left(\boldsymbol{\alpha}_{i}\right) \alpha_{i 1}\left(C_{1}-\alpha_{i 1}\right) \alpha_{i 2}\left(C_{2}-\alpha_{i 2}\right)}\right\} .
\end{aligned}
$$

Do mesmo modo que no caso dos modelos com um parâmetro, as variâncias de $W_{1}$ e $W_{2}, \sigma_{1}^{2}$ e $\sigma_{2}^{2}$, interferem na taxa de aceitação dos valores gerados, $\alpha_{1}^{*}$ e $\alpha_{2}^{*}$, respectivamente. Porém, a taxa de aceitação é determinada diretamente para $\boldsymbol{\alpha}^{*}$. Novamente, procura-se obter uma cadeia cuja taxa de aceitação esteja entre $30 \%$ e $40 \%$.

\section{Atualização de $\omega$}

Na obtenção de $\omega_{i+1}$, seguem-se exatamente os mesmos passos da atualização de $\omega_{i}$, apresentados no caso dos modelos com um parâmetro. A única diferença está no cálculo da probabilidade de aceitação de $\omega^{*}$, ou seja, neste caso tem-se um vetor de parâmetros, ao invés de um único parâmetro. Assim, a partir da eq. 40 , tem-se

$$
\delta\left(\omega_{i}, \omega^{*}\right)=\min \left\{1, \frac{P_{\omega^{*}}\left(\boldsymbol{\alpha}_{i+1}\right)}{P_{\omega_{i}}\left(\boldsymbol{\alpha}_{i+1}\right)}\right\}
$$


Obtenção dos valores iniciais, $\boldsymbol{\alpha}^{(0)}$ e $\omega^{(0)}$

Os valores iniciais, $\boldsymbol{\alpha}^{(0)}$ e $\omega^{(0)}$, são obtidos de maneira semelhante ao caso dos modelos com um parâmetro, sendo os dois parâmetros do vetor $\boldsymbol{\alpha}^{(0)}$ gerados independentemente. A regra utilizada na obtenção de $\alpha^{(0)}$ é válida para cada um dos parâmetros do vetor $\boldsymbol{\alpha}^{(0)}$. Portanto, simula-se $\alpha_{1}^{(0)}$ de uma $U=\left(0, C_{1}\right), \alpha_{2}^{(0)}$ de uma $U\left(0, C_{2}\right)$ e, assim, tem-se $\left(\alpha^{(0)}\right)^{\prime}=\left[\begin{array}{ll}\alpha_{1}^{(0)} & \alpha_{2}^{(0)}\end{array}\right]$.

\section{Resumo do algoritmo de estimação}

De uma forma resumida, o algoritmo para o caso do modelo com dois parâmetros, segue os seguintes passos:

(a) obtêm-se os valores iniciais da cadeia: $\boldsymbol{\alpha}^{(0)}$ e $\omega^{(0)}$;

(b) atualiza-se $\boldsymbol{\alpha}_{i}$, através dos passos:

b.1. calcula-se $\boldsymbol{\alpha}^{*}$, a partir de $\boldsymbol{\alpha}_{i}$;

b.2. calcula-se, $\delta\left(\boldsymbol{\alpha}_{i}, \boldsymbol{\alpha}^{*}\right)$, a partir de (41);

b.3. gera-se um valor $u$, tal que $U \sim(0,1)$;

b.4. $\boldsymbol{\alpha}_{i+1}$ é dado por:

$$
\boldsymbol{\alpha}_{i+1}= \begin{cases}\boldsymbol{\alpha}^{*}, & \text { se } \delta\left(\boldsymbol{\alpha}_{i}, \boldsymbol{\alpha}^{*}\right) \geq u \\ \boldsymbol{\alpha}_{i}, & \text { se } \delta\left(\boldsymbol{\alpha}_{i}, \boldsymbol{\alpha}^{*}\right)<u\end{cases}
$$

(c) atualiza-se $\omega_{i}$, através dos passos:

c.1. obtém-se $\omega^{*}$, a partir de $\omega_{i}$;

c.2. calcula-se, $\delta\left(\omega_{i}, \omega^{*}\right)$, a partir de (42);

c.3. gera-se um valor $u$, tal que $U \sim(0,1)$;

c.4. $\omega_{i+1}$ é dado por:

$$
\omega_{i+1}= \begin{cases}\omega^{*}, & \text { se } \delta\left(\omega_{i}, \omega^{*}\right) \geq u \\ \omega_{i}, & \text { se } \delta\left(\omega_{i}, \omega^{*}\right)<u\end{cases}
$$


(d) repetem-se os passos (b)-(c) até que se tenha uma cadeia do tamanho desejado.

Assim, ao final do processo tem-se uma amostra dos parâmetros $\alpha_{1}$ e $\alpha_{2}$, que é utilizada para se estimar a densidade de interesse $\pi(\boldsymbol{\alpha} \mid \mathcal{E})$ e, conseqüentemente a verossimilhança $G(\boldsymbol{\alpha})$. A diferença, em relação ao modelo com um parâmetro, é que se tem uma superfície representando a verossimilhança, pois são dois parâmetros. Assim, a verossimilhança aproximada é obtida, utilizando-se a função bkde2D, do pacote KernSmooth, já implementado em R.

Para exemplificar a utilização do modelo com dois parâmetros, apresentado em (26) e comparar as estimativas obtidas, através do processo de estimação proposto neste trabalho, com as obtidas através da metodologia proposta por Gibson (1997b), são analisados os dados simulados, a partir do modelo (26) e dados de incidência de doenças em plantas. Esses últimos dados referem-se a: três viroses do lúpulo, previamente analisados por Pethybridge \& Madden (2003), dados da incidência de cancro cítrico e morte súbita dos citros.

\section{Definição dos intervalos de $\alpha$ e das características da cadeia}

Os valores iniciais de $\boldsymbol{\alpha}$ e $\omega$ são obtidos, conforme já descrito. Na aproximação de Gibson (1997b), cada um dos valores do vetor de parâmetros $\boldsymbol{\alpha}^{(0)}$, $\alpha_{1}^{(0)}$ e $\alpha_{2}^{(0)}$, é obtido a partir de uma distribuição uniforme discreta, tal que $\alpha_{1} \in$ $\{0,0,125,0,250, \ldots, 2,500\}$ e $\alpha_{2} \in\{0,0,175,0,350, \ldots, 3,500\}$. Na aproximação proposta neste trabalho, assume-se, a priori, que $\alpha_{1} \sim U(0 ; 2,5)$ e $\alpha_{2} \sim U(0 ; 3,5)$. Assim, os valores iniciais, $\alpha_{1}^{(0)}$ e $\alpha_{2}^{(0)}$, são simulados a partir dessas duas distribuições, respectivamente.

O valor inicial de $\omega, \omega^{(0)}$, é obtido conforme descrito anteriormente, bastando definir qual é a infecção inicial, isto é, o conjunto de plantas doentes no tempo $t_{0}$. Quando se tem a avaliação do látice em vários tempos, basta considerar como infecção inicial, o conjunto das plantas doentes no tempo imediatamente anterior. Nesta situação, enquadram-se: 
- dados simulados: a infecção inicial refere-se à planta central do látice;

- viroses do lúpulo: são avaliadas em dois anos (1996 e 1997) e, assim, a infecção inicial refere-se ao conjunto das plantas doentes no primeiro ano;

- morte súbita dos citros: os talhões são avaliados em até 23 tempos, então a infecção inicial refere-se ao conjunto de plantas doentes no tempo imediatamente anterior ao tempo que está sendo considerado nas análises.

Porém, na coleta de dados da incidência do cancro cítrico, os talhões são avaliados uma única vez, isto é, em um único tempo, pois depois de detectada a doença, as plantas são destruídas. Entretanto, este problema, de se ter a avaliação em um tempo apenas, pode ser contornado considerando-se que, no tempo $t_{0}$, tem-se uma planta doente, a qual representa a infecção inicial. Essa planta, é escolhida aleatoriamente entre todas as plantas doentes do talhão avaliado.

No processo de estimação através da metodologia proposta neste trabalho, para o caso dos dados simulados, é gerada uma cadeia com 11000 iterações, com um burn-in igual a 1000. Nas análise dos demais conjuntos de dados, as definições do tamanho da cadeia e burn-in foram as mesmas, ou seja, obteve-se uma cadeia com 6000 iterações, sendo as primeiras 1000 referentes ao burn-in. Assim, tem-se uma amostra de tamanho 5000 dos parâmetros $\alpha_{1}$ e $\alpha_{2}$, que é utilizada na obtenção de $\hat{\pi}(\alpha \mid \mathcal{E})$. Na utilização da metodologia original, de Gibson (1997b), as características da cadeia são as mesmas em todas as análises, ou seja, são geradas 520 distribuições, das quais 500 são utilizadas na obtenção de $\hat{\pi}(\alpha \mid \mathcal{E})$, conforme definido na eq. (32) e 20 referem-se ao período de burn-in. O processo de mutação, para a geração de $\omega_{i+1}$ a partir de $\omega_{i}$, é repetido 500 vezes. Estes valores são os mesmos utilizados por Gibson (1997a), Gottwald et al. (1999) e Pethybridge \& Madden (2003). 


\section{RESULTADOS E DISCUSSÃO}

A seguir são apresentados os resultados obtidos, utilizando-se dados simulados e dados reais no ajuste de modelos estocásticos espaço-temporais, considerando os modelos definidos nas eq. (25) e (26).

\subsection{Dados simulados}

\subsubsection{Dados simulados a partir de um modelo com um parâmetro}

Os mapas representando os quatro látices simulados, utilizando-se o modelo apresentado na eq. (25), estão apresentados na Figura 14. Observa-se nesses mapas que, à medida que o parâmetro $\alpha$ utilizado na simulação aumenta, o grau de agregação das plantas doentes também aumenta. Isso é reflexo do que representa o parâmetro no modelo, isto é, para valores de $\alpha$ mais altos, tem-se que a transmissão da doença ocorre apenas para as plantas vizinhas mais próximas. Neste modelo, um padrão espacial aleatório é descrito quando $\alpha=0$. Além disso, pode-se observar que para valores de $\alpha$ iguais a 2,0 e 3,0, as plantas doentes já estão bastante agregadas e esse grau de agregação é limitado, isto é, a partir de um determinado valor de $\alpha$, as plantas doentes se localizam tão próximas que, para qualquer valor acima deste, o grau de agregação é o mesmo, ou seja, as plantas doentes estão o mais próximas possível. 
A

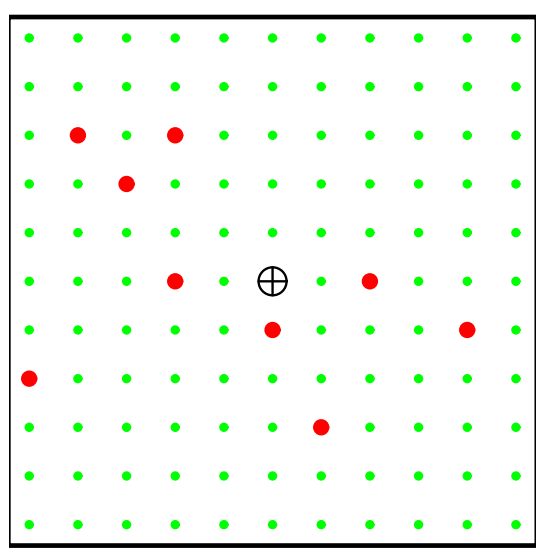

B

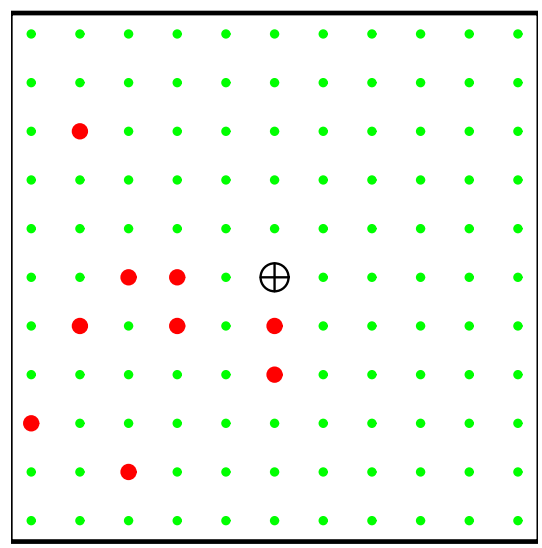

C

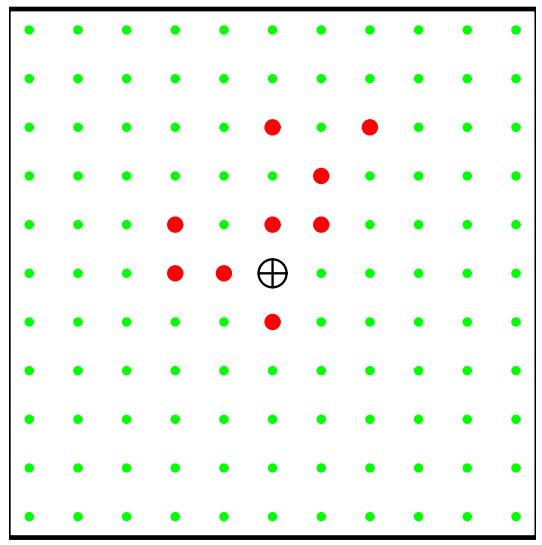

D

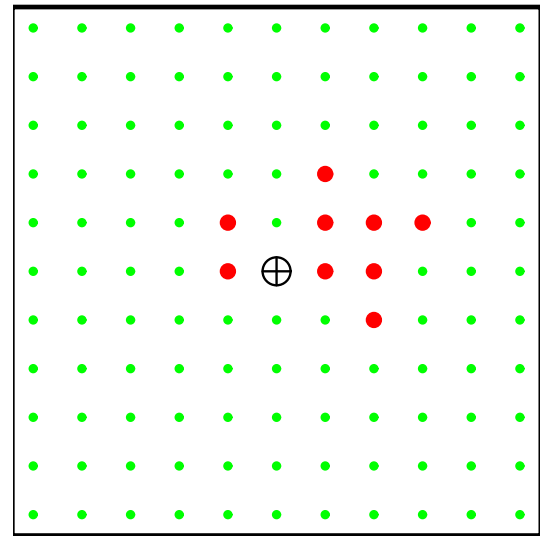

Figura 14 - Mapas simulados considerando um látice 11x11 e o modelo apresentado em (25), em que $\oplus$ representa a planta doente inicialmente, • são as novas plantas infectadas e $\bullet$ referem-se às plantas sadias. Os valores do parâmetro utilizados nas simulações foram: A. $\alpha=0,5$; B. $\alpha=1,0$; C. $\alpha=2,0$ e D. $\alpha=3,0$ 
Os gráficos com a verossimilhança exata e as aproximadas, considerando os látices da Figura 14, estão apresentados na Figura 15. Observa-se que os máximos das funções estão relacionados a valores de $\alpha$ muito próximos aos utilizados nas simulações, com exceção do caso da Figura 15D. Neste último gráfico, o comportamento da verossimilhança, com o aumento de $\alpha$, é muito diferente do que nos demais gráficos. Neste caso, a curva é assintótica, isto é, a verossimilhança tem um aumento significativo, com o aumento de $\alpha$, até um determinado ponto, a partir do qual a tendência é se tornar constante. Se a verossimilhança é aproximadamente a mesma, a partir de um determinado valor de $\alpha$, pode-se concluir que, qualquer valor acima deste, pode ser considerado como a estimativa de máxima verossimilhança, do parâmetro $\alpha$. Em termos práticos, isto significa que, a partir de um determinado valor de $\alpha$, em torno de 3,0, como pode ser observado na Figura 15D, as plantas infectadas se tornam tão agregadas que, qualquer valor de $\alpha$ acima deste, representaria o mesmo padrão espacial extremamente agregado. Este comportamento é perfeitamente coerente e dá suporte à afirmação de Pethybridge \& Madden (2003), de que valores do parâmetro em torno de 3,0 são considerados extremamente altos.

As estimativas de máxima verossimilhança do parâmetro $\alpha$, obtidas através do cálculo exato de $\pi(\alpha \mid \mathcal{E})$ e através das duas aproximações, para os casos das Figuras 15A, 15B e 15C, estão apresentadas na Tabela 3. A partir desses resultados, pode-se concluir que estima-se com acurácia o parâmetro do modelo considerado, através das três metodologias diferentes, pois os valores estimados são iguais ou muito próximos aos utilizados nas simulações. Uma grande diferença entre os três processos de estimação, está no tempo computacional gasto. A determinação da densidade exata, $\pi(\alpha \mid \mathcal{E})$, é bem mais demorada e pode ser obtida apenas quando se tem um número pequeno de novas infecções. 


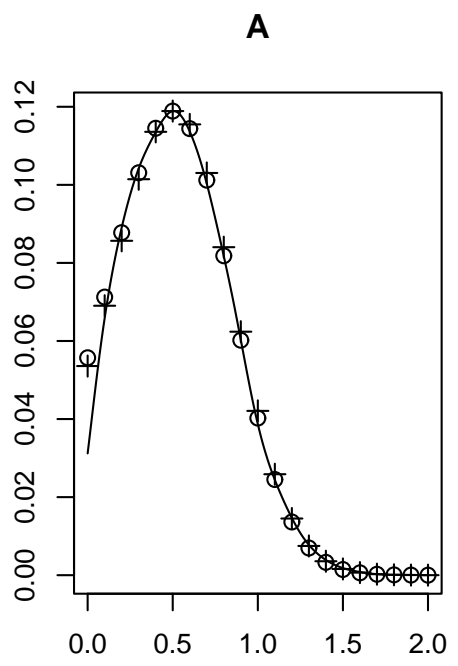

$\alpha$

C

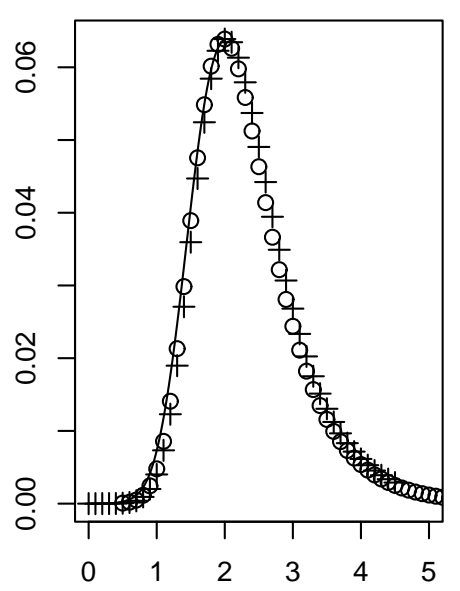

$\alpha$
B

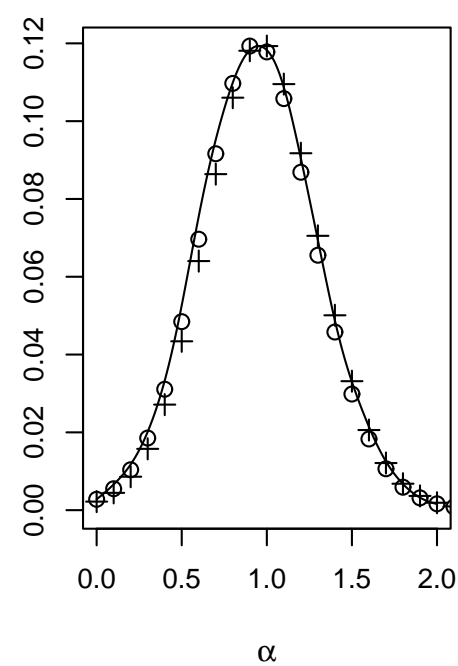

D

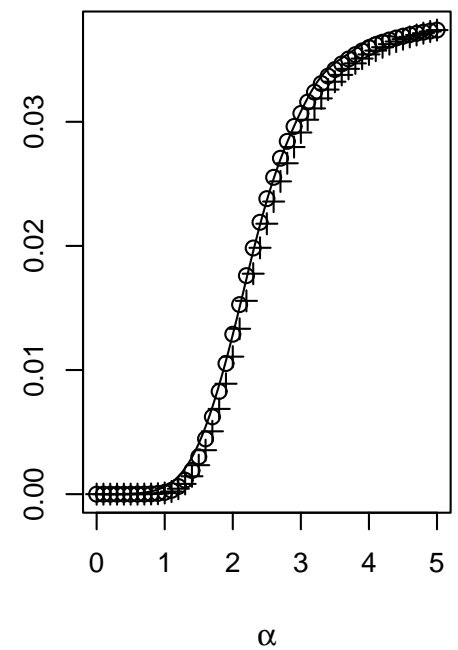

Figura 15 - Valor exato (o) e estimativas de $\pi(\alpha \mid \mathcal{E})$, obtidas pelo método proposto por Gibson (1997b) (+) e proposto neste trabalho (-), para os dados da Figura 14, considerando o modelo (25). Valores de $\alpha$ utilizados nas simulações: A. $\alpha=0,5$; B. $\alpha=1,0$; C. $\alpha=2,0$ e D. $\alpha=3,0$ 
Tabela 3. Estimativas de $\alpha$, do modelo (25), para o caso dos mapas apresentados nas Figuras 14A, 14B e 14C, obtidas através de três metodologias diferentes

\begin{tabular}{cccc}
\hline $\begin{array}{c}\text { Parâmetro } \\
\alpha \text { utilizado }\end{array}$ & $\pi(\alpha \mid \mathcal{E})$ & $\hat{\alpha}$ & \\
na simulação & Exata & Gibson (1997b) & proposta \\
\hline 0,5 & 0,5 & 0,5 & 0,5049 \\
1,0 & 0,9 & 1,0 & 0,9511 \\
2,0 & 2,0 & 2,0 & 2,0001 \\
\hline
\end{tabular}

Neste exemplo, com nove novas infecções, em um computador com processador AMD Athlon XP 2000+, com 512 MB de RAM, foram necessários em torno de 30min, na determinação da verossimilhança exata, para os látices apresentados nas Figuras 14A e 14B e de 70min, para cada um dos mapas das Figuras 14C e 14D. Apesar de se ter o mesmo número de novas infecções nos quatro látices, o tempo nos dois primeiros é bem menor, devido ao fato de que, o intervalo do parâmetro $\alpha$ considerado nas análises, é menor. Nas análises dos látices das Figuras 14A e 14B, o conjunto de valores discretos de $\alpha$ é dado por $\{0,0,1,0,2, \ldots, 2,0\}$, enquanto que, no caso das Figuras $14 \mathrm{C}$ e $14 \mathrm{D}$, tem-se o conjunto $\{0,0,1,0,2, \ldots, 5,0\}$. Isto exemplifica muito bem, o quanto é dispendioso o cálculo envolvendo $N$ ! $\omega$ 's, para cada um dos valores discretos de $\alpha$.

O tempo computacional gasto nas duas aproximações é bem menor do que na exata. Utilizando o mesmo computador, na análise de cada um dos látices apresentados na Figura 14, foram gastos em torno de 7min, utilizando-se a metodologia original de Gibson, considerando-se os mesmos intervalos para $\alpha$ utilizados na determinação da verossimilhança exata. Porém, o efeito da diferença na amplitude dos intervalos, bastante evidente na análise anterior, foi desprezível. No caso da aproximação obtida utilizando-se a nova metodologia proposta, foram necessários apenas 2min, em cada uma das quatro análises. Apesar de o tempo gasto na determinação 
das verossimilhança aproximadas, $7 \mathrm{~min}$ ou $2 \mathrm{~min}$, não ser um tempo excessivamente grande, vale lembrar que este é apenas um pequeno exemplo e que, na prática, látices bem maiores e com número bem maior de plantas doentes são comuns. Assim, vale ressaltar o ganho significativo, em termos de tempo computacional gasto nas análises, da metodologia original para a proposta neste trabalho.

\subsubsection{Dados simulados a partir de um modelo com dois parâmetros}

Os mapas com as infecções simuladas, utilizando-se o modelo apresentado na eq. (26), estão apresentados na Figura 16. Pode-se observar que, nos mapas apresentados nas Figuras 16A, 16B, 16C, a tendência é de se formarem grupos de plantas doentes, mas com padrões espaciais bem diferentes, enquanto que, no mapa da Figura 16D, as plantas doentes estão localizadas de uma forma mais espalhada por toda a área, característica de um padrão espacial aleatório.

Na realidade, o látice da Figura 16D foi obtido sob a condição de que as plantas infectadas estivessem localizadas de uma forma completamente aleatória, pois os parâmetros utilizados na simulação foram: $\alpha_{1}=0,1$ e $\alpha_{2}=0$. Na situação em que $\alpha_{2}$ é nulo, para qualquer valor positivo de $\alpha_{1}$, qualquer planta sadia tem a mesma probabilidade de se tornar doente, independente de sua localização em relação às plantas doentes do látice, em qualquer tempo $t$. Esta afirmação é facilmente confirmada, observando-se o processo de simulação, apresentado em 3.1.1. No cálculo da probabilidade de uma planta sadia ser infectada, o termo que leva em consideração

a distância entre uma planta sadia $x$ e uma planta doente $y,|y-x|^{-2 \alpha_{2}}$, sempre será igual a um, pois $\alpha_{2}=0$. Assim, a chance de uma planta sadia ser infectada, em um tempo $t$, independe da sua localização e da sua distância, em relação às plantas doentes. Nesta simulação, a ocorrência de plantas doentes mais próximas é simplesmente devido ao acaso. 
A

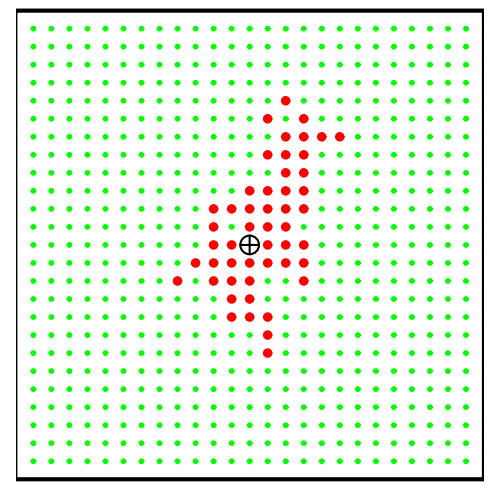

C

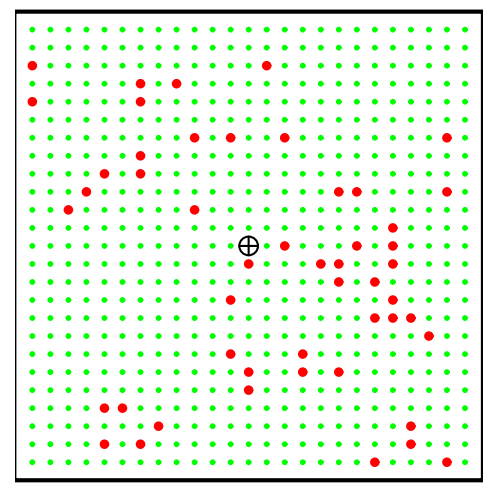

B

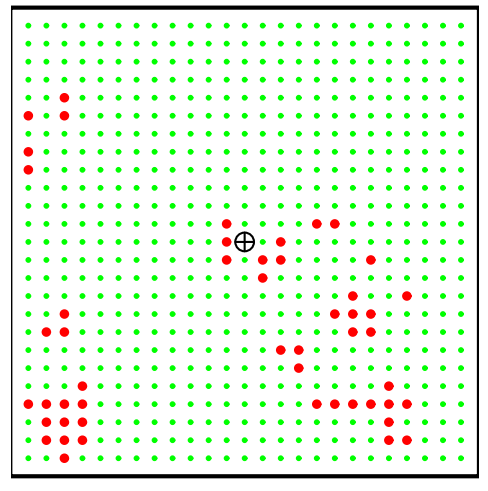

D

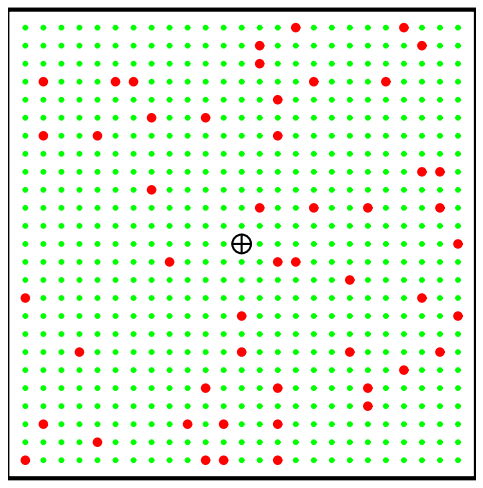

Figura 16 - Mapas simulados considerando um látice 25x25 e utilizando o modelo apresentado em (26), em que $\oplus$ representa a planta doente inicialmente, - são as novas plantas doentes e • são as plantas sadias. Os valores dos parâmetros utilizados foram: A. $\alpha_{1}=0,1, \alpha_{2}=0$; B. $\alpha_{1}=0, \alpha_{2}=2,0$; C. $\alpha_{1}=0,1, \alpha_{2}=2,0$ e D. $\alpha_{1}=0,1, \alpha_{2}=1,0$ 
Na Figura 16A, foram utilizados $\alpha_{1}=0$ e $\alpha_{2}=2,0$, no processo de simulação, o que representa a situação na qual a infecção ocorre apenas entre plantas dentro de um mesmo talhão. $\mathrm{O}$ valor de $\alpha_{2}=2,0$ é considerado alto, o que indica que a transmissão da doença ocorre apenas em curtas distâncias. Assim, conforme pode ser visto na Figura 16A, tem-se a presença de um único grupo, muito bem definido, de plantas doentes bastante agregadas. Assim, pode-se concluir que, a disseminação da doença ocorre apenas entre plantas vizinhas, ou seja, da planta infectada para as plantas sadias mais próximas.

Analisando visualmente os padrões espaciais apresentados nas Figuras 16B e 16C, pode-se observar que estes são completamente diferentes do padrão espacial no caso da Figura 16A. Porém, observa-se que as plantas doentes também tendem a se localizar, umas próximas das outras, mas formando pequenos grupos de plantas doentes, que estão distribuídos pela área. Estes tipos de padrões espaciais são característicos de situações nas quais a disseminação da doença, também ocorre entre plantas próximas, porém, existe outra fonte de infecção, que favorece o aparecimento de outros focos de infecção mais distantes, como por exemplo, uma fonte externa de infecção ou a presença de um vetor, que favorece a disseminação da doença, para pontos mais distantes dos focos de infecção, dentro da mesma área. A diferença entre os padrões espaciais das Figuras 16B e 16C, que pode ser visualmente identificada, está no grau de agregação dos pequenos grupos, o que é reflexo dos diferentes parâmetros utilizados nas simulações. Enquanto que, na Figura 16B foram utilizados $\alpha_{1}=0,1$ e $\alpha_{2}=2,0$, na Figura 16C utilizaram-se $\alpha_{1}=0,1$ e $\alpha_{2}=1,0$. Assim, na Figura 16B, as plantas doentes estão mais próximas ou mais agregadas, formando pequenos grupos mais bem definidos do que na Figura 16C, pois o parâmetro $\alpha_{2}$ é maior, o que significa que a infecção de uma planta sadia por uma planta doente, ocorre apenas entre plantas vizinhas mais próximas. Observa-se na Figura 16C, que a localização das plantas doentes já se torna mais dispersa pela área, apesar de existirem grupos de plantas doentes, mas não muito agregadas, formando grupos bem definidos, como na Figura 16B. Este comportamento é explicado pelo fato de que $\alpha_{2}$ 
é menor na Figura 16C, o que significa que, a transmissão da doença de uma planta infectada para uma planta sadia, pode ocorrer em distâncias maiores do que no caso da Figura 16B. Porém, vale ressaltar que à medida que o parâmetro $\alpha_{1}$ aumenta, a tendência é a de ocorrerem padrões espaciais menos agregados, até se chegar a uma disposição completamente aleatória das plantas doentes.

Os mapas apresentados na Figura 16 são exemplos muito bons, de como a simulação de dados favorece a descrição e o entendimento do processo de disseminação de uma doença em plantas, explicado através de modelos estocásticos. Além disso, é fácil visualizar o que acontece com o padrão espacial, ao se considerarem diferentes valores para os parâmetros do modelo. Isso auxilia na compreensão do que realmente representam os parâmetros no modelo, o que favorece na interpretação dos resultados obtidos em análises de outros conjuntos de dados. Observando os mapas da Figura 16, pode-se concluir que, apesar do processo de disseminação de uma determinada doença envolver a interação de vários fatores, este processo pode ser descrito através de um modelo estocástico, relativamente simples. Portanto, o modelo apresentado em (26), pode ser utilizado na descrição de diferentes padrões espaciais, o que está diretamente ligado aos mecanismos de dispersão de uma doença em plantas, com base em apenas dois parâmetros: $\alpha_{1}$, que está relacionado a fontes externas de infecção ou mecanismos de dispersão da doença, a longas distâncias e $\alpha_{2}$, que está associado à transmissão da doença entre plantas vizinhas.

As verossimilhanças aproximadas, obtidas utilizando-se a metodologia proposta por Gibson e a proposta neste trabalho, considerando-se os mapas apresentados na Figura 16A, 16B, 16C e 16D, estão apresentadas, respectivamente, nas Figuras 17, 18, 19 e 20. Com exceção da Figura 20, nas demais observa-se um máximo bastante evidente, em torno dos valores utilizados nas simulações. Como já foi dito, estes máximos estão associados às estimativas de máxima verossimilhança dos parâmetros do modelo, que estão apresentadas na Tabela 4. 

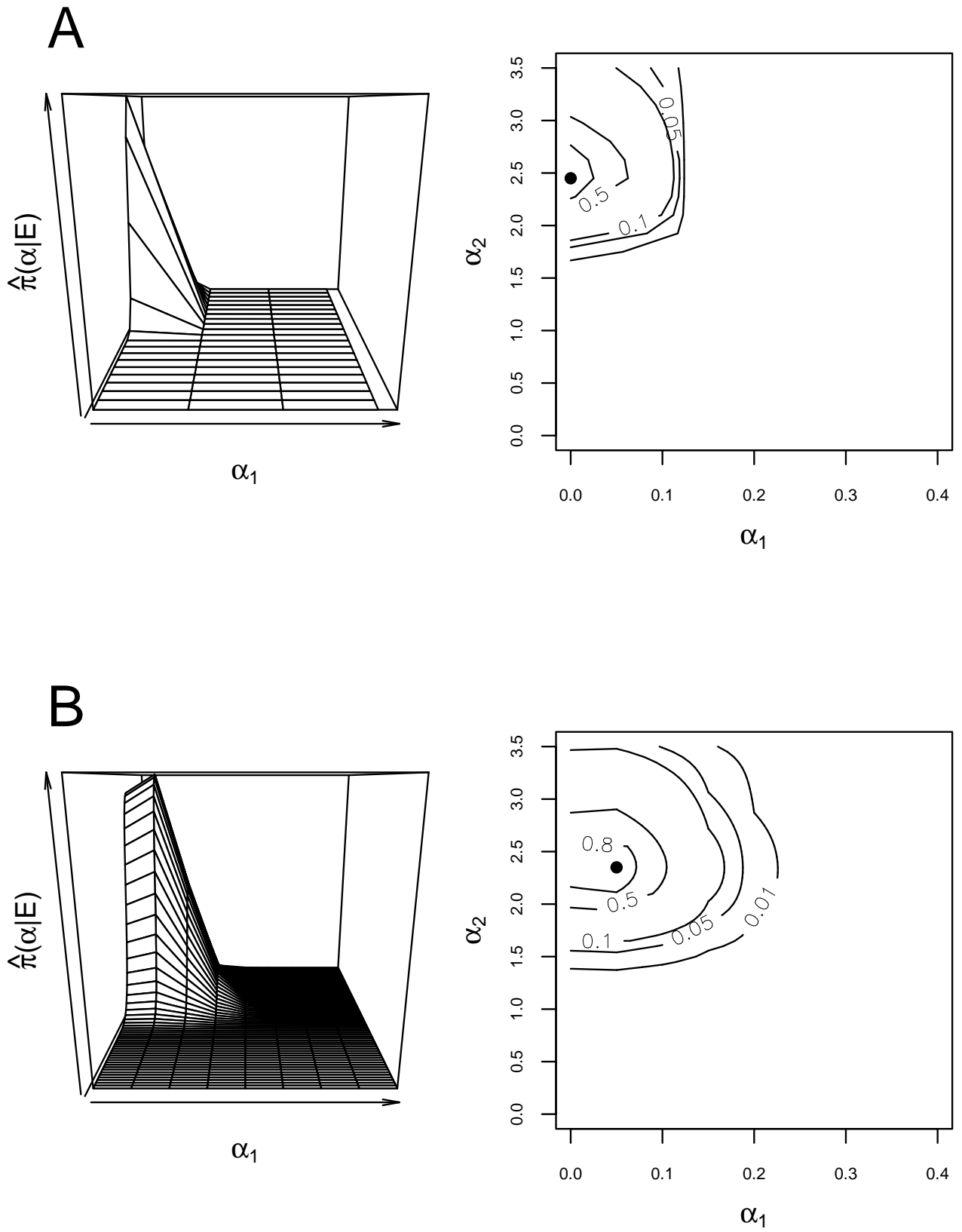

Figura 17 - Gráficos com as verossimilhanças aproximadas, $\hat{\pi}(\boldsymbol{\alpha} \mid \mathcal{E})$, padronizadas, de tal forma que o máximo seja igual a 1,0 e gráficos de contornos, obtidos utilizandose as metodologias de Gibson (A) e proposta (B), considerando o látice apresentado na Figura 16A, simulado utilizando-se o modelo (26), com parâmetros: $\alpha_{1}=0$ e $\alpha_{2}=2$, em que $\bullet$ representa o máximo da verossimilhança 

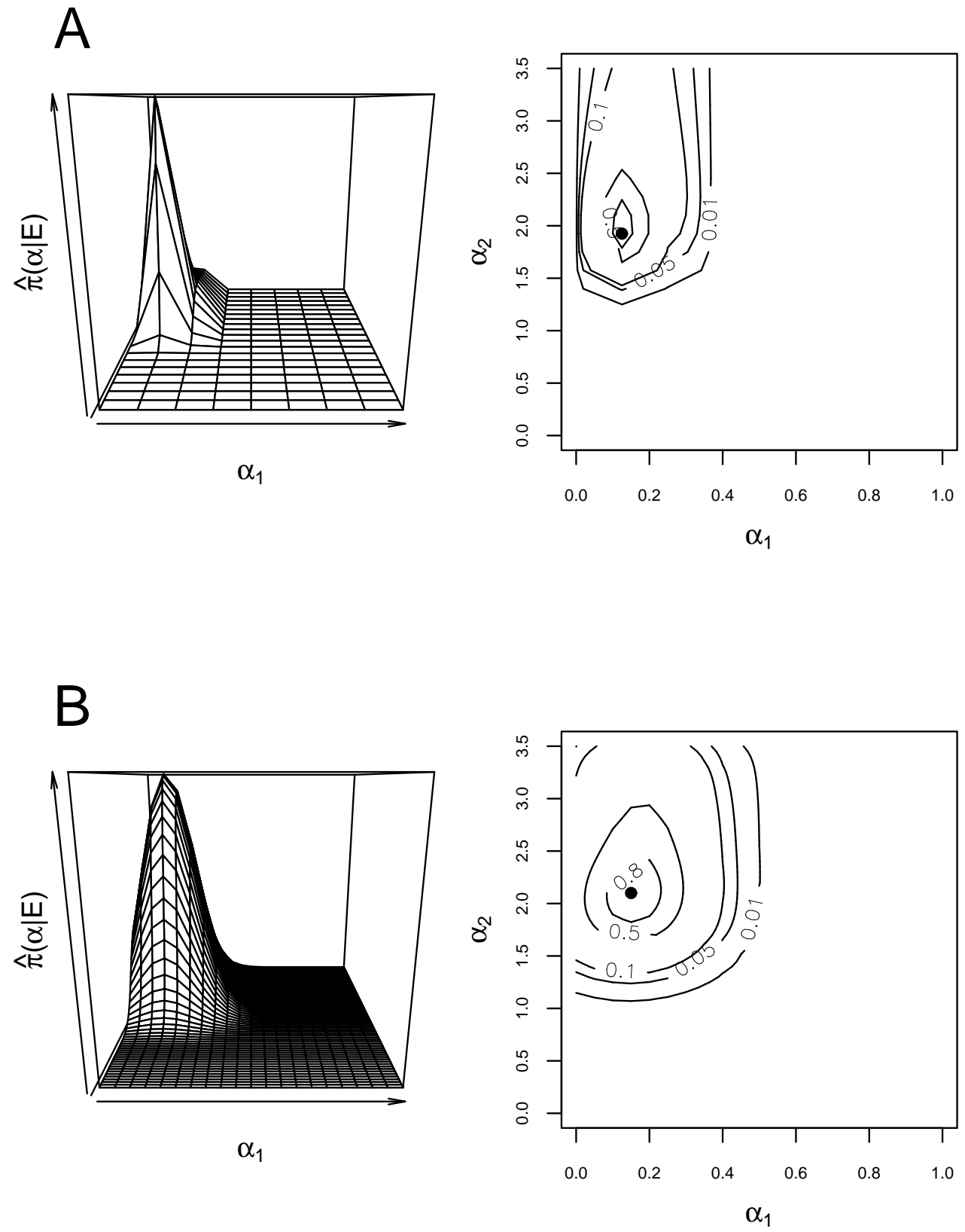

Figura 18 - Gráficos com as verossimilhanças aproximadas, $\hat{\pi}(\boldsymbol{\alpha} \mid \mathcal{E})$, padronizadas, de tal forma que o máximo seja igual a 1,0 e gráficos de contornos, obtidos utilizandose as metodologias de Gibson (A) e proposta (B), considerando o látice apresentado na Figura 16B, simulado utilizando-se o modelo (26), com parâmetros: $\alpha_{1}=0,1$ e $\alpha_{2}=2$, em que $\bullet$ representa o máximo da verossimilhança 

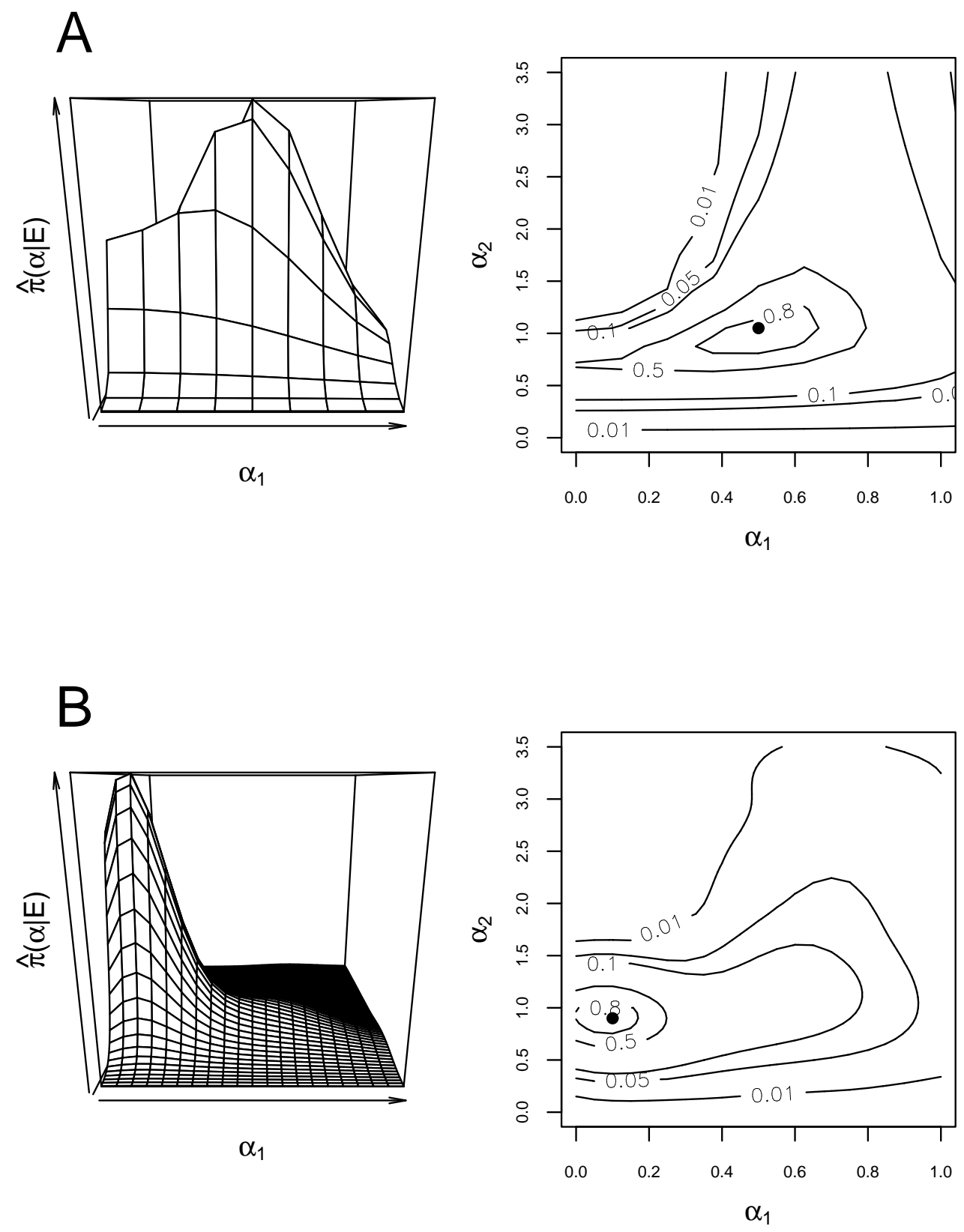

Figura 19 - Gráficos com as verossimilhanças aproximadas, $\hat{\pi}(\boldsymbol{\alpha} \mid \mathcal{E})$, padronizadas, de tal forma que o máximo seja igual a 1,0 e gráficos de contornos, obtidos utilizandose as metodologias de Gibson (A) e proposta (B), considerando o látice apresentado na Figura 16C, simulado utilizando-se o modelo (26), com parâmetros: $\alpha_{1}=0,1$ e $\alpha_{2}=1$, em que $\bullet$ representa o máximo da verossimilhança 

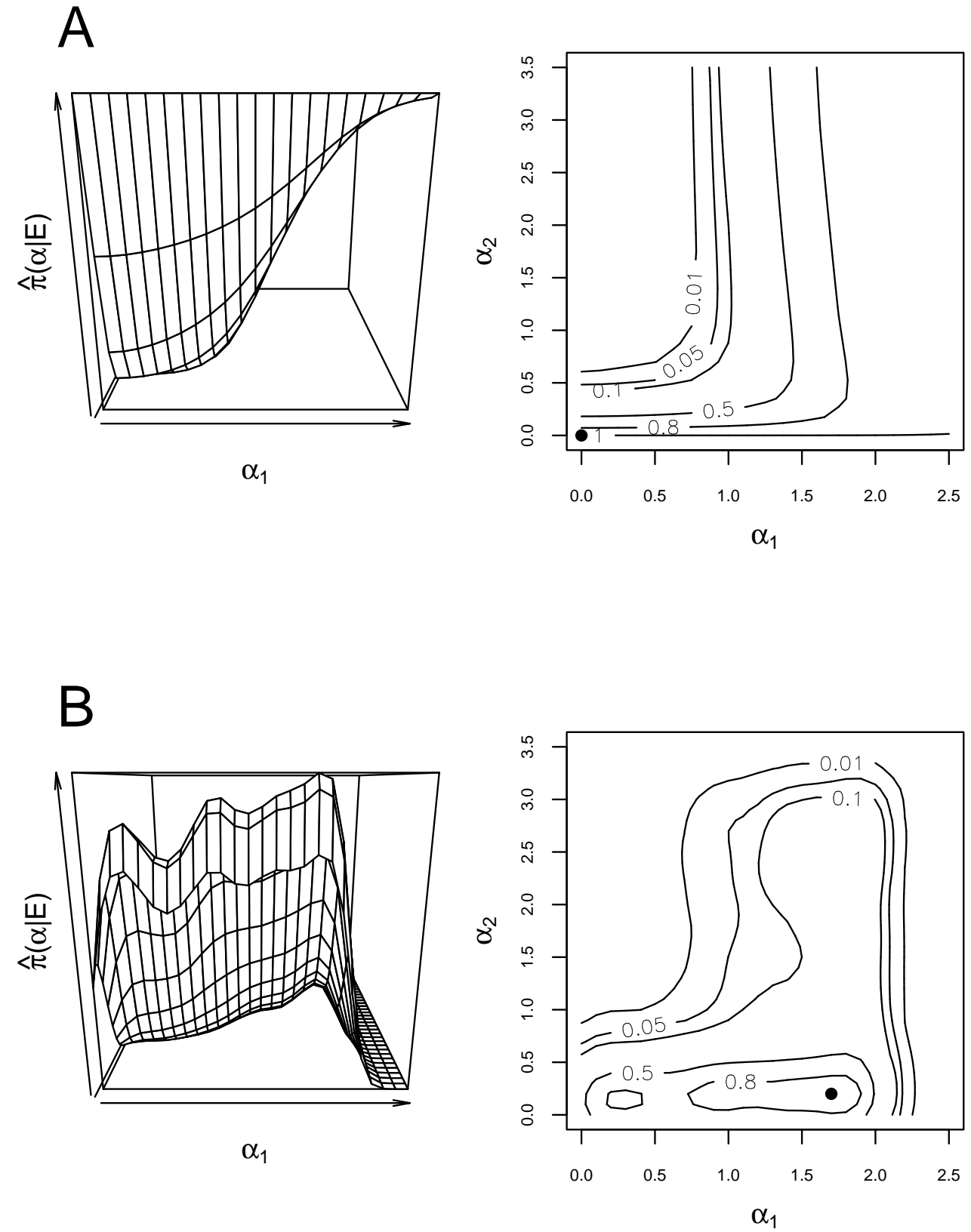

Figura 20 - Gráficos com as verossimilhanças aproximadas, $\hat{\pi}(\boldsymbol{\alpha} \mid \mathcal{E})$, padronizadas, de tal forma que o máximo seja igual a 1,0 e gráficos de contornos, obtidos utilizandose as metodologias de Gibson (A) e proposta (B), considerando o látice apresentado na Figura 16D, simulado utilizando-se o modelo (26), com parâmetros: $\alpha_{1}=0,1$ e $\alpha_{2}=0$ 
Tabela 4. Estimativas de $\alpha_{1}$ e $\alpha_{2}$, do modelo (26), para o caso dos látices apresentados na Figura 16

\begin{tabular}{|c|c|c|c|c|}
\hline \multirow{3}{*}{$\begin{array}{c}\text { Parâmetros utilizados } \\
\text { na simulação }\end{array}$} & \multirow{2}{*}{\multicolumn{2}{|c|}{$\begin{array}{l}\text { Metodologia de } \\
\text { Gibson (1997b) }\end{array}$}} & \multirow{2}{*}{\multicolumn{2}{|c|}{$\begin{array}{c}\text { Metodologia } \\
\text { proposta }\end{array}$}} \\
\hline & & & & \\
\hline & $\hat{\alpha}_{1}$ & $\hat{\alpha}_{2}$ & $\hat{\alpha}_{1}$ & $\hat{\alpha}_{2}$ \\
\hline A. $\alpha_{1}=0,0$ e $\alpha_{2}=2,0$ & 0,00 & 2,45 & 0,02 & 2,32 \\
\hline B. $\alpha_{1}=0,1$ e $\alpha_{2}=2,0$ & 0,12 & 1,92 & 0,16 & 2,08 \\
\hline C. $\alpha_{1}=0,1$ e $\alpha_{2}=1,0$ & 0,5 & 1,05 & 0,08 & 0,92 \\
\hline D. $\alpha_{1}=0,1$ e $\alpha_{2}=0,0$ & - & - & - & - \\
\hline
\end{tabular}

Pode-se observar, na Tabela 4 e nas Figuras 17, 18 e 19, que as estimativas obtidas estão bastante próximas dos parâmetros utilizados na simulação, indicando que, em ambas aproximações, estimam-se, com bastante acurácia, os parâmetros do modelo. Como por exemplo, no látice apresentado na Figura 16B, foram utilizados os parâmetros $\alpha_{1}=0,1$ e $\alpha_{2}=2,0$ na simulação, obtendo-se as estimativas $\hat{\alpha}_{1}=0,12$ e $\hat{\alpha}_{2}=1,92$, através da metodologia de Gibson e $\hat{\alpha}_{1}=0,16$ e $\hat{\alpha}_{2}=2,08$, pela metodologia proposta. Observa-se que, no caso da Figura 17, em que os parâmetros utilizados na simulação foram $\alpha_{1}=0$ e $\alpha_{2}=2,0$, que as estimativas de $\alpha_{2}$ obtidas, estão um pouco acima do valor utilizado na simulação, isto é, estimativas iguais a 2,45 e 2,32, nas metodologias de Gibson e proposta, respectivamente. Como já foi dito, este resultado é perfeitamente aceitável. O importante é verificar a coerência das estimativas obtidas. Uma única discrepância, pode ser observada na estimativa de $\alpha_{1}$, obtida pela metodologia de Gibson, para o caso do látice da Figura 11C. Na simulação, foi utilizado $\alpha_{1}=0,1$, mas as estimativas obtidas pelas duas aproximações são muito diferentes. Enquanto a estimativa obtida através da metodologia proposta neste trabalho, $\hat{\alpha}_{1}=0,08$, está próxima do valor utilizado na simulação, a obtida através da metodologia original foi igual a 0,5, o que está muito distante. Este valor superestimado pode ser um problema com a metodologia origi- 
nal, o que é pouco provável, ou é apenas um problema de simulação, que pode ter acontecido devido ao acaso, o que é mais provável. O que pode ser feito para a verificação se existe algum problema mais grave, é obter várias estimativas, utilizando-se ambas as metodologias e verificar se, em média, as estimativas estarão coerentes com o valor utilizado na simulação e se existe coerência nos resultados obtidos pelas duas aproximações.

O comportamento da verossimilhança na Figura 20 é muito diferente das demais, porém está perfeitamente coerente com o padrão espacial apresentado pelos dados simulados. Nesta situação, em que se utilizaram os parâmetros $\alpha_{1}=0,1$ e $\alpha_{2}=0$, tem-se um padrão espacial aleatório. De acordo com o modelo utilizado, apresentado na eq. (26), o padrão espacial aleatório, como já foi dito, pode acontecer em duas situações: 1 . quando $\alpha_{2}=0$ e $\alpha_{1}$ assume qualquer valor positivo e 2. quando o valor de $\alpha_{1}$ é muito alto, geralmente maior do que 2,5 e $\alpha_{2}$ assume qualquer valor positivo. Portanto, observa-se na Figura 20, que as verossimilhanças aproximadas estão coerentes com a primeira situação. Na Figura 20A, em que se utiliza a metodologia original de Gibson, o máximo da superfície está em $\alpha_{2}=0$, para qualquer valor de $\alpha_{1}$ do conjunto $\{0,0,125, \ldots, 2,5\}$, sendo esta região de máximo de $\hat{\pi}(\boldsymbol{\alpha} \mid \mathcal{E})$, muito bem caracterizada. Na Figura 20B, esta região de máximo não está tão bem definida como na Figura 20A, devido ao processo utilizado para a obtenção da verossimilhança, a partir da amostra obtida dos parâmetros. No método proposto, em uma situação como esta, a tendência é que valores maiores de $\alpha_{1}$, tenham uma aceitação maior no algoritmo de Metropolis-Hastings. Porém, o que importa é o comportamento geral da verossimilhança, o que levará às conclusões sobre o padrão espacial. Na Figura 20B, observa-se que a tendência é de se ter um máximo na região de $\alpha_{2}$ próximo de zero, para qualquer valor de $\alpha_{1}$ no intervalo definido. Portanto, pode-se concluir que este comportamento da verossimilhança está associado a um padrão espacial aleatório.

Os tempos gastos nas análises, utilizando-se o mesmo computador já citado, foram bastante diferentes, entre as duas metodologias. Na metodologia ori- 
ginal foram gastas pouco mais de duas horas, para a análise de cada um dos látices da Figura 16, enquanto que, com a metodologia proposta neste trabalho, foram necessários 26 minutos. Com a metodologia proposta, foi gerada uma cadeia com 11000 iterações. Porém, uma cadeia em torno de 5000 a 6000 iterações, seria suficiente, conforme pôde ser verificado através de outros estudos realizados, nos quais as estimativas foram obtidas com uma amostra de tamanho 5000, considerando-se um burn-in de 1000 iterações. Assim, o tempo das análises, utilizando-se a metodologia proposta, seria ainda menor. Este ganho, em termos de tempo computacional gasto nas análises, pode parecer não muito significativo, se for considerado a caso da análise de um ou de poucos látices ou talhões. Porém, se o número de talhões a serem analisados for grande, com a diminuição pra 15 ou $20 \%$ do tempo gasto inicialmente, tem-se um ganho enorme de tempo nas análises, sem perda de acurácia nas estimativas obtidas.

\subsection{Dados reais}

\subsubsection{Tristeza dos citros}

Os dados de tristeza dos citros, apresentados previamente, são analisados considerando o modelo com um único parâmetro $\alpha$, apresentado em (25). Este modelo também foi utilizado por Gibson (1997b), no ajuste de modelos estocásticos espaço-temporais, considerando esses mesmos dados. As verossimilhanças estimadas, referentes estão apresentadas na Figura 21. Ambos os gráficos reproduzem exatamente os resultados obtidos por Gibson (1997b), o que é uma garantia de que os programas utilizados nas análises foram implementados corretamente.

A Figura 21A, refere-se à análise das infecções ou plantas doentes, identificadas no ano de 1981. Nesse caso foram obtidas as seguintes estimativas: $\hat{\alpha}=1,13$, pela metodologia de Gibson e $\hat{\alpha}=1,12$, utilizando o processo de estimação proposto. Na Figura 21B, a qual refere-se às verossimilhanças estimadas para os 
dados da avaliação no ano de 1982, têm-se $\hat{\alpha}=1,3$ e 1,33, para as metodologias de Gibson e proposta neste trabalho, respectivamente. Portanto, observa-se que não existe praticamente diferença entre as estimativas, obtidas pelas duas metodologias. Novamente, a grande vantagem está no tempo de análise. No caso das análises de 1981, em que se tinham 131 novas infecções, foi necessário em torno de uma hora, na análise utilizando-se o processo proposto. Com a metodologia original, no mesmo computador, foram necessárias por volta de 7 horas. Para as análises de 1982 não foi muito diferente. Foram necessárias 2,5 horas e 30min, nos casos da metodologia original e proposta, respectivamente. Assim, tem-se um ganho substancial em termos de tempo da análise, com as modificações propostas, sem uma alteração significativa nas estimativas.
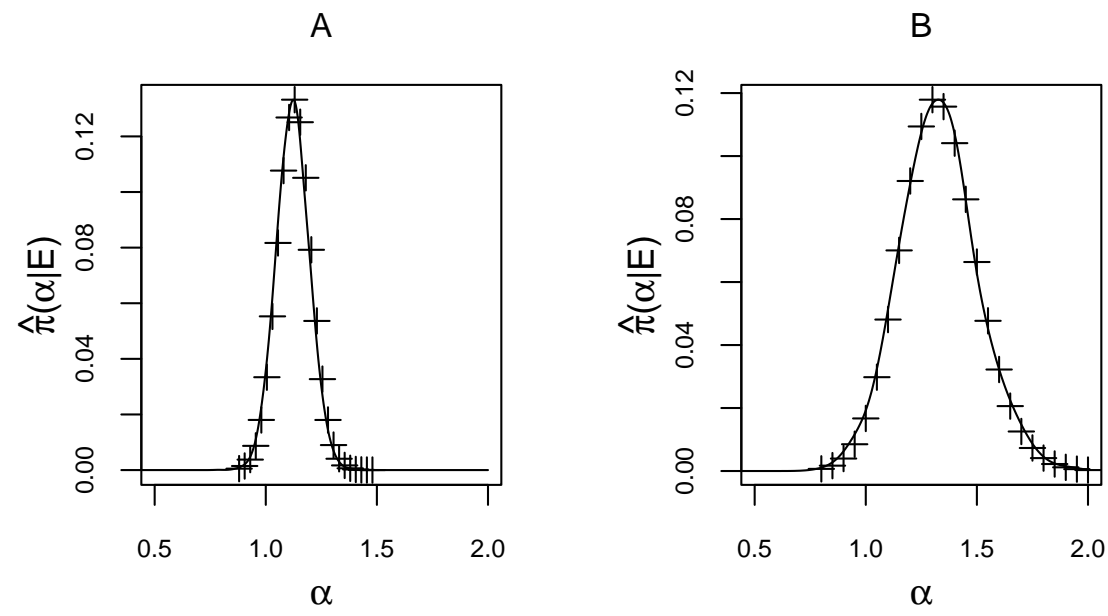

Figura 21 - Estimativas de $\pi(\alpha \mid \mathcal{E})$, obtidas pelo método proposto por Gibson (1997b) $(+)$ e proposto neste trabalho (-), para os dados da Figura 12, considerando o modelo (25)

Pode-se observar na Figura 21 que a incerteza, com relação ao parâmetro $\alpha$, é maior no caso dos dados de 1982, quando se tinham apenas 45 novas infecções. A menor incerteza em 1981, está associada diretamente ao número 
de plantas doentes nesse ano, que é igual a 131. Portanto, pode-se concluir que as 131 novas infecções de 1981 fornecem muito mais informação sobre o parâmetro do modelo, do que as 45 de 1982.

\subsubsection{Viroses do lúpulo}

Nas Figuras 22, 23 e 24 estão apresentadas as verossimilhanças estimadas, assim como os gráficos de contornos, para os dados das viroses do lúpulo, HpLV, HpMV e ApMV, respectivamente. Nesse conjunto de dados, é considerado o modelo com dois parâmetros, $\alpha_{1}$ e $\alpha_{2}$, assim como nas análises apresentadas por Pethybridge \& Madden (2003). Novamente, os resultados obtidos coincidem com os resultados já publicados. Assim, tem-se uma maior confiabilidade nos programas desenvolvidos para se executarem as análises.

As estimativas obtidas pelas duas metodologias estão bastante próximas, conforme pode ser visto na Tabela 5. Além disso, pode-se observar que as estimativas obtidas neste trabalho são as mesmas ou praticamente as mesmas obtidas por Pethybridge \& Madden (2003), as quais foram: $\hat{\alpha}_{1}=0$ e $\hat{\alpha}_{2}=3,5$, no caso da $\operatorname{HpLV}, \hat{\alpha}_{1}=1,25$ e $\hat{\alpha}_{2}=3,5$, para a HpMV e $\hat{\alpha}_{1}=1,35$ e $\hat{\alpha}_{2}=3,5$, para a ApLV.

Tabela 5. Estimativas de $\alpha_{1}$ e $\alpha_{2}$, do modelo (26), para o caso dos látices apresentados na Figura 13

\begin{tabular}{ccccc}
\hline & \multicolumn{2}{c}{ Metodologia de } & \multicolumn{2}{c}{ Metodologia } \\
& \multicolumn{2}{c}{ Gibson $(1997 \mathrm{~b})$} & \multicolumn{2}{c}{ proposta } \\
Virose & $\hat{\alpha}_{1}$ & $\hat{\alpha}_{2}$ & $\hat{\alpha}_{1}$ & $\hat{\alpha}_{2}$ \\
\hline HpLV & 0,00 & 3,5 & 0,05 & 3.42 \\
HpMV & 1,25 & 3,5 & 1,2 & 3,37 \\
ApMV & 1,35 & 3,5 & 1,10 & 3,31 \\
\hline
\end{tabular}



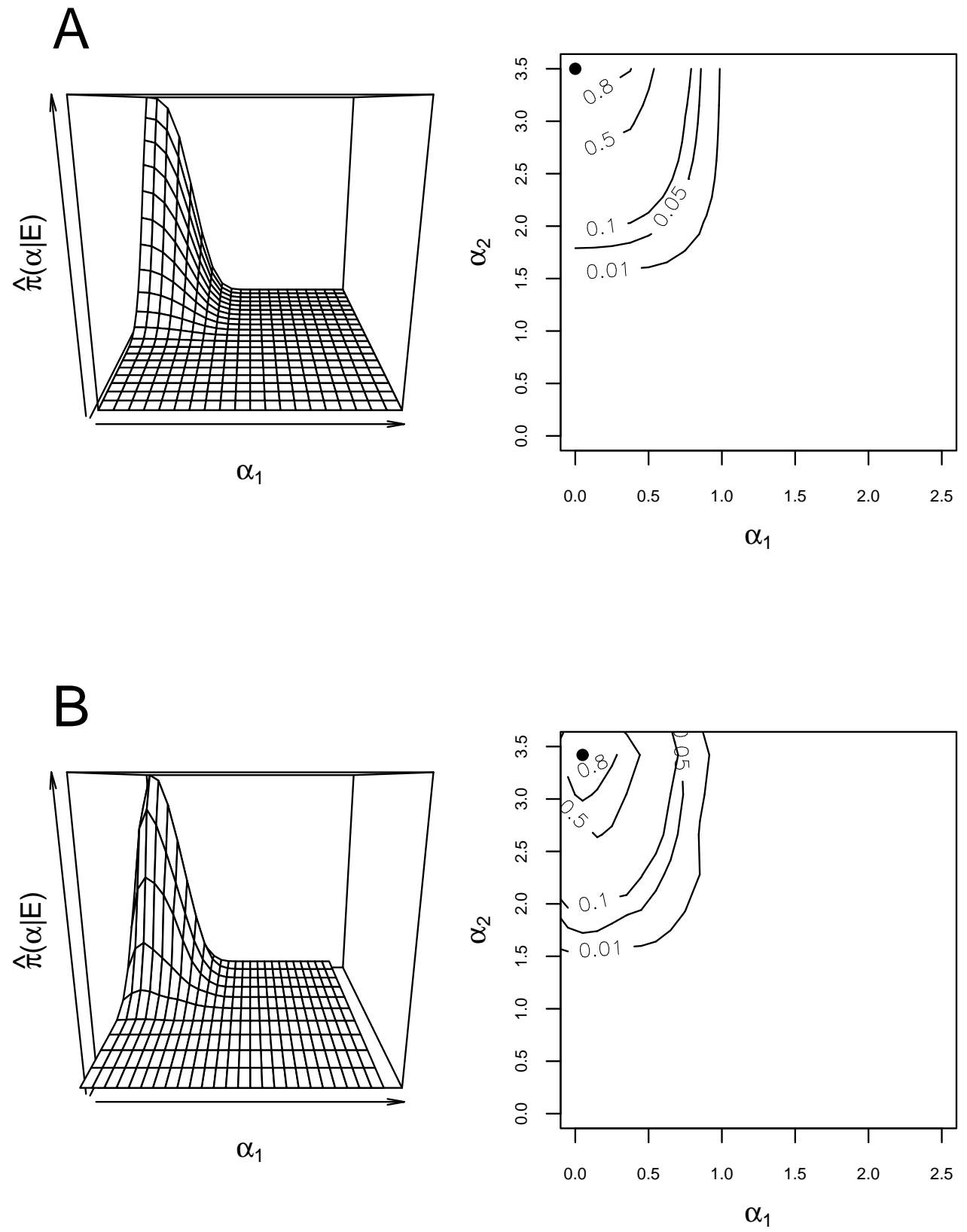

Figura 22 - Gráficos com as verossimilhanças aproximadas, $\hat{\pi}(\boldsymbol{\alpha} \mid \mathcal{E})$, padronizadas, de tal forma que o máximo seja igual a 1,0 e gráficos de contornos, obtidos utilizandose as metodologias de Gibson (A) e proposta (B), considerando o látice apresentado na Figura 13A e o modelo (26). • representa o máximo da verossimilhança 

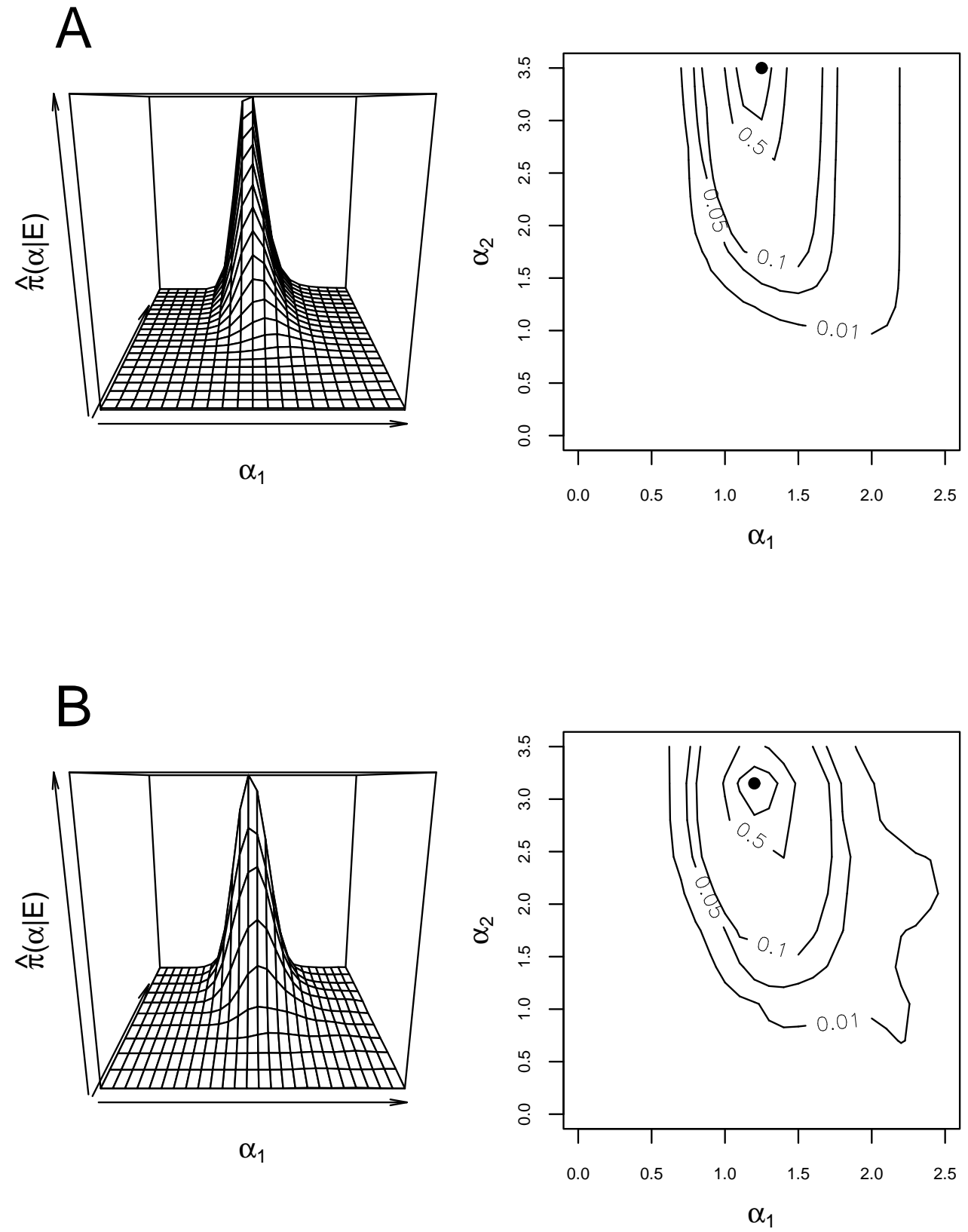

Figura 23 - Gráficos com as verossimilhanças aproximadas, $\hat{\pi}(\boldsymbol{\alpha} \mid \mathcal{E})$, padronizadas, de tal forma que o máximo seja igual a 1,0 e gráficos de contornos, obtidos utilizandose as metodologias de Gibson (A) e proposta (B), considerando o látice apresentado na Figura 13B e o modelo (26). • representa o máximo da verossimilhança 

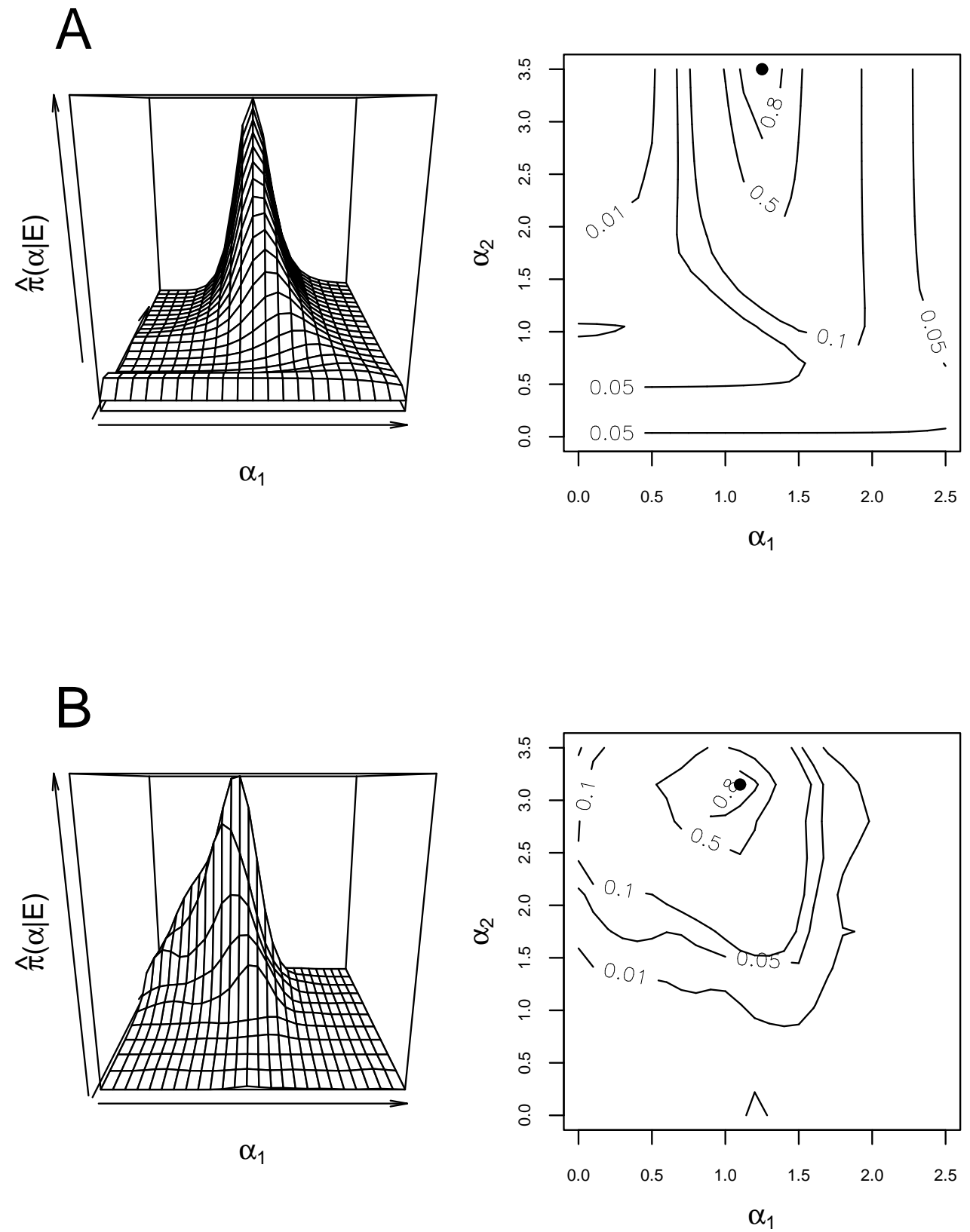

Figura 24 - Gráficos com as verossimilhanças aproximadas, $\hat{\pi}(\boldsymbol{\alpha} \mid \mathcal{E})$, padronizadas, de tal forma que o máximo seja igual a 1,0 e gráficos de contornos, obtidos utilizandose as metodologias de Gibson (A) e proposta (B), considerando o látice apresentado na Figura 13C e o modelo (26). • representa o máximo da verossimilhança 
Como conclusões práticas desses, tem-se que, para qualquer uma das três viroses, é bastante evidente que a transmissão da doença ocorre para plantas vizinhas, muito próximas, pois obtiveram-se estimativas altas para o parâmetro $\alpha_{2}$. Além disso, no caso de HpMV e ApMV, tem-se, associada à transmissão da doença para as vizinhas, uma fonte de infecção externa ao látice, uma vez que valores de $\hat{\alpha}_{1}>1$, diferente de $\mathrm{HpLV}$, em que $\hat{\alpha}_{1}$ pode ser considerada como nula.

É importante destacar que, apesar de as estimativas estarem muito próximas, um pequeno problema foi detectado durante as análises, isto é, com a metodologia proposta, tem-se uma maior dificuldade de se estimarem valores extremos. Não que seja um problema do processo em si, é um problema devido à maneira como se obtém a superfície, utilizando-se técnicas de suavização de uma curva ou superfície. Uma maneira de se contornar esse problema, é definindo intervalos mais amplos para os parâmetros, isto é, alterando-se as informações que se têm, a priori, sobre os parâmetros.

\subsubsection{Cancro cítrico}

Nesse trabalho são apresentados os resultados das análises de apenas três diferentes talhões: C02, K026 e K097. Outros talhões também foram analisados e seus resultados serão apresentados posteriormente em artigos científicos.

As verossimilhanças estimadas pelas duas metodologias e os gráficos de contornos estão apresentados nas Figuras 25, 26 e 27, as quais referem-se, respectivamente, aos talhões C02, K026 e K097. As estimativas obtidas para os parâmetros $\alpha_{1}$ e $\alpha_{2}$, do modelo dado na eq. (26), estão apresentadas na Tabela 6 .

Novamente, percebe-se uma enorme concordância entre os resultados, o que vem dar mais suporte à nova metodologia proposta neste trabalho. Foram escolhidos mapas que apresentassem padrões espaciais visualmente diferentes, com intuito de verificar se a técnica do ajuste de modelos estocásticos, conseguiria detectar essas diferenças, no caso de dados reais. 
O talhão C02, conforme pode ser visto na Figura 10, apresenta um único grupo, muito bem definido, de plantas agregadas. Essa particularidade foi detectada com as duas metodologias, pois têm-se estimativas de $\alpha_{1}$ nulas, ou praticamente nulas, e um valor de $\hat{\alpha}_{2}$ bastante alto, próximo de três, que podem ser vistas na Tabela 6. Observa-se que o valor estimado para $\alpha_{2}$, utilizando-se a metodologia proposta, é razoavelmente maior. Isto é devido ao fato de que, no caso de padrões espaciais muito agregados, em que se têm valores altos para $\alpha_{2}$, na obtenção da cadeia existe uma tendência maior de se aceitar valor sempre maior do que o valor atual. Esse fato, foi discutido durante a descrição dos resultados em 4.1.1, onde foram considerados dados simulados, a partir do modelo com um único parâmetro $\alpha$.

Nos outros dois talhões, em que as plantas se encontram mais espalhadas pela área, as estimativas de $\alpha_{2}$ são bem menores, como é de se esperar. Porém, os padrões espaciais são bastante diferentes em K026 e K097. No talhão K026, as plantas doentes se encontram bem mais distantes umas das outras, do que em K097, porém essas plantas doentes não parecem estar localizadas de uma forma totalmente aleatória, dentro do talhão. As plantas doentes estão localizadas mais na parte central do talhão, mas de uma forma mais esparsa. De acordo com as estimativas obtidas e observando-se os mapas, apresentados na Figura 10, pode-se concluir que, em ambos os casos, existe uma fonte de infecção interna, que garanta a transmissão da doença a longas distâncias ou uma fonte externa ao látice, pois têm-se valores de $\alpha_{1}$ maiores do que zero. Além disso, a transmissão da doença também ocorre entre plantas vizinhas, sendo que, no caso do talhão K097, esta disseminação da doença ocorre em distâncias mais curtas, pois $\hat{\alpha}_{2}$ é maior. Claro que, para concluir se um parâmetro é ou não igual a outro ou se é significativamente não nulo, é necessário que se aplique um teste de hipóteses ou que se obtenha intervalos de confiança. Assim, o estudo de tais casos será considerado em trabalhos futuros. 

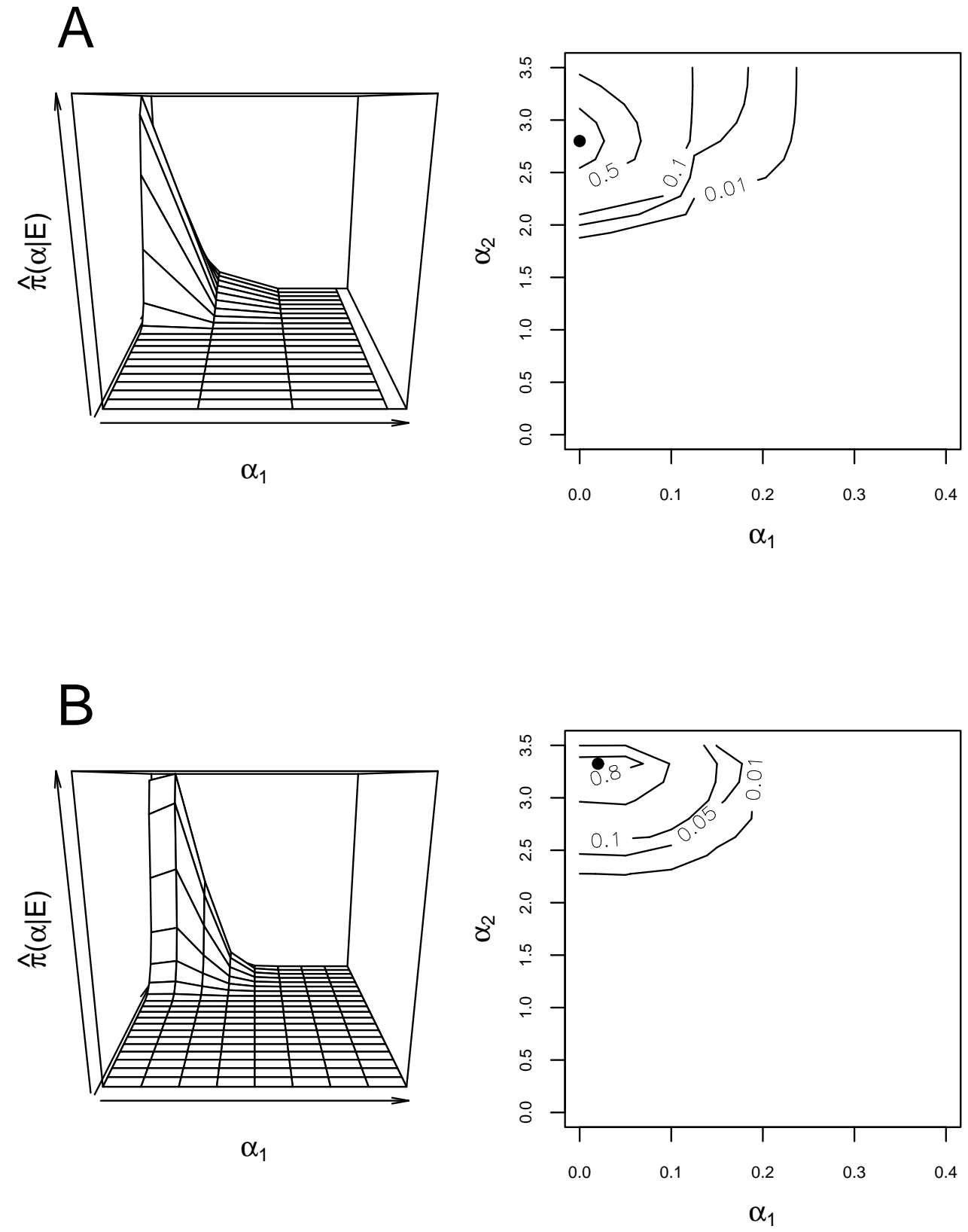

Figura 25 - Gráficos com as verossimilhanças aproximadas, $\hat{\pi}(\boldsymbol{\alpha} \mid \mathcal{E})$, padronizadas, de tal forma que o máximo seja igual a 1,0 e gráficos de contornos, obtidos utilizandose as metodologias de Gibson (A) e proposta (B), considerando o látice apresentado na Figura 10A e o modelo (26). • representa o máximo da verossimilhança 

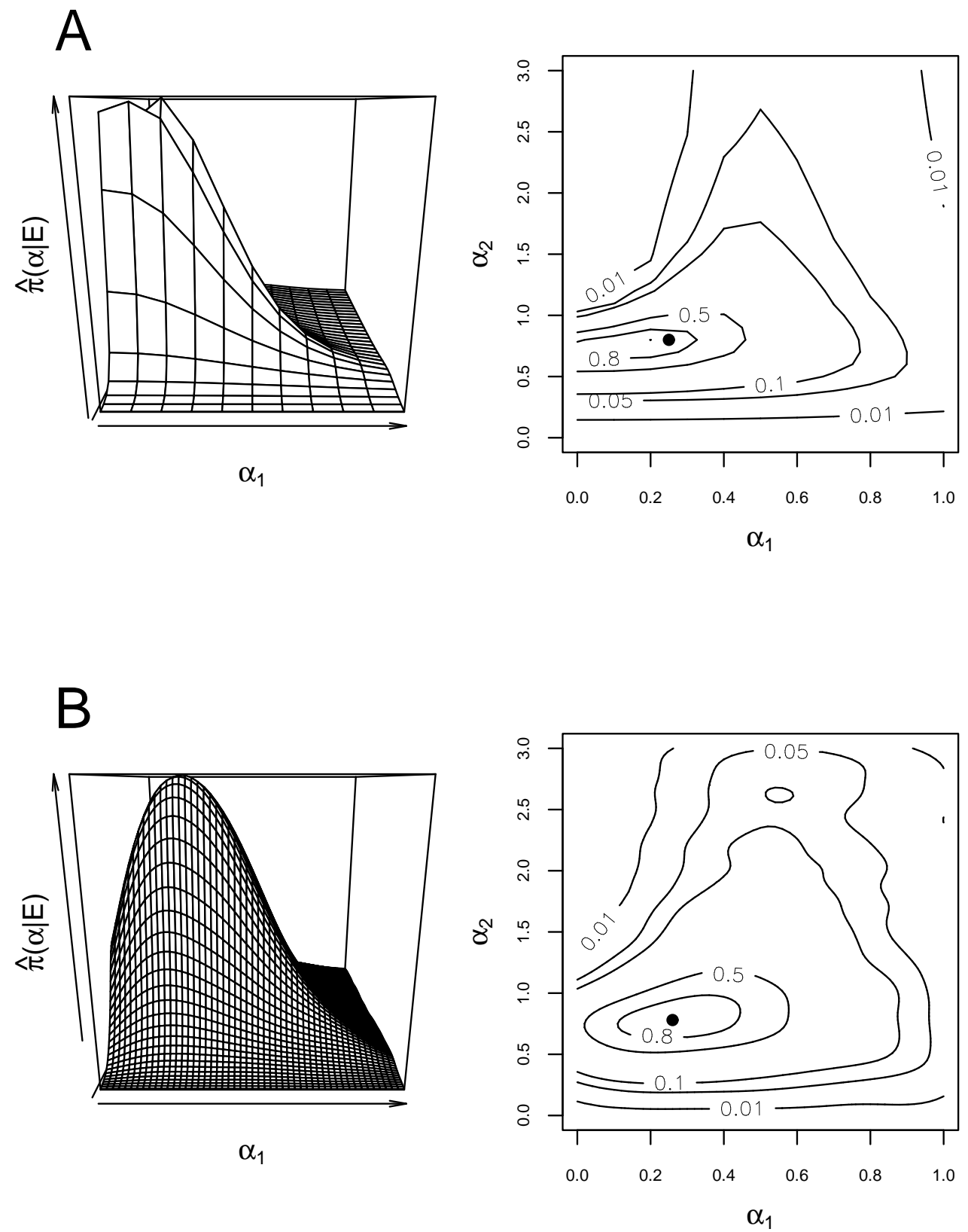

Figura 26 - Gráficos com as verossimilhanças aproximadas, $\hat{\pi}(\boldsymbol{\alpha} \mid \mathcal{E})$, padronizadas, de tal forma que o máximo seja igual a 1,0 e gráficos de contornos, obtidos utilizandose as metodologias de Gibson (A) e proposta (B), considerando o látice apresentado na Figura 10B e o modelo (26). • representa o máximo da verossimilhança 

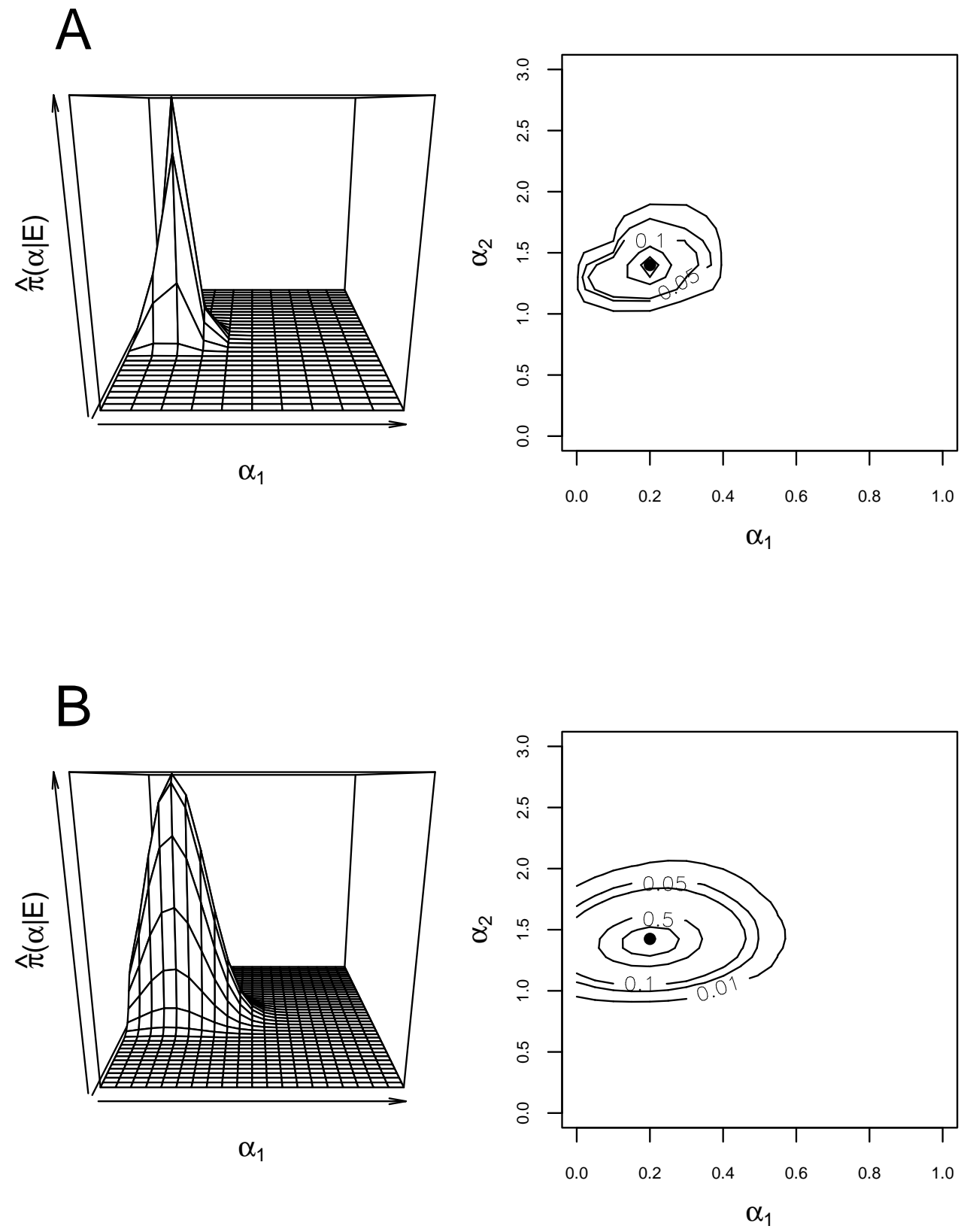

Figura 27 - Gráficos com as verossimilhanças aproximadas, $\hat{\pi}(\boldsymbol{\alpha} \mid \mathcal{E})$, padronizadas, de tal forma que o máximo seja igual a 1,0 e gráficos de contornos, obtidos utilizandose as metodologias de Gibson (A) e proposta (B), considerando o látice apresentado na Figura 10C e o modelo (26). • representa o máximo da verossimilhança 
Tabela 6. Estimativas de $\alpha_{1}$ e $\alpha_{2}$, do modelo (26), para o caso dos látices apresentados na Figura 10

\begin{tabular}{ccccc}
\hline & \multicolumn{2}{c}{ Metodologia de } & \multicolumn{2}{c}{ Metodologia } \\
& Gibson $(1997 \mathrm{~b})$ & \multicolumn{2}{c}{ proposta } \\
Talhão & $\hat{\alpha}_{1}$ & $\hat{\alpha}_{2}$ & $\hat{\alpha}_{1}$ & $\hat{\alpha}_{2}$ \\
\hline C02 & 0,00 & 2,8 & 0,02 & 3.36 \\
K026 & 0,25 & 0,8 & 0.34 & 0,86 \\
K097 & 0,2 & 1,4 & 0,23 & 1,42 \\
\hline
\end{tabular}

Outra característica interessante está na incerteza em relação ao parâmetro. Pode-se observar que nos talhões C02 e K097, em que se tem um maior número de plantas doentes (82 e 99, respectivamente), a verossimilhança tem um máximo bem mais evidente, de tal forma que, à medida que se afasta do ponto onde está localizado o máximo, o valor da verossimilhança diminui rapidamente, em contraste com o comportamento apresentado na Figura 26, em que se tem um número bem menor de plantas doentes, apenas 31 .

Com relação ao tempo gasto nas análises, com as modificações propostas, obtêm-se os resultados com 15 a 20\% do tempo gasto com a utilização da metodologia original. Isso facilita a caracterização de padrões espaciais, quando se têm muitos talhões a serem analisados, como é o caso do conjunto de dados de incidência de cancro cítrico.

\subsubsection{Morte súbita dos citros}

As estimativas dos parâmetros, $\alpha_{1}$ e $\alpha_{2}$, obtidas nas análises de dois talhões, 107C e 303, infectados com morte súbita dos citros, estão apresentadas na Tabela 7. Gráficos com esses valores foram construídos e estão apresentados na Figura 28. A interpretação de um grupo de estimativas, como esse apresen- 
tado, é muito difícil. Uma verificação interessante é observar se, ao longo do tempo, ocorre alguma tendência nas estimativas dos parâmetros. Nos gráficos da Figura 28, observa-se que apenas as estimativas de $\alpha_{2}$, no caso do talhão 303, tem uma tendência mais definida de aumentar, com o avanço no tempo. Isso significa que, com o tempo, a transmissão da doença entre plantas, ocorre das plantas infectadas para as plantas sadias cada vez mais próximas, desde que não haja também, um aumento nos valores de $\hat{\alpha}_{1}$, pois sabe-se que, quando $\alpha_{1}$ é alto, tem-se um padrão espacial aleatório.

As estimativas de $\alpha_{1}$, nas análises do talhão 107C, mostram uma leve tendência de se aproximar de zero, o que indicaria que com o tempo, o principal mecanismo de disseminação da doença é a infecção de plantas sadias por plantas vizinhas infectadas mais próximas.

Estas conclusões são obtidas com base na análise de apenas dois talhões e, portanto, não podem ser assumidas como características da disseminação da morte súbita dos citros. Para se ter uma conclusão mais abrangente é necessário que outros talhões sejam analisados. Porém, na verificação da concordância das estimativas, obtidas utilizando-se duas metodologias diferentes, estes exemplos são válidos. De maneira geral, observa-se que os resultados são muito próximos, demonstrando mais uma vez que, mesmo com as modificações propostas, não ocorre uma alteração significativa nos resultados. Apenas o tempo computacional gasto nas análises diminui bastante com as modificações propostas.

Uma outra maneira de apresentar os resultados, que é utilizada por Gibson (1997a) e Gottwald et al. (1999), é multiplicar as verossimilhanças obtidas em cada um dos tempos e obter uma verossimilhança conjunta de todos os tempos. Assim, mesmo tendo inspeções em vários tempos diferentes, para cada talhão, temse uma única verossimilhança e, conseqüentemente, uma única estimativa de cada parâmetro do modelo. 
Tabela 7. Estimativas de $\alpha_{1}$ e $\alpha_{2}$, do modelo (26), para o caso dos talhões $107 \mathrm{C}$ e 303, apresentados na Figura 11

\begin{tabular}{|c|c|c|c|c|c|}
\hline \multirow[b]{2}{*}{ Talhão } & \multirow[b]{2}{*}{ Data } & \multicolumn{2}{|c|}{$\begin{array}{l}\text { Metodologia de } \\
\text { Gibson (1997b) }\end{array}$} & \multicolumn{2}{|c|}{$\begin{array}{c}\text { Metodologia } \\
\text { proposta }\end{array}$} \\
\hline & & $\hat{\alpha}_{1}$ & $\hat{\alpha}_{2}$ & $\hat{\alpha}_{1}$ & $\hat{\alpha}_{2}$ \\
\hline \multirow[t]{10}{*}{$107 \mathrm{C}$} & $27 / 08 / 01$ & 0,50 & 2,62 & 0,56 & 2,32 \\
\hline & $24 / 09 / 01$ & 0,87 & 0,87 & 0,94 & 2,32 \\
\hline & $25 / 10 / 01$ & 1,25 & 3,50 & 1,14 & 3,40 \\
\hline & $20 / 11 / 01$ & 0,87 & 3,50 & 0,94 & 3,44 \\
\hline & $31 / 12 / 01$ & 1,00 & 2,10 & 0,60 & 1,08 \\
\hline & $22 / 01 / 02$ & 1,12 & 3,50 & 1,24 & 2,96 \\
\hline & $22 / 02 / 02$ & 0,00 & 1,05 & 0,08 & 1,04 \\
\hline & $22 / 03 / 02$ & 1,25 & 1,05 & 1,30 & 1,02 \\
\hline & $24 / 04 / 02$ & 0,00 & 1,75 & 0,10 & 1,76 \\
\hline & $10 / 05 / 02$ & 0,00 & 1,05 & 0,04 & 1,16 \\
\hline \multirow[t]{16}{*}{303} & $01 / 08 / 01$ & 0,37 & 1,05 & 0,38 & 1,06 \\
\hline & 08/08/01 & 0,75 & 0,87 & 0,76 & 0,86 \\
\hline & $16 / 08 / 01$ & 0,50 & 0,87 & 0,46 & 0,82 \\
\hline & $22 / 08 / 01$ & 0,37 & 2,10 & 0,28 & 1,62 \\
\hline & 06/09/01 & 0,00 & 1,05 & 0,05 & 1,18 \\
\hline & $12 / 09 / 01$ & 1,12 & 1,57 & 1,24 & 1,62 \\
\hline & 06/10/01 & 0,00 & 1,05 & 0,06 & 0,98 \\
\hline & $10 / 10 / 01$ & 0,87 & 1,22 & 0,88 & 1,00 \\
\hline & $07 / 11 / 01$ & 0,75 & 0,87 & 0,86 & 0,96 \\
\hline & $06 / 12 / 01$ & 0,12 & 1,57 & 0,18 & 1,58 \\
\hline & 08/01/02 & 0,00 & 1,75 & 0,10 & 1,66 \\
\hline & $12 / 02 / 02$ & 0,37 & 3,50 & 0,40 & 3,00 \\
\hline & $15 / 03 / 02$ & 0,00 & 3,50 & 0,12 & 3,04 \\
\hline & $05 / 04 / 02$ & 0,00 & 2,10 & 0,11 & 2,32 \\
\hline & $24 / 04 / 02$ & 1,75 & 3,50 & 1,88 & 3,00 \\
\hline & $08 / 05 / 02$ & 0,00 & 2,27 & 0,12 & 2,38 \\
\hline
\end{tabular}



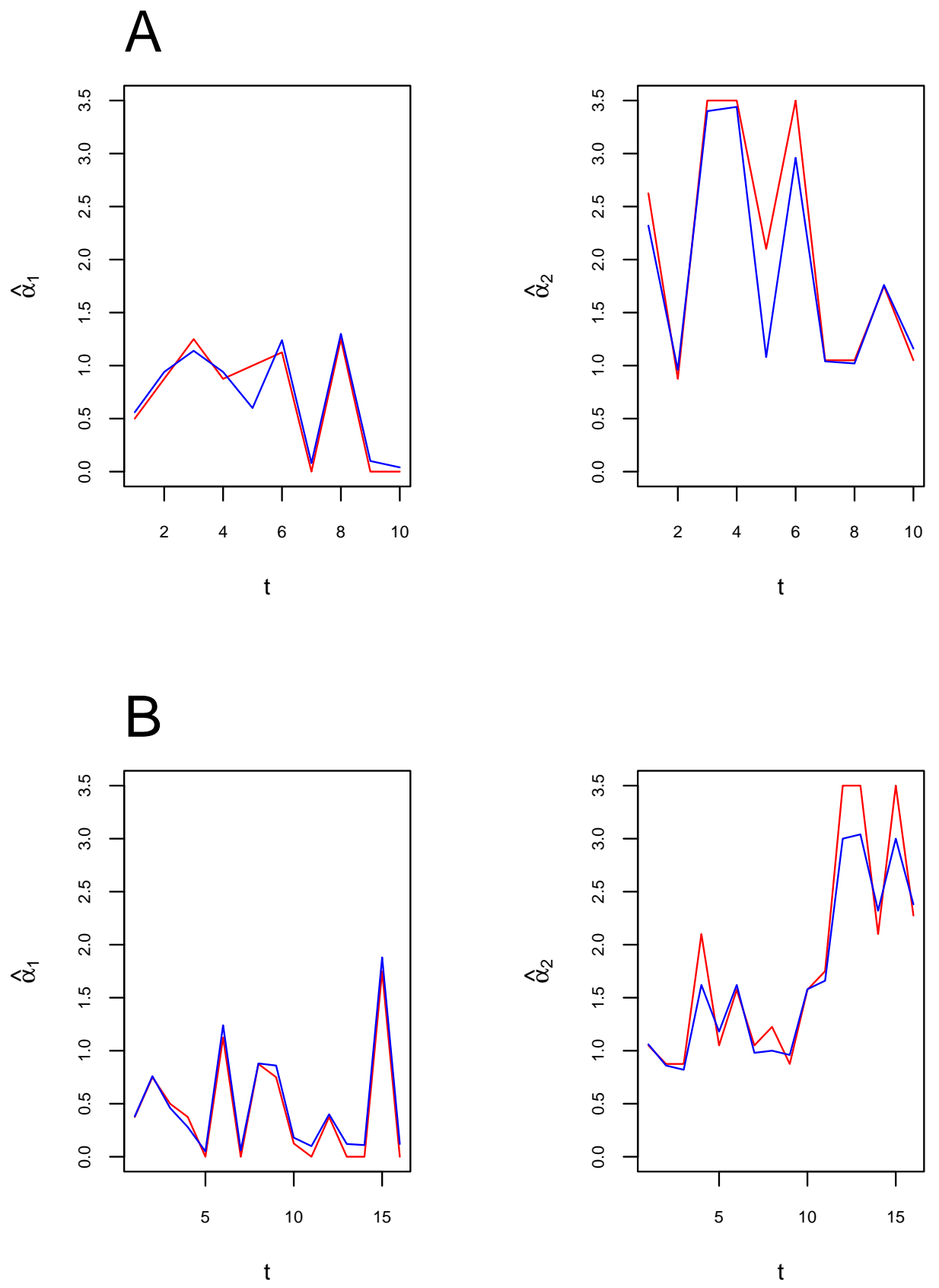

Figura 28 - Estimativas dos parâmetros $\alpha_{1}$ e $\alpha_{2}$, obtidas em diferentes tempos, $t$, de avaliação dos talhões A. 107C e B. 303. —— são as estimativas obtidas utilizando-se a metodologia original e_-, a proposta nesse trabalho 


\section{CONCLUSÕES}

Nesse trabalho foram propostas modificações na metodologia original de ajuste de modelos estocásticos espaço-temporais, obtendo-se um novo processo de estimação dos parâmetros, bem mais rápido, em termos de tempo computacional gasto nas análises.

As estimativas obtidas dos parâmetros, seja do modelo com um parâmetro ou no modelo com dois parâmetros, foram tão acuradas quanto as obtidas pelo processo original, como pôde ser observado na análise de dados simulados e na reprodução de resultados de outros artigos científicos.

O principal ganho com o novo processo de estimação foi em relação aos tempos utilizados nas análises. Com as modificações propostas, foram necessários apenas em torno de $15 \%$ a $20 \%$ do tempo gasto inicialmente, com a metodologia original.

A estimação de parâmetros dos modelos estocásticos espaço-temporais utilizando métodos MCMC, mostrou-se como sendo uma ferramenta bastante poderosa na caracterização de padrões espaciais de doenças de plantas, conseguindo diferenciar claramente diferentes padrões espaciais e, conseqüentemente diferentes mecanismos de dispersão de uma doença em plantas. Claro que essa não é uma metodologia que irá suprir as deficiências de várias outras técnicas utilizadas na caracterização de padrões espaciais. Essa é mais uma, que vem somar esforços no estudo de padrões espaciais.

Em relação a propostas futuras de trabalho, pretende-se utilizar a metodologia proposta, na análise de conjuntos maiores de dados, como é o caso dos dados de cancro cítrico e morte súbita dos citros, além de comparar os resul- 
tados, obtidos através de diferentes métodos de avaliação de padrões espaciais, com resultados obtidos através do ajuste de modelos estocásticos espaço-temporais. 


\section{REFERÊNCIAS BIBLIOGRÁFICAS}

ABECITRUS. Novo mapeamento do sistema agroindustrial citrícola. http://www.abecitrus.com.br/informa.html (01 nov. 2004)

BARTLETT, M.S. The spectral analysis of two-dimensional point processes. Biometrika, v. 51, p. 299-311, 1964.

BASSANEZI, R.B.; BERGAMIN FILHO, A.; AMORIM, L.; GIMENESFERNANDES, N.; GOTTWALD, T.R.; BOVÉ, J.M. Spatial and temporal analyses of citrus sudden death as a tool to generate hypotheses concerning its etiology. Phytopathology, v.93, n.4, p.502-512, 2003a.

BASSANEZI, R.B.; GIMENES-FERNANDES, N.; YAMAMOTO, P.T. Morte súbita dos citros. Araraquara: Fundecitrus, 2003b. 62p.

BERGAMIN FILHO, A.; AMORIM, L.; LARANJEIRA, F.; GOTTWALD, T.R. Epidemiology of citrus canker in Brazil with and without asian citrus leaf miner. In: INTERNATIONAL CITRUS CANKER RESEARCH WORKSHOP. Ft. Pierce, 2000. Proceedings,Ft. Pierce: USDA, 2000, p.6.

BERGAMIN FILHO, A.; HAU, B.; AMORIM, L.; LARANJEIRA, F.F. Análise espacial de epidemias. Revisão Anual de Patologia de Plantas, v.10, p.155$218,2002$.

BERGAMIN FILHO, A.; HUGHES, G. Citrus canker epidemiology - methodologies and approches: a moderated discussion session. In: INTERNATIONAL CITRUS CANKER RESEARCH WORKSHOP. Ft. Pierce, 2000. Proceedings, Ft. Pierce: USDA, 2000, p.24-25. 
BESAG, J.E. Discussion on Dr Ripley's paper. In: RIPLEY, B.D. Modelling spatial patterns. Journal of the Royal Statistical Society B, v. 39, n. 2, p. 172-192, 1977.

BORGATTO, A.F. Modelos para proporções com superdispersão e excessos de zeros - um procedimento Bayesiano. Piracicaba, 2004. 90p. Tese (Doutorado) - Escola Superior de Agricultura "Luiz de Queiroz", Universidade de São Paulo

BRITO, A. Identificado vetor de doença dos citros. http://agenciact.mct.gov.br/index.php?action=/content/view\&cod_objeto=16188 (05 nov. 2004)

BROADBENT, P.; GOTTWALD, T.R.; GILKESON, C.F.; FRANKS, N.; DEPHOFF, C.M. Identification of citrus blight in the Riverina, New South Wales. Australas Plant Pathology, v. 25, n. 2, p. 126-134, 1996.

CAMPBELL, C.L.; MADDEN, L.V. Introduction to plant disease epidemiology. New York: John Wiley, 1990. 560p.

CENTRO DE CITRICULTURA. Morte súbita dos citros: o que se sabe da doença até agora. http://www.centrodecitricultura.br/informativos/ 2003/setembro.pdf (02 nov. 2004)

CHELLEMI, D.O.; ROHRBACH, K.G.; YOST, R.S.; SONODA, R.M. Analysis of the spatial pattern of plant pathogens and disease plants using geostatistics. Phytopathology, v. 78, n. 2, p. 221-226, 1988.

CHIB, S.; GREENBERG, E. Understanding the Metropolis-Hastings algorithm. American Statistician, v. 49, n. 4, p. 327-335, 1995.

CHRISTIANO, R.S.C. Componentes monocíclicos do cancro cítrico no sistema Xanthomonas axonopodis pv. citri-limão tahiti-Phyllocnistis citrella, sob condições controladas. Piracicaba, 2003. 104p. Dissertação (Mestrado) - Escola Superior de Agricultura "Luiz de Queiroz", Universidade de São Paulo. 
CLIFF, A.D.; ORD, J.K. Spatial processes: models and applications. London: Pion, 1981. 266p.

COLLETT, D. Modelling binary data. London: Chapman \& Hall, 1991. 369p.

CRESSIE, N.A.C. Statistics for spatial data. New York: John Wiley, 1993. 900p.

DIGGLE, P.J. Statistical analysis of spatial point patterns. London: Academic Press, 1983. 148p.

FAOSTAT data, 2004. http://apps.fao.org/faostat (02 Nov. 2004)

FEICHTENBERGER, E.; MÜLLER, G.W.; GUIRADO, N. Doenças de citros. In: KIMATI, H.; AMORIM, L.; BERGAMIN FILHO, A.; CAMARGO, L.E.A.; REZENDE, J.A.M. Manual de Fitopatologia. 3.ed. São Paulo: Agronômica Ceres, 1997. v2. p.261-296.

FERRANDINO, F.J. A distribution-free method for estimating the effects of aggregated plant damage on crop yield. Phytopathology, v. 79, n. 11, p. 1229-1232, 1989.

FERRANDINO, F.J. Two-dimensional distance class analysis of disease-incidence data: problems and possible solutions. Phytopathology, v. 86, n. 7, p. 685-691, 1996.

FERRANDINO, F.J. Past nonrandomness and aggregation to spatial correlation: 2DCORR, a new approach for discrete data. Phytopathology, v. 88, n. 2, p. 84-91, 1998.

FLEISS, J.L. Measuring nominal scale agreement among many raters. Phychology Bulletin, v. 76, p. 378-382, 1971.

FNP CONSULTORIA \& COMERCIO. AGRIANUAL 2004: Anuário da agricultura brasileira. São Paulo, 2004. p. 244-246. 
FREEMAN, G.H. Spread of diseases in a rectangular plantation with vacancies. Biometrika, v. 40, n. 3/4, p. 287-296, 1953.

FUNDECITRUS. Manual de cancro cítrico. Araraquara: Fundecitrus, 2003. 11p.

FUNDECITRUS. Cancro cítrico. http://www.fundecitrus. com.br/doencas/ cancro.html (01 nov. 2004a)

FUNDECITRUS. Concluído o levantamento do cancro cítrico. http://www.fundecitrus.com.br/informativo/nota_lcancro0604.html (01 nov. 2004b)

FUNDECITRUS. Divulgado o novo mapeamento do sistema agroindustrial citrícola. http://www.fundecitrus.com.br/informativo/ nota_mapcadeia0404.html (01 nov. 2004c)

FUNDECITRUS. Fundecitrus conclui levantamento e verifica que a MSC avançou $60 \mathrm{~km}$ em um ano. http://www.fundecitrus.com.br/informativo/nota_levmsc0204.html (01 nov. 2004d)

FUNDECITRUS. Morte súbita dos citros - MSC. http://www.fundecitrus. com.br/doencas/morte_subita.html (01 nov. 2004e)

FUNDECITRUS. O Fundecitrus. http://www.fundecitrus.com.br/fundec_br.html (01 nov. 2004f)

FUNDECITRUS. Opinião. http://www.fundecitrus.com.br/editorial_br.html (01 nov. 2004g)

FUNDECITRUS. Principais doenças e pragas. http://www.fundecitrus. com.br/doencas/dpragas_br.html (01 nov. 2004h)

GAMERMAN, D. Markov chain Monte Carlo: stochastic simulation for bayesian inference. London: Chapman \& Hall, 1997. 245p. 
GElman, A.E.; CARLIN, J.B.; STERN, H.S.; RUBIN, D.B. Bayesian data analysis. London: Chapman \& Hall, 1997. 256p.

GIBSON, G.V. Investigating mecanisms of spatiotemporal epidemic spread using stochastic models. Phytopathology, v. 87, n. 2, p. 139-146, 1997a.

GIBSON, G.V. Markov Chain Monte Carlo methods for fitting spatiotemporal stochastic models in plant epidemiology. Applied Statistics, v. 46, n. 2, p. 215-233, 1997b.

GIBSON, G.V.; AUSTIN, E.J. Fitting and testing spatiotemporal stochastic models with application in plant epidemiology. Plant Pathology, v. 45, p. 172-184, 1996.

GIMENES-FERNANDES, N.; BASSANEZI, R.B. Doença de causa desconhecida afeta pomares cítricos no norte de São Paulo e sul do Triângulo Mineiro. Summa Phytopathologica, v.27, p.93, 2001. /Resumo/

GOTTWALD, T.R. Spatio-temporal analysis and isopath dynamics of citrus scab in nursery plots. Phytopathology, v. 85, n. 10, p. 1082-1092, 1995.

GOTTWALD, T.R.; AVINENT, L.; LLACER, G.; HERMOZA DE MENDOZA, A.; CAMBRA, M. Analysis of spatial spread of sharka (plum pox virus) in apricot and peach orchards in eastern Spain. Plant Disease, v. 79, n. 3, p. 266-278, 1995.

GOTTWALD, T.R.; CAMBRA, M.; MORENO, P.; CAMARASA, E.; PIQUER, J. Spatial and temporal analyses of citrus tristeza virus in eastern Spain. Phytopathology, v. 86, n. 1, p. 45-55, 1996.

GOTTWALD, T.R.; GIBSON, G.J.; GARNSEY, S.M.; IREY, M. Examination of the effect of aphid vector population composition on the spatial dynamics of citrus tristeza virus spread by stochastic modeling. Phytopathology, v. 89, n. 7, p. 603-608, 1999. 
GOTTWALD, T.R.; SUN, X.; RILEY, T.; GRAHAM, J.H.; FERRANDINO, F.; TAYLOR, E.L. Geo-referenced spatiotemporal analysis of the urban citrus canker epidemic in Florida. Phytopathology, v. 92, n. 4, p. 361-377, 2002.

GRAY, S.M.; MOYER, J.W.; BLOOMFIELD, P. Two-dimensional distance class model for quantitative description of virus-infected plant distribution lattices. Phytopathology, v. 76, n. 2, p. 243-248, 1986.

GUMPERTZ, M.L.; GRAHAM, J.M.; RISTAINO, J.B. Autologistic model of spatial pattern of Phytophthora epidemic in bell pepper: effects of soil variables on disease presence. Journal of Agricultural, Biological, and Environmental Statistics, v. 2, n. 2, p. 131-156, 1997.

HASTINGS, W.K. Monte Carlo sampling methods using Markov chains and their applications. Biometrika, v. 57, n. 1, p. 97-109, 1970.

HINDE, J.; DEMÉTRIO, C.G.B. Overdispersion model and estimation. Computational Statistics \& Data Analysis, v. 27, n. 2, p. 151-170, 1998.

HUGHES, G. Spatial heterogeneity in crop loss assessment models. Phytopathology, v. 78, n. 7 , p. 883-884, 1988.

HUGHES, G.; MADDEN, L.V. Aggregation and incidence of disease. Plant Pathology, v. 41, n. 4, p. 657-660, 1992.

HUGHES, G.; MADDEN, L.V. Using the beta-binomial distribution to describe aggregated patterns of disease incidence. Phytopathology, v. 83, n. 7, p. 759763, 1993.

HUGHES, G.; MADDEN, L.V. Aggregation and incidence of disease: some implications for sampling. Aspects of Applied Biology, v. 37, p. 25-31, 1994.

HUGHES, G.; MADDEN, L.V. Some methods allowing for aggregated patterns of disease incidence in the analysis of data from designed experiments. Plant Pathology, v. 44, n. 6, p. 927-943, 1995. 
HUGHES, G.; GOTTWALD, T.R. Survey methods for assessment of citrus tristeza virus incidence. Phytopathology, v. 88, n. 7, p. 715-723, 1998.

HUGHES, G.; MADDEN, L.V. Some methods for eliciting expert knowledge of plant disease epidemics and their application in cluster sampling for disease incidence. Crop Protection, v. 21, n. 3, p. 203-215, 2002.

HUGHES, G.; GOTTWALD, T.R.; YAMAMURA, K. Survey methods for assessment of citrus tristeza virus incidence in urban citrus populations. Plant Disease, v. 86, n. 4, p. 367-372, 2002.

HUGHES, G.; MCROBERTS, N.; MADDEN, L.V.; NELSON, S.C. Validating mathematical models of plant-disease progress in space and time. IMA Journal of Mathematics Applied in Medicine \& Biology, v. 14, p. 85-112, 1997.

JESUS JÚNIOR, W.C.; BASSANEZI, R.B. Análise da dinâmica e estrutura de focos da morte súbita dos citros. Fitopatologia Brasileira, v.29, n.4, p.399-405, 2004.

JONES, P.W.; SMITH, P. Stochastic processes: An introduction. London: Arnold, 2001. 259p.

LARANJEIRA, F.F.; BERGAMIN-FILHO, A.; AMORIM, L. Dinâmica e estrutura de focos da clorose variegada dos citros (CVC). Fitopatologia Brasileira, v.23, n.1, p.36-41, 1998.

LEANDRO, R.A. Introdução à Estatística Bayesiana. In: Simpósio de Estatística Aplicada à Experimentação Agronômica, 9., Reunião Anual da Região Brasileira da Sociedade Internacional de Biometria, 44., Piracicaba, 2001. Introdução à Estatística Bayesiana. Piracicaba: RBRAS, 2001. 51p.

LEVANTAMENTO concluído. Revista do Fundecitrus, n.122, p.6-7, mai./jun. 2004 .

MADDEN, L.V. Aggregation of Colletotrichum acutatum in response to simulated rain episodes. Journal of Phytopathology, v. 138, n. 2, p. 145-156, 1993. 
MADDEN, L.V.; HUGHES, G. BBD - Computer software for fitting the betabinomial distribution to disease incidence data. Plant Disease, v. 78 , n. 5 , p. 536-540, 1994.

MADDEN, L.V.; NUTTER JÚNIOR, F.W. Modeling crop losses at field scale. Canadian Journal of Plant Patholology, v. 17, n. 2, p. 124-137, 1995.

MADDEN, L.V.; HUGHES, G. Plant disease incidence: distributions, heterogeneity, and temporal analysis. Annual Review of Phytopathology, v. 33, p. 529-564, 1995.

MADDEN, L.V.; HUGHES, G. Sampling for plant disease incidence. Phytopathology, v. 89, n. 11, p. 1088-1103, 1999.

MADDEN, L.V.; HUGHES, G.; ELLIS, M.A. Spatial heterogeneity of the incidence of grape downy mildew. Phytopathology, v. 85, n. 3, p. 269-275, 1995.

MADDEN, L.V.; HUGHES, G.; MUNKVOLD, G.P. Plant disease incidence: inverse sampling, and confidence intervals when observed mean incidence is zero. Crop Protection, v. 15, n. 7, p. 621-632, 1996.

MADDEN, L.V.; LOUIE, R.; ABT, J.J.; KNOKE, J.K. Evaluation of tests for randomness of infected plants. Phytopathology, v.72, n.2, p.195-198, 1982.

MARCUS; R.; SVETLANA, F.; TALPAZ, H.; SALOMON, R.; BAR-JOSEPH, M. On the spatial distribution of citrus tristeza virus disease. Phytoparasitica, v. 12, p. $45-52,1984$.

MARION, G.; GIBSON, G.; RENSHAW, E. Estimating likelihoods for spatiotemporal models using importance sampling. Statistics and Computing, v. 13, n. 2, p.111-119, 2003.

MENGERSEN, K.L.; TWEEDIE, R.L. Rates of convergence of the Hastings and Metropolis algorithms The Annals of Statistics, v. 24, n. 1, p. 101-121, 2003. 
METROPOLIS, N.; ROSENBLUTH, M. TELLER, E. Equations of state calculations by fast computing machines. Journal of Chemical Physics, v. 21, p. 1087-1092, 1953.

MEYER, P.L. Probabilidade: aplicações à Estatística. 2.ed. Rio de Janeiro: LTC Editora, 1983. 426p.

MILLER, S.A.; MADDEN, L.V.; SCHMITTHENNER, A.F. Distribution of Phytophthora ssp. in field soils determined by immunoassay. Phytopathology, v. 87, n. 1, p. 101-107, 1997.

MINISTÉRIO DA AGRICULTURA, PECUÁRIA E ABASTECIMENTO. Agronegócio Brasileiro: uma oportunidade de investimentos. http://www.agricultura.gov.br/portal/page?_pageid=36,476957\&_dad=portal\& sschema=PORTAL (01 nov. 2004)

MOOD, A.M.; GRAYBILL, F.A.; BOES, D.C. Introduction to the theory of statistics. 3.ed. São Paulo: McGraw-Hill, 1974. 564p.

MORGAN, B.J.T. Applied stochastic modelling. London: Arnold, 2000. 297p.

MUNKVOLD, G.P.; DUTHIE, J.A.; MAROIS, J.J. Spatial patterns of grapevines with Eutypa dieback in vineyards with or without perithecia. Phytopathology, v. 83, n. 12, p. 1440-1448, 1993.

NELSON, S.C. Spatiotemporal distance class analysis of plant disease epidemics. Phytopathology, v.85, n.1, p.37-43, 1995.

NELSON, S.C. A simple analysis of disease foci. Phytopathology, v.86, n.3, p.332339, 1996.

NELSON, S.C.; MARSH, P.L.; CAMPBELL, C.L. 2DCLASS, a two-dimensional distance class analysis software for the personal computer. Plant Disease, v. 76, n. 4, p. 427-432, 1992. 
NOVA AVALIAÇÃO: PENSA/USP faz mapeamento e quantifica a importância da laranja. Revista do Fundecitrus, n.122, p.8-9, mai./jun. 2004.

PATIL, G.P.; STITELER, W.M. Concepts of aggregation and their quantification: a critical review with some news results and applications. Researches on Population Ecology, v. 15, p. 238-254, 1974.

PETHYBRIDGE, S.J.; MADDEN, L.V. Analysis of spatiotemporal dynamics of virus spread in an Australian hop garden by stochastic modeling. Plant Disease, v. 87, n. 1, p. 56-62, 2003.

PRENTICE, R.L. Binary regression using an extended beta-binomial distribution, with discussion of correlation induced by covariate measurement errors. Journal of the American Statistical Association, v. 81, n. 394, p. 321-327, 1986.

QUEENSLAND GOVERNMENT. Canker http://www.dpi.qld.gov.au/citruscanker (02 Nov. 2004)

REYNOLDS, K.M.; MADDEN, L.V. Analysis of epidemics using spatio-temporal autocorrelation. Phytopathology, v. 78, n. 2, p. 240-246, 1988.

RIBEIRO JÚNIOR, P.J. Métodos geoestatísticos no estudo da variabilidade espacial de parâmetros do solo. Piracicaba, 1995. 99p. Dissertação (Mestrado) - Escola Superior de Agricultura "Luiz de Queiroz".

RIDOUT, M.S.; XU, X.-M. Relationships between several quadrat-based statistical measures used to characterize spatial aspects of disease incidence data. Phytopathology, v. 90 , n. 6 , p. 568-575, 2000.

RIDOUT, M.S.; DEMÉTRIO, C.G.B.; FIRTH, D. Estimating intraclass correlation for binary data. Biometrics, v. 55, n. 1, p. 137-148, 1999.

RIPLEY, B.D. The second-order analysis of stationary point processes. Journal of Applied Probability, v. 13, n. 2, p. 255-266, 1976. 
RIPLEY, B.D. Modelling spatial patterns. Journal of the Royal Statistical Society B, v. 39, n. 2, p. 172-192, 1977.

RIPLEY, B.D. Spatial Statistics. New York: John Wiley, 1981. 252p.

ROSS, S.M. Introduction to probability models. 5.ed. London: Academic Press, 1993. 556p.

SCHUBERT, T.S.; RIZVI, S.A.; SUN, X.; GOTTWALD, T.R.; GRAHAM, J.H.; DIXON, W.N. Meeting the challenge of eradicating citrus canker in Florida Again. Plant Disease, v. 85, n. 4, p. 340-356, 2001.

SCOTT, L. Injunction reprieve for citrus trees. The Weekend Australian, Adelaide, 10-11 Jul. 2004. p. 7.

SECRETARIA DE AGRICULTURA E ABASTECIMENTO DO ESTADO DE SÃO PAULO. bf Cadeia de produção de citros e a morte súbita: análise e estratégias da Secretaria de Agricultura e Abastecimento do Governo de São Paulo. Fev. 2003. http://www.apta.sp.gov.br/Morte_Subita.htm (02 Nov. 2004)

SMITH, A.F.M.; ROBERTS, G.O. Bayesian computation via the Gibbs sampler and related Markov chain Monte Carlo methods Journal of Royal Statistical Society B, v. 55, n. 1, p. 3-23, 1993.

SMITH, D.M. Maximum likelihood estimation of the parameters of the beta binomial distribution. Applied Statistics, v. 32, n. 2, p. 192-204, 1983.

SOUZA, A.C. Frutas cítricas: singularidades do mercado. Preços Agrícolas, n.173, p.8-10, mai./jun. 2001.

STEIN, A.; KOCKS, C.G.; ZADOCKS, J.C.; FRINKING, H.D.; RUISSEN, M.A.; MYERS, D.E. A geostatistical analysis of the spatio-temporal development of downy mildew epidemics in cabbage. Phytopathology, v. 84, n. 10, p. 1227$1239,1994$. 
TAYLOR, L.R. Aggregation, variance and the mean. Nature, v. 189, n. 476, p. $732-735,1961$.

TAYLOR, L.R.; WOIWOD, I.P.; PERRY, J.N. The density-dependence of spatial behaviour and the rarity of randomness. Journal of Animal Ecology, v. 47, n. 3, p. 383-406, 1978.

TODD, H. A note on random associations in a square point lattice. Journal of the Royal Statistical Society, v. 7, n. 1, p. 78-82, 1940.

TURECHEK, W.W.; MADDEN, L.V. Spatial pattern analysis and sequential sampling for the incidence of leaf spot on strawberry in Ohio. Plant Disease, v. 83, n. 11, p. 992-1000, 1999a.

TURECHEK, W.W.; MADDEN, L.V. Spatial pattern analysis of strawberry leaf blight in perennial production systems. Phytopathology, v. 89, n. 5, p. 421433, $1999 \mathrm{~b}$.

TURECHEK, W.W.; MADDEN, L.V. Analysis of the association between the incidence of two spatially aggregated foliar diseases of strawberry. Phytopathology, v. 90, n. 2 , p. $157-170,2000$.

TURECHEK, W.W.; MADDEN, L.V. Effect of scale on plant disease incidence and heterogeneity in a spatial hierarchy. Ecological Modelling, v. 144, n. 1, p. 77-95, 2001.

TURECHEK, W.W.; ELLIS, M.A.; MADDEN, L.V. Sequential sampling for incidence of Phomopsis leaf blight of strawberry. Phytopathology, v. 91, n. 4, p. 336-347, 2001.

UPTON, G.J.G.; FINGLETON, B. Spatial data analysis by example: Point pattern and quantitative data. New York: John Wiley, 1985. v.1. 410p.

VAN MAANEN, A.; XU, X.-M. Modelling plant disease epidemics. European Journal of Plant Pathology, v.109, n.7, p.669-682, 2003. 
XU, X.-M.; RIDOUT, M.S. Effects of initial epidemic conditions, sporulation rate, and spore dispersal gradient on the spatio-temporal dynamics of plant disease epidemics. Phytopathology, v. 88, n. 10, p. 1000-1012, 1998.

XU, X.-M.; RIDOUT, M.S. Effects of quadrat size and shape, initial epidemic conditions, and spore dispersal gradient on spatial statistics of plant disease epidemics. Phytopathology, v. 90, n. 7, p. 738-750, 2000.

XU, X.-M.; RIDOUT, M.S. Effects of prevailing wind direction on spatial statistics of plant disease epidemics. Journal of Phytopathology, v. 149, n. 2, p. 155-166, 2001.

ZADOKS, J.C.; VAN DEN BOSCH, F. Expansion and spatial spread of disease. Annual Review of Phytopathology , v. 32, p. 503-521, 1994.

YANG, X.B. Analysis of variance-mean relationships of plant diseases. Journal of Phytopathology, v. 143, n. 9, p. 513-518, 1995. 
APÊNDICE 


\section{APÊNDICE 1 - Cálculo de $P_{\omega}(\boldsymbol{\alpha})$}

Como pode ser visto em Gibson \& Austin (1996) e Gibson (1997b), $P_{\omega}(\boldsymbol{\alpha})$ representa a probabilidade de que as plantas do conjunto $S_{1} \backslash S_{0}$, isto é, as novas infecções ocorridas entre os tempos $t_{0}$ e $t_{1}$, se tornem infectadas antes de qualquer outra planta sadia no tempo $t_{1}$, ou seja, antes de qualquer planta pertencente ao conjunto $L \backslash S_{1}$. Isso significa que os tempos em que as plantas de $S_{1} \backslash S_{0}$ são infectadas têm que ser menores do que o tempo em que qualquer planta de $L \backslash S_{1}$ venha a ser infectada. Assumindo a ordem de ocorrência das novas infeç̧ões como sendo $\omega=\{1,2, \ldots, N\}, P_{\omega}(\boldsymbol{\alpha})$ é definido por

$$
\begin{aligned}
P_{\omega}(\boldsymbol{\alpha}) & =P\left[t_{\alpha}\left(x_{\omega(1)}\right)<t_{\alpha}\left(x_{\omega(2)}\right)<\ldots<t_{\alpha}\left(x_{\omega(N)}\right)<\min \left\{t_{\alpha}(z) \mid z \in L \backslash S_{1}\right\}\right] \\
& =P\left[t_{\alpha}\left(x_{1}\right)<t_{\alpha}\left(x_{2}\right)<\ldots<t_{\alpha}\left(x_{N}\right)<\min \left\{t_{\alpha}(z) \mid z \in L \backslash S_{1}\right\}\right],
\end{aligned}
$$

em que $x_{i}, i=1,2, \ldots, N$, representam plantas sadias no tempo $t_{0}$ e infectadas em $t_{1}$ e $z$ é qualquer planta sadia no tempo $t_{1}$.

Nessa definição, considera-se uma ordem específica de ocorrência das novas infecções, o que facilitará a demonstração de como calcular $P_{\omega}(\boldsymbol{\alpha})$, mas a generalização para qualquer $\omega$, dos $N$ ! possíveis, é direta.

Considere a sequência de conjuntos de plantas doentes

$$
S_{0}=A_{0} \rightarrow A_{1} \rightarrow A_{2} \rightarrow \ldots \rightarrow A_{i} \rightarrow \ldots \rightarrow A_{N}=S_{1},
$$

em que $A_{i+1}=A_{i} \cup\left\{x_{i+1}\right\}, \quad 0 \leq i \leq N-1$. Gibson \& Austin (1996) e Gibson (1997b) definem $P_{\omega}(\boldsymbol{\alpha})$ como o produtório das probabilidades das mudanças de $A_{i}$ para $A_{i+1}$, 
para um dado $\boldsymbol{\alpha}$, por

$$
P_{\omega}(\boldsymbol{\alpha})=\prod_{i=0}^{N-1} P\left(A_{i} \rightarrow A_{i+1} \mid \boldsymbol{\alpha}\right),
$$

em que $P\left(A_{i} \rightarrow A_{i+1} \mid \boldsymbol{\alpha}\right)=P\left(x_{i+1}\right.$ se torne infectada antes de qualquer outra planta sadia pertencente ao conjunto $L \backslash A_{i}$ ).

Essa probabilidade pode ser calculada, condicionando em relação ao tempo $t$ decorrido entre a infecção de $x_{i}$ e a infecção de $x_{i+1}$ e, então, integrando em relação a $t$.

Considere um processo de Poisson com taxa unitária $\lambda$. Seja $W_{t}$ o número de ocorrências do processo no intervalo $[0, t]$. Assim, $W_{t} \sim P(\lambda t)$, isto é

$$
P\left(W_{t}=w\right)=\frac{e^{-\lambda t}(\lambda t)^{w}}{w !} I_{\{0,1,2, \ldots\}}(w) .
$$

Seja $T$ a variável aleatória contínua que representa o tempo de espera para a ocorrência da primeira infecção de uma planta, no intervalo entre $t_{0}$ e $t_{1}$, sendo a função de distribuição de $T, G_{T}(t)$, definida, para $t>0$, por

$$
G_{T}(t)=P(T \leq t)=1-P(T>t) .
$$

Se o tempo de espera para a primeira ocorrência é maior do que $t$, então, no intervalo $[0, t], W_{t}=0$, isto é

$$
P(T>t)=P\left(W_{t}=0\right)=\frac{e^{-\lambda t}(\lambda t)^{0}}{0 !}=e^{-\lambda t} .
$$

Assim, de (44), tem-se

$$
G_{T}(t)=1-e^{-\lambda t} I_{(0, \infty)}(t)
$$

e a função densidade de probabilidade (f.d.p.) de $T$ é dada por

$$
\begin{aligned}
g_{T}(t) & =\frac{d}{d t} G_{T}(t) \\
& =\frac{d}{d t}\left(1-e^{-\lambda t}\right) \\
& =-e^{-\lambda t}(-\lambda) \\
& =\lambda e^{-\lambda t} I_{(0, \infty)}(t)
\end{aligned}
$$


que é a f.d.p. da distribuição exponencial, isto é, $T \sim \operatorname{Exp}(\lambda)$.

Na situação presente, tem-se que o evento $\left(A_{i} \rightarrow A_{i+1} \mid \boldsymbol{\alpha}\right)$ corresponde à infecção da planta $x_{i+1}$, que ocorre com uma taxa dada por $\lambda=C\left(x_{i+1} \mid A_{i}\right)$. $C\left(x_{i+1} \mid A_{i}\right)$ pode ser definido de diferentes maneiras dependendo de qual modelo é utilizado, porém seguindo sempre o mesmo raciocínio de se quantificar a pressão infectiva sofrida por $x_{i+1}$. Para os três modelos apresentados em (24), (25) e (26), têm-se respectivamente, $C\left(x_{i+1} \mid A_{i}\right)=\sum_{y \in A_{i}} e^{-\alpha\left|y-x_{i+1}\right|}, C\left(x_{i+1} \mid A_{i}\right)=\sum_{y \in A_{i}} \mid y-$ $\left.x_{i+1}\right|^{-2 \alpha}$ e $C\left(x_{i+1} \mid A_{i}\right)=\alpha_{1}+\sum_{y \in A_{i}}\left|y-x_{i+1}\right|^{-2 \alpha_{2}}$.

Já foi visto que a variável aleatória tempo de espera para a ocorrência da primeira infecção, $T \sim \operatorname{Exp}(\lambda)$ e esse resultado também é válido para o tempo de espera entre infeç̧ões sucessivas das $N$ novas infecções ocorridas entre $t_{0}$ e $t_{1}$. Assim, $T$ é a variável aleatória que representa o tempo de espera para a ocorrência da próxima infecção, a de $x_{i+1}$, que ocorre a uma taxa $\lambda=C\left(x_{i+1} \mid A_{i}\right)$. Portanto, de (46) tem-se

$$
g_{T}(t)=C\left(x_{i+1} \mid A_{i}\right) \cdot \exp \left\{-C\left(x_{i+1} \mid A_{i}\right) t\right\} I_{(0, \infty)}(t) .
$$

Considere a variável aleatória $I$, tal que

$$
I= \begin{cases}1 & \text { se ocorrer o evento } \mathcal{D} \\ 0 & \text { caso contrário, }\end{cases}
$$

em que $\mathcal{D}$ representa o evento em que $x_{i+1}$ é infectada antes de qualquer outra planta sadia do conjunto $L \backslash A_{i}$, que pode ser representado por $\mathcal{D}=\left(A_{i} \rightarrow A_{i+1} \mid \boldsymbol{\alpha}\right)$. Assim, define-se

$$
\begin{aligned}
E(I) & =\sum_{i=0}^{1} i \cdot P(I=i) \\
& =0 \cdot P(\overline{\mathcal{D}})+1 \cdot P(\mathcal{D}) \\
& =P(\mathcal{D}) \\
& =P\left(A_{i} \rightarrow A_{i+1} \mid \boldsymbol{\alpha}\right) .
\end{aligned}
$$

Mas,

$$
E(I)=E[E(I \mid T=t)]
$$


em que

$$
\begin{aligned}
E(I \mid T=t) & =\sum_{i=0}^{1} i \cdot P(I=i \mid T=t) \\
& =P(I=1 \mid T=t)
\end{aligned}
$$

é a probabilidade de ocorrência do evento $\mathcal{D}$, dado que o tempo de espera para a ocorrência da infecção de $x_{i+1}$ seja $t$.

A definição da probabilidade $P(I=1 \mid T=t)$ exige um pouco mais de raciocínio em relação à ocorrência do evento $\mathcal{D}$. Considere o conjunto de plantas sadias, até um determinado tempo inferior a $t$, como sendo $L \backslash A_{i}$, em que $x_{i+1} \subset L \backslash A_{i}$ e $x_{i+1}$ torna-se infectada antes de qualquer outra planta sadia $z \in L \backslash A_{i}$. Supondo que a planta $x_{i+1}$ se torne infectada nesse tempo $t$, o conjunto de plantas sadias passa a ser $L \backslash A_{i+1}$, pois o conjunto das plantas infectadas passa a ser $A_{i+1}=A_{i} \cup\left\{x_{i+1}\right\}$. Portanto, pode-se afirmar que toda e qualquer planta $z \in L \backslash A_{i+1}$ se tornará infectada em um tempo superior a $t$, isto é, $T_{z}>t$, para toda planta sadia $z \in L \backslash A_{i+1}$. Assim, pode-se concluir que a probabilidade de que $x_{i+1}$ se torne infectada com tempo de espera igual a $t$ é dada por

$$
P(I=1 \mid T=t)=\prod_{z \in L \backslash A_{i+1}} P\left(T_{z}>t\right),
$$

uma vez que os tempos de infecção de cada planta sadia $z \in L \backslash A_{i+1}$ são independentes.

Dado $\lambda=C\left(z \mid A_{i}\right)$ como sendo a taxa ou peso para que cada uma das plantas $z \in L \backslash A_{i}$ se torne doente e considerando a definição apresentada em (45), tem-se

$$
P\left(T_{z}>t\right)=\exp \left\{-C\left(z \mid A_{i}\right) t\right\}
$$

e assim, de (50) e (51),

$$
E(I \mid T=t)=\prod_{z \in L \backslash A_{i+1}} \exp \left\{-C\left(z \mid A_{i}\right) t\right\} .
$$

A partir das equações (48) e (49) tem-se

$$
P\left(A_{i} \rightarrow A_{i+1} \mid \boldsymbol{\alpha}\right)=E[E(I \mid T=t)]
$$


em que $E(I \mid T=t)$ é uma função do tempo de espera, dada por $g_{T}(t)$, definida em (47) e, portanto,

$$
P\left(A_{i} \rightarrow A_{i+1} \mid \boldsymbol{\alpha}\right)=\int_{0}^{\infty} E(I \mid T=t) g_{T}(t) \mathrm{d} t .
$$

Substituindo (47) e (52) em (53), tem-se

$$
\begin{aligned}
P\left(A_{i} \rightarrow A_{i+1} \mid \boldsymbol{\alpha}\right) & =\int_{0}^{\infty} C\left(x_{i+1} \mid A_{i}\right) \exp \left\{-C\left(x_{i+1} \mid A_{i}\right) t\right\} \prod_{z \in L \backslash A_{i+1}} \exp \left\{-C\left(z \mid A_{i}\right) t\right\} \mathrm{d} t \\
& =C\left(x_{i+1} \mid A_{i}\right) \int_{0}^{\infty} \exp \left\{-C\left(x_{i+1} \mid A_{i}\right) t\right\} \exp \left\{-\sum_{z \in L \backslash A_{i+1}} C\left(z \mid A_{i}\right) t\right\} \mathrm{d} t \\
& =C\left(x_{i+1} \mid A_{i}\right) \int_{0}^{\infty} \exp \left\{-\left[C\left(x_{i+1} \mid A_{i}\right)+\sum_{z \in L \backslash A_{i+1}} C\left(z \mid A_{i}\right)\right] t\right\} \mathrm{d} t .
\end{aligned}
$$

Sabe-se que $L \backslash A_{i}=L \backslash A_{i+1} \cup\left\{x_{i+1}\right\}$ e assim,

$$
C\left(x_{i+1} \mid A_{i}\right)+\sum_{z \in L \backslash A_{i+1}} C\left(z \mid A_{i}\right)=\sum_{z \in L \backslash A_{i}} C\left(z \mid A_{i}\right) .
$$

Portanto,

$$
P\left(A_{i} \rightarrow A_{i+1} \mid \boldsymbol{\alpha}\right)=C\left(x_{i+1} \mid A_{i}\right) \int_{0}^{\infty} \exp \left\{-\sum_{z \in L \backslash A_{i}} C\left(z \mid A_{i}\right) t\right\} \mathrm{d} t .
$$

Se $T \sim \operatorname{Exp}(\lambda)$, sabe-se que $g_{T}(t)=\lambda e^{-\lambda t} I_{(0, \infty)}(t)$ e

$$
\int_{0}^{\infty} \lambda e^{-\lambda t}=1 \Rightarrow \int_{0}^{\infty} e^{-\lambda t}=\frac{1}{\lambda} .
$$

Assim, de (54),

$$
\int_{0}^{\infty} \exp \left\{-\sum_{z \in L \backslash A_{i}} C\left(z \mid A_{i}\right) t\right\} \mathrm{d} t=\frac{1}{\sum_{z \in L \backslash A_{i}} C\left(z \mid A_{i}\right)}
$$

e então,

$$
P\left(A_{i} \rightarrow A_{i+1} \mid \boldsymbol{\alpha}\right)=\frac{C\left(x_{i+1} \mid A_{i}\right)}{\sum_{z \in L \backslash A_{i}} C\left(z \mid A_{i}\right)} .
$$

De acordo com Gibson (1997b), cada termo do produtório no lado direito da equação (43), que está definido em (55), pode ser interpretado como a razão da pressão infectiva sobre a planta sadia $x_{i+1}$ sobre a soma das pressões infectivas sofridas por todas as plantas sadias. 